\title{
ESPÉCIES DE EUCOILINAE (HYMENOPTERA: FIGITIDAE) \\ PARASITÓIDES DE LARVAS FRUGÍVORAS (DIPTERA: \\ TEPHRITIDAE E LONCHAEIDAE) NO BRASIL
}

\section{JORGE ANDERSON GUIMARÃES}

Biólogo

Orientador: Prof. Dr. ROBERTO ANTONIO ZUCCHI

Dissertação apresentada à Escola Superior de Agricultura "Luiz de Queiroz", Universidade de São Paulo, para obtenção do título de Mestre em Ciências, Área de Concentração: Entomologia.

PIRACICABA

Estado de São Paulo - Brasil

Outubro - 1998 


\section{Guimarāes, Jorge Anderson}

Espécies de eucoilinae (Hymenoptera: Figitidae) parasitóides de larvas frugivoras (Diptera: Tephritidae e Lonchaeidae) no Brasil / Jorge Anderson Guimarães. Piracicaba, 1998.

$$
86 \text { p. : il. }
$$

Dissertação (mestrado) - Escola Superior de Agricultura Luiz de Queiroz, 1998. Bibliografia.

1. Entomologia 2. Inseto-para-controle biológico 3. Inseto-parasitóide 4. Moscadas-frutas 1. Título 
Aos meus pais, Adolfo Vieira Guimarães e Selva A. S. Guimarães pelo carinho e incentivo e aos meus Celi, Ivete, Silvia e Cézar pelo companheirismo e apoio,

\section{DEDICO}




\section{AGRADECIMENTOS}

Ao Prof. Dr. Roberto Antonio Zucchi, pela orientação, presteza e apoio na realização deste trabalho.

À CAPES pela bolsa concedida.

À Dra. Norma Beatriz Diaz, pela identificação dos parasitóides, envio de material bibliográfico e sugestões para a melhoria do trabalho.

Ao Eng. Agr. Miguel F. de Souza Filho, Prof. Manoel A. Uchôa Fernandes, Dr. Luiz Antônio Salles, Biol. Regina L. Sugayama, Eng. Agr. Romulo S. Carvalho, Prof. Ayres O. Menezes Júnior, Prof. Nelson Augusto Canal Daza e Prof Elen L. Aguiar Menezes, pelo envio de material.

Aos professores do Departamento de Entomologia ESALQ/USP, pelos conhecimentos transmitidos.

Ao Dr. Nelson W. Periotto, pelo estágio, atenção e presteza.

À Dra. Maria Angélica Martins pelo envio de bibliografias.

À Regina C. Botequio de Moraes e à Ana Gabriela, do CPD do Departamento de Entomologia ESALQ/USP, pelo apoio na parte computacional. 
Ao Prof. Kitagima do NAPMEPA - ESALQ, pela orientação e auxílio na parte de Microscopia Eletrônica.

Aos colegas do Departamento de Entomologia da ESALQ/USP, pelo apoio, companheirismo e amizade.

À todos que direta ou indiretamente contribuíram para a realização deste trabalho. 


\section{SUMÁRIO}

LISTA DE FIGURAS.........................................................................................vii

LISTA DE TABELAS.........................................................................................

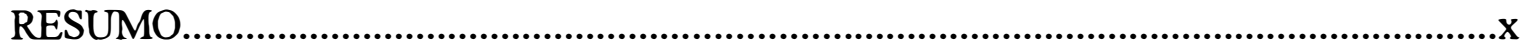

SUMMARY

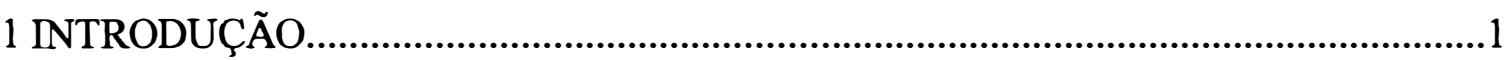

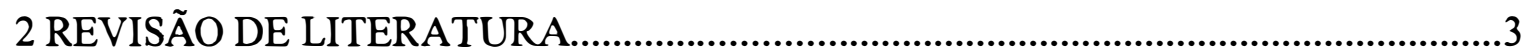

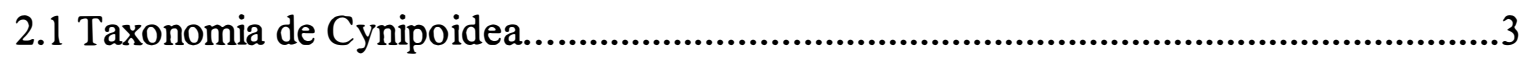

2.2 Taxonomia de Figitidae.......................................................................................

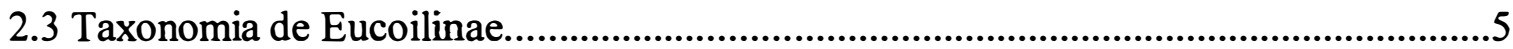

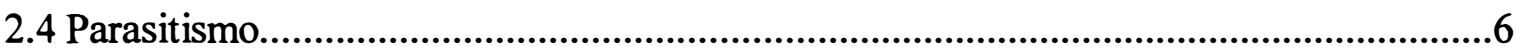

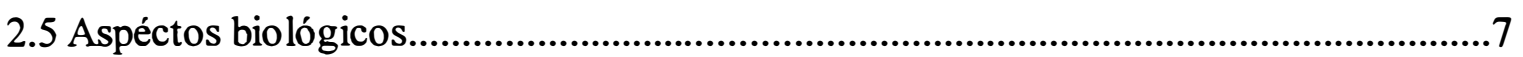

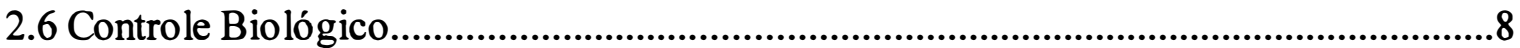

2.7 Espécies de Eucoilinae parasitóides de larvas frugívoras (Dip.: Tepritoidea)

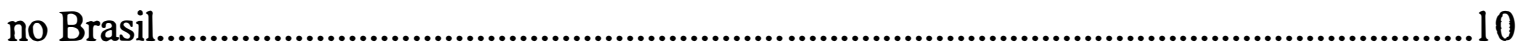

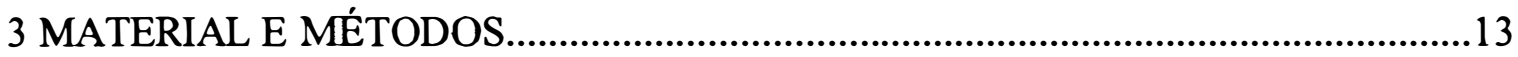

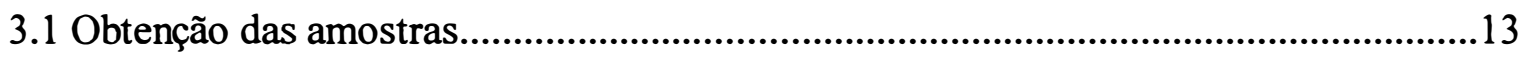

3.2 Preparação das amostras para identificação...........................................................14

3.3 Identificação dos parasitóides..................................................................................14

3.4 Chave de identificação......................................................................................14

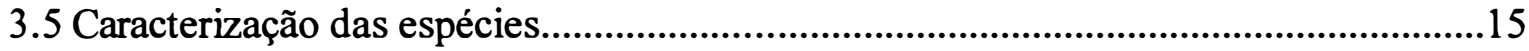

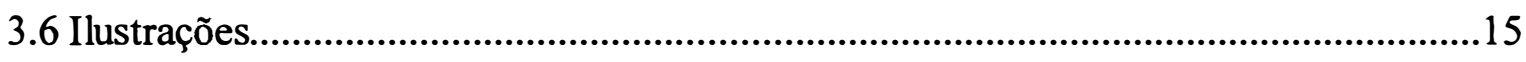

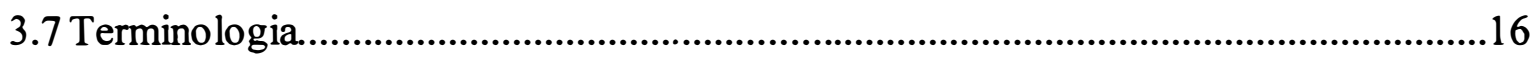

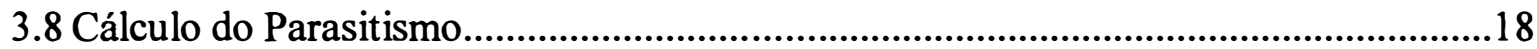

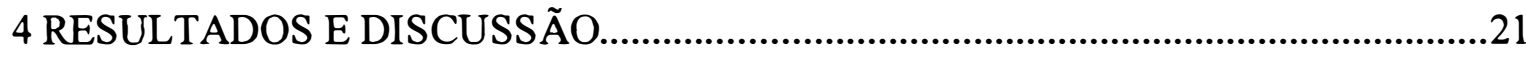

4.1 Espécies de Eucoilinae.................................................................................21

4.2 Chave ilustrada para algumas espécies de Eucoilinae (Hymenoptera: Figitidae) parasitóides de larvas frugívoras (Dip.: Tephritoidea) no Brasil.......................................23 
4.3 Caracterização das espécies de Eucoilinae parasitóides de larvas frugívoras (Diptera: Tephritoidea)........................................................................29

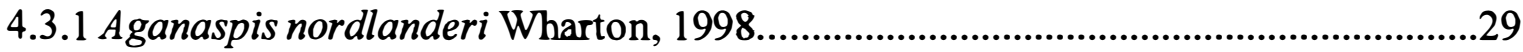

4.3.2 Aganaspis pelleranoi (Brèthes, 1924)......................................................... 34

4.3.3 Dicerataspis flavipes (Kieffer, 1909) .......................................................... 40

4.3.4 Lopheucoila anastrephae (Rhower, 1919)................................................... 45

4.3.5 Odontosema anastrephae Borgmeier, 1935 .................................................... 50

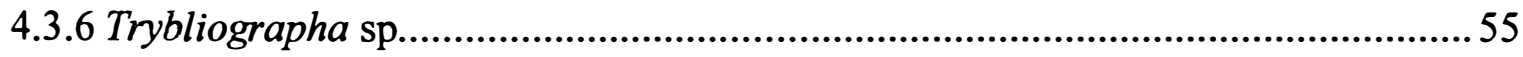

4.4 Distribuição geográfica dos Eucoilinae no Brasil...................................................59

4.5 Relação Tritrófica (Eucoilinae/hospedeiro/frutíferas)............................................63

4.6 Percentagem de parasitismo........................................................................69

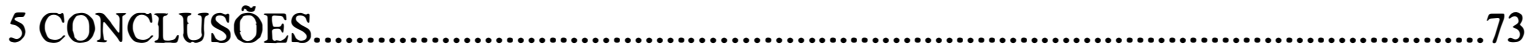

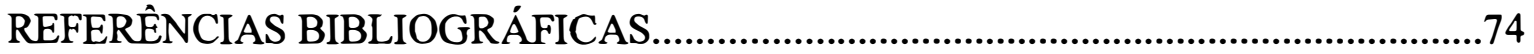




\section{LISTA DE FIGURAS}

1 Eucoilinae adulto, apresentando as estruturas taxônomicas da cabeça, mesosoma e metasoma (vista lateral)........................

2 Características morfológicas dos Eucoilinae. A. Placa pronotal; B. Mesosoma, em vista dorsal, apresentando as estruturas do mesoescuto e escutelo; C. Asa anterior.

3 Aganaspis nordlanderi. A. Antena do macho (Escala $=0,5 \mathrm{~mm}$ ). B. Antena do macho, apresentando os segmentos 3 e 4; C. Antena da fêmea $($ Escala $=0,5 \mathrm{~mm})$. D. Placa pronotal, vista dorso-frontal.

4 Aganaspis nordlanderi. A. Cabeça, mesosoma e metasoma, vista lateral; B. Mesosoma, vista lateral; C. Mesoescuto, vista dorsal; D. Cúpula escutelar, vista dorsal.

5 Aganaspis pelleranoi.; A. Antenômeros 3 e 4 do macho; B. Antena da fêmea; C. Placa pronotal, vista dorso-frontal. D. Mesoescuto, vista dorsal.

6 Aganaspis pelleranoi. A. Cúpula escutelar vista dorsal; B. Mesoescuto, vista lateral; C. Cabeça, mesosoma e metasoma, vista lateral.

7 Dicerataspis flavipes. A. Cabeça, vista frontal; B. Antenômeros 3 e 4 do macho; C. Antena da fêmea; D. Placa pronotal, vista dorso-frontal; E. Mesoescuto, vista dorsal.

8 Dicerataspis flavipes. A. Cúpula, vista dorsal; B. Mesosoma, vista lateral; C. Cabeça, mesosoma e metasoma, vista lateral.

9 Lopheucoila anastrephae. A. Antenômeros 3 e 4 do macho; B. Antena da fêmea; C. Placa pronotal, vista dorso-frontal; D. Mesoescuto, vista dorsal..

10 Lopheucoila anastrephae. A. Cúpula, vista dorsal; B. Mesosoma, vista lateral; C. Cabeça, mesosoma e metasoma, vista lateral; D. Metasoma, vista lateral, apresentando detalhes das estrias na base do tergito III............. 
11 Odontosema anastrephae. A. Antenômeros 3 e 4 do macho; B. Antena da fêmea; C. Placa pronotal, vista dorso-frontal; D. Mesoescuto, vista dorsal.

12 Odontosema anastrephae. A. Cúpula, vista dorsal; B. Cúpula escutelar, vista lateral e detalhes da mesopleura e da metapleura; D. Cabeça, mesosoma e metasoma, vista lateral.

13 Trybliographa sp. A. Antena do macho; B. Antena da fêmea; C. Placa pronotal; D. Mesosoma, vista dorsal; E. Macho, vista lateral; F. Asa anterior. (Escalas A, B, D, E, F =0,5 mm; C = 0,2 mm).

14 Distribuição das espécies de Eucoilinae parasitóides de larvas frugívoras (Dip.: Tephritidae e Lonchaeidae) no Brasil. 


\section{LISTA DE TABELAS}

1 Espécies e número de eucoilíneos examinados

Página

2 Distribuição e número das espécies de Eucoilinae parasitóides de larvas frugívoras (Dip.: Tephritidae e Lonchaeidae) no Brasil

3 Espécies de eucoilíneos, seus hospedeiros e frutos hospedeiros das larvas frugivoras (Dip.: Tephritoidea).

4 Número de eucoilíneos e associações com os respectivos frutos hospedeiros das larvas frugivoras (Dip.: Tephritoidea) no Brasil....................

5 Percentagem de parasitismo de larvas frugivoras por eucoilíneos em frutos coletados em Manaus e Iranduba (AM).

6 Percentagem de parasitismo de larvas frugívoras por eucoilíneos em frutos coletados em Pelotas (RS)

7 Percentagem de parasitismo de larvas frugívoras por eucoilíneos em frutos coletados em 37 municípios do Estado de São Paulo. 


\title{
ESPÉCIES DE EUCOILINAE (HYMENOPTERA: FIGITIDAE) \\ PARASITÓIDES DE LARVAS FRUGÍVORAS (DIPTERA: TEPHRITIDAE \\ E LONCHAEIDAE) NO BRASIL
}

\author{
Autor: JORGE ANDERSON GUIMARÃES \\ Orientador: Prof. Dr. ROBERTO ANTONIO ZUCCHI
}

\section{RESUMO}

Os Eucoilinae e os Opiinae (Braconidae), são os mais importantes parasitóides de larvas de moscas da superfamília Tephritoidea. No sentido de se conhecer as espécies de eucoilíneos no Brasil, sua distribuição geográfica, hospedeiros associados e percentagem de parasitismo, 170 amostras de parasitóides provenientes de 51 municípios das cinco regiões do Brasil foram examinadas. Obtiveram-se 2025 eucoilíneos, dos quais seis espécies $(42,82 \%)$ estão associadas às larvas de moscas da superfamília Tephritoidea. Foi possivel associar os parasitóides à seis espécies de moscas e à 34 espécies de frutíferas de 15 famílias.

As espécies de eucoilíneos identificadas são generalistas, parasitando tanto as espécies do gênero Anastrepha (Tephritidae) quanto as da família Lonchaeidae. Aganaspis pelleranoi (Brèthes) é o eucoilíneo mais abundante $(29,93 \%)$ e com a mais ampla distribuição no Brasil. Dicerataspis flavipes (Kieffer) só foi obtido no Estado de São Paulo, associado às espécies do gênero Anastrepha. Esse parasitóide é mais atraído por carambola, pois $96,34 \%$ das espécies de $D$. flavipes foram obtidas de larvas de moscas nesse fruto. Lopheucoila anastrephae (Rhower) foi associada à Anastrepha pseudoparallela (Loew) e a Neosilba spp. em Passifloraceae (primeiros registros). Aganaspis nordlanderi Wharton foi associada à Anastrepha bahiensis Lima no Estado do Amazonas (primeiros registros de localidade e de mosca hospedeira) e à Neosilba sp. em Pouteria torta (Mart.) no Estado de São Paulo. Aganaspis pelleranoi, D. flavipes e $L$. anastrephae foram associados à Anastrepha amita Zucchi em pombeiro (Citharexylum 
myrianthum Cham.) no Estado de São Paulo (primeiros registros de localidade e de mosca hospedeira). Trybliographa sp. que parasita principalmente lonqueídeos, é registrado pela primeira vez no Estado de São Paulo.

A percentagem de parasitismo variou de 0,07 a $42,86 \%$, em razão do local da coleta, espécies de frutos e moscas hospedeiras.

Foi elaborada uma chave ilustrada de identificação e as seis espécies obtidas neste trabalho foram caracterizadas. 


\title{
SPECIES OF EUCOILINAE (HYMENOPTERA: FIGITIDAE) PARASITOIDS \\ OF FRUGIVOROUS LARVAE (DIPTERA: TEPHRITIDAE AND \\ LONCHAEIDAE) IN BRAZIL
}

\author{
Author: JORGE ANDERSON GUIMARÃES \\ Adviser: Prof. Dr. ROBERTO ANTONIO ZUCCHI
}

\section{SUMMARY}

The Eucoilinae and the Opiinae (Braconidae) are considered the most important parasitoids of the larvae of the superfamily Tephritoidea. In order to provide knowledge on the Eucoilinae species in Brazil such as geographic distribution, hosts and parasitism levels, 170 samples of parasitoids from 51 counties of the five Brazilian regions were examined. A total of 2025 Eucoilinae were obtained. From this total, six species $(42,82 \%)$ were associated to larvae of Tephritoidea. The parasitoids were associated to seven species of larvae, which feed on the fruits of 34 species belonging to 15 families.

The Eucoilinae species are generalists; they can parasite Anastrepha species (Tephritidae) as well as Neosilba spp. (Lonchaeidae). Aganaspis pelleranoi (Brèthes) was the most abundant Eucoilinae (29,93\%) and with the broadest distribution in Brazil. Dicerataspis flavipes (Kieffer) was collected only in São Paulo State, associated to Anastrepha species. This parasitoid is attracted to star fruits (Averrhoa carambola L.), since $96,34 \%$ of $D$. flavipes was obtained in larvae into this host fruit. Lopheucoila anastrephae (Rhower) were associated to Anastrepha pseudoparallela (Loew) and to species of Neosilba in Passifloraceae (first records). Aganaspis nordlanderi Wharton was recorded in Amazonas State associated to Anastrepha bahiensis Lima (first records) and to Neosilba sp. in Pouteria torta (Mart.) in São Paulo State. Aganaspis pelleranoi, D. flavipes and L. anastrephae were associated to Anastrepha amita Zucchi in "pombeiro" (Citharexylum myrianthum Cham.) in São Paulo State (first records). Trybliographa sp. parasites mainly lonchaeids larvae. It was recorded for the first time in the State of São Paulo. 
The parasitism levels varied from 0.07 to $42.86 \%$, depending on collection sites, fruit types and host flies.

An illustrated key to Eucoilinae species was elaborated and six species associated to frugivorous larvae were characterized in this study. 


\section{INTRODUÇÃO}

Os Eucoilinae são endoparasitóides coinobiontes de dípteros ciclorrafos pertencentes à superfamília Cynipoidea. Várias espécies parasitam larvas de moscas da superfamília Tephritoidea, tais como as espécies do gênero Anastrepha Schiner e Ceratitis capitata (Wiedemann), além de espécies de lonqueídeos, principalmente as do gênero Neosilba. Devido a consideráveis perdas econômicas causadas à fruticultura mundial, torna-se muito importante o controle dessas moscas. Dessa forma, visando um manejo eficiente dessas pragas, utiliza-se o controle integrado de pragas, através dos métodos químicos, culturais e biológicos. Esse último é baseado no uso de microhimenópteros parasitóides, dentre os quais, destacam-se os braconídeos e os eucoilíneos (Nascimento et al., 1984; Zucchi, 1988; Salles, 1995; Wharton et al., 1998).

Espécies de eucoilíneos, tais como Aganaspis pelleranoi (Brèthes), já foram utilizadas em programas de controle biológico de tefritídeos em várias partes do mundo. Atualmente essa espécie está sendo criada massalmente no México (Wharton, 1989; Reyes et al., 1998).

Todavia, para possibilitar uma maior utilização desses parasitóides em programas de manejo, há a necessidade do desenvolvimento dos estudos básicos. A taxonomia desse grupo ainda não está esclarecida. Isso dificulta a identificação das espécies e, conseqüentemente, pode levar a utilização equivocada de parasitóides em determinadas situações e assim, causar o fracasso de um programa de controle. Portanto, faz-se necessária uma ampla revisão dos gêneros dessa subfamília, visando esclarecer problemas taxonômicos. Além disso, é também de grande importância, o estabelecimento das associações tritróficas desses parasitóides. 
O pequeno número de pesquisadores em todo mundo trabalhando com o grupo, a ausência de chaves de identificação e a escassez de literatura atualizada que trate dos Eucoilinae neotropicais, principalmente as espécies que ocorrem no Brasil, contribuem para o pouco conhecimento à respeito desse grupo.

Dessa forma, no sentido de contribuir com o conhecimento desses parasitóides, este trabalho teve como objetivos: identificar as espécies de eucoilíneos parasitóides de larvas de moscas-das-frutas da família Tephritidae e de Lonchaeidae no Brasil; caracterizar as espécies; estabelecer a distribuição geográfica das espécies no Brasil; determinar a relação tritrófica (parasitóide/hospedeiro/frutífera) e estimar a percentagem de parasitismo natural. 


\section{REVISÃO DE LITERATURA}

\subsection{Taxonomia de Cynipoidea}

A superfamília Cynipoidea é constituída por cerca de 3000 espécies em aproximadamente 255 gêneros. Porém, Nordlander (1984) estimou que esse grupo seja composto por cerca de 20000 espécies. Atualmente, há uma certa indefinição com relação à posição sistemática de algumas famílias de Cynipoidea, havendo na literatura de 1952 à 1995, seis classificações distintas (Ronquist, 1995a).

A classificação atualmente aceita é a de Ronquist (1995a), que se baseia em caracteres morfológicos e biológicos, dividindo Cynipoidea em dois grupos: macrocinipóideos e microcinipóideos. O primeiro inclui as famílias Austrocynipidae, Ibaliidae e Liopteridae. São insetos grandes que possuem ovipositores adaptados para o parasitismo de larvas de coleópteros (Buprestidae) e de vespas (Siricidae) em coníferas. Todavia, os Liopteridae parasitam também espécies de Lepidoptera. Já os microcinipóideos são insetos de pequeno porte, agrupados, de acordo com seus hábitos alimentares e comportamentais, em fitófagos galhadores e inquilinos (Cynipidae) e em parasitóides larvais (Figitidae lato sensu) (Ronquist, 1994; 1995b; Nordlander et al., 1996; Liljeblad \& Ronquist, 1998).

Fergusson (1995) e Diaz (1998) estabeleceram a diagnose para as famílias de Cynipoidea. Assim, os representantes desse grupo caracterizam-se por medir, em média, de 1 a $5 \mathrm{~mm}$, exceto alguns representantes de Ibaliidae, que alcançam mais de $30 \mathrm{~mm}$. A coloração do corpo é geralmente escurecida, sendo ambos os sexos alados, porém espécies ápteras são encontradas nas famílias Figitidae e Cynipidae. As fêmeas de Cynipoidea apresentam antenas bem desenvolvidas com 13 segmentos, clavadas ou 
filiformes, enquanto os machos possuem antenas filiformes de 14 a 15 antenômeros, com o terceiro segmento antenal encurvado. $O$ pronoto alcança a tégula e apresenta uma crista pronotal nos macrocinipóideos. Mesosoma, com escutelo quase tão largo quanto o propódeo. Mesoescuto ornamentado nos macrocinipóideos e geralmente liso e brilhante nos microcinipóideos. O escutelo apresenta-se freqüentemente com esculturações, entretanto, em algumas famílias pode estar modificado em forma de espinho ou em cúpula. As asas anteriores apresentam um padrão de nervação reduzido, com célula radial subtriangular distinta nos representantes dos microcinipóideos, porém os macrocinipóideos apresentam padrão de nervação mais complexo. O metasoma é comprimido lateralmente e os tarsos são pentâmeros.

\subsection{Taxonomia de Figitidae}

De acordo com a mais recente classificação dos Cynipoidea, Figitidae "lato sensu" contém todas as famílias de cinipóideos que são parasitóides larvais, tais como, Eucoilidae, Charipidae e Anacharitidae, que passam as ser consideradas como subfamilias. Os Figitidae são parasitóides cosmopolitas, com cerca de 110 gêneros e aproximadamente 1500 espécies. Entretanto, poucos estudos taxonômicos têm sido desenvolvidos com esse grupo (Fergusson, 1995; Ronquist, 1995a).

Para separação das subfamílias de Figitidae, utilizam-se os caracteres dos tergitos III e IV do abdômen. Dessa forma, é possível dividir os figitídeos em 3 grupos. O primeiro grupo contém três subfamílias, onde os Aspiceratinae apresentam o tergito III linguliforme, não alcançando a metade do comprimento do gáster. São parasitóides de sirfideos (Diptera). Os Anacharitinae são parasitóides de neurópteros Chrysopidae e Hemerobiidae, caracterizados por apresentar o tergito III normal (não linguliforme) e pecíolo desenvolvido. Ainda tratando-se dos integrantes do primeiro grupo, há os Figitinae, que apresentam o tergito III normal e pecíolo séssil. São parasitóides de dípteros coprófagos, tais como, Sarcophagidae (Weld, 1952; Quinlan, 1979; Nordlander, 1982a; Diaz, 1986; Diaz et al., 1996; Diaz, 1998).

O segundo grupo é representado pela subfamília Charipinae, hiperparasitóides de 
braconídeos e parasitóides primários de Coccoidea e de Aphidoidea. Caracterizam-se por apresentar o tergito III alcançando ou superando a metade do comprimento do abdômen (Weld, 1952; Nordlander, 1982a; Fergusson, 1995; Diaz, 1998).

O terceiro grupo é constituído por duas subfamílias, que se caracterizam pelos tergitos III e IV fundidos, e formando quase a totalidade do abdômen. Os representantes desse grupo são divididos de acordo com a presença (Eucoilinae) e ausência (Pycnostigmatinae) de cúpula na escutelo. Os Pycnostigmatinae apresentam célula radial pequena, semelhante a um pterostigma. Sua biologia é desconhecida e são encontrados apenas no continente africano (Weld, 1952; Nordlander, 1982a; Fergusson, 1995; Diaz, 1998).

\subsection{Taxonomia de Eucoilinae}

A posição sistemática da subfamília Eucoilinae é ainda motivo de controvérsia entre os pesquisadores. Lima (1962) apresentou uma síntese da nomenclatura atribuída a esse grupo. Por algum tempo foi classificada como Eucoilinae, subfamília de Cynipidae (Weld, 1952). Mais recentemente, Fergusson (1995) considerou-a uma tribo (Eucoilini) da subfamília Figitinae. Porém, a classificação atualmente aceita é a de Ronquist (1995a), que a considera uma subfamília (Eucoilinae) de Figitidae.

Entretanto, de acordo com Diaz ${ }^{1}$, os representantes de Eucoilinae apresentam uma estrutura em forma de cúpula no escutelo. Esse é um caráter autapomórfico muito forte. É encontrado apenas nos representantes desse grupo, conseqüentemente, caracterizando-os como um grupo monofilético e que, possivelmente com os avanços dos estudos filogenéticos, voltará novamente ao status de família.

Wharton et al. (1998) e Schilthuizen et al. (1998) utilizaram "Eucoilidae" em seus trabalhos e, dessa forma, verifica-se que não há um consenso geral à respeito da nova classificação de Ronquist.

\footnotetext{
${ }^{1}$ DIAZ, N.B. Comunicação pessoal,1998.
} 
Os Eucoilinae constituem o maior grupo de Cynipoidea, com aproximadamente 1000 espécies descritas, distribuídas em cerca de 80 gêneros e apresentando uma ampla distribuição geográfica (Ashmead, 1903b; Quinlan, 1979; Gauld \& Bolton, 1988; Fergusson, 1995).

São insetos escuros, com coloração variável nas antenas, pernas e gáster, porém, nunca com coloração metálica. Alcançam de 1,5 a $5 \mathrm{~mm}$, as antenas das fềmeas são 13segmentadas com o ápice dilatado, formando uma clava, que pode apresentar número variável de antenômeros. Os machos possuem antenas filiformes com 15 antenômeros, apresentando pontos sensoriais (rinários) em todos os segmentos, com exceção do escapo e flagelo. As asas anteriores apresentam um padrão de nervação reduzido, com uma célula radial, (aberta ou fechada na margem costal) e sem célula cubital. Pronoto com placa pronotal composta por uma área anterior e uma posterior, unidas através da ponte pronotal. Entre as áreas anterior e posterior verifica-se a presença de orifícios, que podem ser totalmente abertos, semi-abertos ou completamente fechados. Mesoescuto geralmente liso e brilhante, porém carenado em alguns gêneros, notaulices representadas por linhas de pêlos eretos. Escutelo modificado em cúpula. As variações na morfologia dessa estrutura são de grande importância na separação de gêneros e espécies. Mesopleura apresentando ou não um orifício subalar e metapleura com carenas de forma e disposição variável. Abdômen achatado lateralmente, com o terceiro tergito fundido ao quarto, representando quase a totalidade do abdômen. Podem apresentar ou não anel piloso na base do tergito III (Ashmead, 1903b; Weld, 1952; Lima, 1962; Quinlan, 1978; 1979; Gauld \& Bolton, 1988; Ritchie, 1993; Fergusson, 1995).

\subsection{Parasitismo}

Os Eucoilinae são endoparasitóides, que se desenvolvem em larvas de dípteros associados à matéria orgânica, tais como fezes, cadáveres e frutos (Gauld \& Bolton, 1988). São parasitóides coinobiontes, dessa forma, após o parasitismo o hospedeiro ainda permanece vivo até a fase de pupa, permitindo assim, um completo desenvolvimento do parasitóide (Ovruski, 1994b). 
Durante o parasitismo, as fềmeas utilizam três estímulos básicos. O primeiro atrai os parasitóides até o hábitat do hospedeiro (estímulos de longa distância), são substâncias voláteis liberadas dos frutos, dentro dos quais possivelmente se encontram as larvas de moscas-das-frutas. Sendo assim, observa-se que as fềmeas dos parasitóides são mais atraídas pelos voláteis liberados dos frutos do que propriamente por algum estímulo liberado pelas larvas hospedeiras (relação tritrófica). Uma vez no hábitat do hospedeiro, os parasitóides se utilizam da vibrotaxia, ou seja, os eucoilíneos através de sensilos presentes nas antenas e tarsos anteriores conseguem perceber os sons emitidos pelas larvas de moscas no interior do fruto (segundo estímulo) e assim, localizam com precisão o local onde o hospedeiro está alojado. $\mathrm{O}$ terceiro estímulo é utilizado para a seleção do hospedeiro, onde vários fatores são analisados pela fềmea do parasitóide antes da oviposição no interior da larva hospedeira (Ovruski, 1994a).

Aganaspis pelleranoi (Brèthes, 1924) é um parasitóide de larva-pupa de tefritóideos, que é bastante atraído por estímulos de frutos em processo de decomposição. Assim, parasitam preferencialmente larvas maduras, as quais, geralmente se encontram em frutos apodrecidos no solo. É também, uma das poucas espécies conhecidas que penetra no interior dos frutos à procura das larvas das moscas. Esse fato é de grande importância, pois confere à $A$. pelleranoi um nicho de ação exclusivo, pois os Braconidae (Opiinae), que são os parasitóides de moscas-das-frutas mais abundantes, restringem-se apenas ao parasitismo na superfície do fruto, através da introdução do ovipositor (Sivinsky, 1991; Ovruski, 1994a; Sivinsky et al., 1997).

\subsection{Aspectos biológicos}

O ovo é do tipo eucoiliforme, caracterizado por um pedúnculo bem desenvolvido. Cada fềmea deposita apenas um ovo no interior das larvas hospedeiras (James, 1928; Eskafi \& Legner, 1974; Ovruski, 1994b).

$\mathrm{O}$ desenvolvimento larval é do tipo hipermetabólico. As larvas de primeiro e segundo ínstares são do tipo eucoiliforme, com apêndices torácicos e caudal; ânus dorsal e ausência de espiráculos (respiração cutânea). A larva do terceiro ínstar é um tipo de 
transição de eucoiliforme para o tipo himenopteriforme, que apresenta respiração através de espiráculos, que começam a se desenvolver à partir desse estágio. A larva de quarto instar já apresenta espiráculos em todos os segmentos corporais e se desenvolve sobre a pupa do hospedeiro, alimentando-se externamente dela, porém permanecendo ainda dentro do pupário do hospedeiro. Posteriormente, a larva madura entra em fase de prépupa e após um curto período atinge o estágio de pupa (exarada), que dura de 9 a 14 dias (James, 1928; Weld, 1952; Wishart \& Monteith, 1954; Eskafi \& Legner, 1974; Ovruski, 1994b).

Decorridos aproximadamente 26 dias do desenvolvimento, o estágio adulto emerge do pupário, rompendo-o com as mandíbulas. São parasitóides protélicos (vida livre) e os machos geralmente emergem antes das fềmeas (Ovruski, 1994b).

\subsection{Controle Biológico}

Os eucoilíneos têm sido considerados um importante grupo de inimigos naturais de dípteros ciclorrafos em vários microhábitats. Esses parasitóides estão associados à moscas da família Agromyzidae, minadoras de tecidos vegetais e também aos dípteros, que se desenvolvem em fezes e cadáveres, tais como os Sarchophagidae (De Santis et al., 1976; Diaz \& Valadares, 1979; Diaz et al., 1996).

No entanto, algumas espécies estão associadas exclusivamente aos dípteros que se desenvolvem em frutos, tais como os das famílias Tephritidae, Lonchaeidae, Drosophilidae, Neriidae e Otitidae. Algumas espécies já foram utilizadas em vários programas de controle biológico de Tephritidae (Clausen, 1978; Diaz, 1986; 1987; Reyes et al., 1998; Wharton et al. 1998).

Na década de 30, tentou-se a criação e multiplicação de Aganaspis pelleranoi e Aganaspis daci (Weld, 1951), além de outros parasitóides nativos, para o controle de espécies de Anastrepha em pomares de citros em Tucuman, Argentina (Schultz, 1938; Wharton et al., 1998).

Nos anos de 1935 e 1936 foram enviadas duas espécies de eucoilíneos do Brasil para Porto Rico, Eucoila (Hexamerocera) sp. e Ganaspis sp. Nesse mesmo período, 
foram introduzidas em Porto Rico, Pseudeucoila brasiliensis (Ihering, 1914) e Eucoila sp., todas importadas para incrementar o controle de espécies de Anastrepha (Bartlett, 1941).

Em 1942, Aganaspis pelleranoi foi exportada da província de Tucuman na Argentina para o Peru, para implementar o programa de controle biológico de Anastrepha fraterculus (Wiedemann). Houve o estabelecimento desse parasitóide nesse país, porém apenas em Anastrepha striata Schiner (Haywardi, 1940a;b; 1941; 1942; 1943; Clausen, 1956; 1978; Ovruski \& Fidalgo, 1994).

Trybliographa daci Weld (atualmente Aganaspis daci), foi observada parasitando espécies de Dacus em Kuala Lumpur na Malásia. Em 1949, foi introduzida no Havaí, sendo criada em laboratório para liberações (Weld, 1951b). Posteriormente, exemplares dessa espécie foram criados e liberados na Flórida, de 1977 a 1979, juntamente com outros parasitóides, para controlar Anastrepha suspensa (Loew) (Clausen, 1978; Lin, 1987; Baranowski et al., 1993).

O controle biológico das moscas-das-frutas é bastante dificultado pelo fato delas permanecerem na cultura, mesmo após as colheitas. Outro fato é que a fruticultura exige níveis de dano muito baixos, o que toma o uso de agentes biológicos, inviáveis como único meio de controle. A maioria dos parasitóides de moscas-das-frutas são generalistas tanto em relação aos hospedeiros quanto aos frutos e, assim, dificulta o seu uso para o controle biológico dessas pragas, pois os parasitóides dispersam da espécie-alvo (Aluja, 1994).

Porém, atualmente, através das novas táticas de criação de insetos, que usam pupas irradiadas para a multiplicação dos parasitóides e o seu emprego em liberações inundativas, juntamente com moscas estéreis, vem sendo alcançado resultados satisfatórios em vários países (Aluja, 1994; Reyes et al., 1998).

O programa, que visa erradicar espécies de moscas-das-frutas de importância quarentenária do México, vem criando massalmente e liberando de forma inundativa o eucoilíneo Aganaspis pelleranoi juntamente com braconídeos (Opiinae) (Reyes et al. 1998; Wharton et al., 1998).

No Brasil, Guimarães et al. (1998a,b) vêm desenvolvendo estudos taxonômicos 
com eucoilíneos visando seu uso em programas futuros de controle biológico de moscasdas-frutas de importância econômica.

\subsection{Espécies de Eucoilinae parasitóides de larvas frugívoras (Dip.: Tephritoidea) no Brasil}

São conhecidos aproximadamente 29 gêneros e 55 espécies de Eucoilinae no Brasil, dentre os quais seis gêneros e onze espécies destacam-se como parasitóides de dípteros da superfamília Tephritoidea (De Santis, 1980). As sinonímias de cada espécie estão no item 4.3.

Aganaspis Lin, 1987

A. pelleranoi (Brèthes, 1924)

A. nordlanderi Wharton, 1998

O gênero Aganaspis criado foi recentemente. Lin (1987), após estudar algumas espécies do gênero Trybliographa Förster, concluiu que a espécie Trybliographa daci Weld, 1951 não se caracterizava com nenhum membro desse grupo. Assim, criou o gênero Aganaspis para essa espécie. Esse gênero conta atualmente com seis espécies, sendo quatro holárticas - $A$. daci (Weld, 1951); A. contracta Lin, 1987; A. major Lin, 1987 e $A$. ocellata Lin, 1987 e duas neotropicais, $A$. pelleranoi (Brèthes, 1924) e $A$. nordlanderi Wharton, 1998.

Dicerataspis Ashmead, 1895

D. flavipes (Kieffer, 1909)

O gênero Dicerataspis foi descrito por Ashmead em 1895, tendo como espécietipo Dicerataspis grenadensis Ashmead, 1895, proveniente da Ilha de Granada, nas Antilhas. Esse gênero caracteriza-se pelo escutelo rugoso com duas projeções dentiformes. O gênero Dicerataspis pertence ao grupo Gronotoma e apenas D. flavipes 
foi constatada no Brasil, no Estado do Pará (Kieffer, 1909; Nordlander, 1982a). O gênero Dicerataspis é bastante relacionado a Dissodontaspis Kieffer, um gênero neotropical descrito em 1909, que posteriormente foi considerado sinônimo júnior de Dicerataspis (Weld, 1921). O gênero Dicerataspis está associado às espécies de Anastrepha. Entretanto, Hemández-Ortiz (1993) observou espécies de Dicerataspis parasitando Rhagoletis no México e Wharton et al. (1998) criaram $D$. grenadensis de pupários de Drosophilidae.

\section{Lopheucoila Weld, 1951}

L. anastrephae (Rhower, 1919)

L. truncicola Weld, 1951

O gênero Lopheucoila é constituído por três espécies neotropicais, $L$. anastrephae, L. mexicana Weld, 1951 e $L$. truncicola (Weld, 1951a). De acordo com Díaz \& Galardo (1997), Lopheucoila pertence ao grupo Zaeucoila, que é constituído por mais de sete gêneros, todos neotropicais, totalizando 32 espécies. No Brasil, $L$. anastrephae (anteriormente Diglyphosema anastrephae) está associada às moscas-dasfrutas das familias Tephritidae e Lonchaeidae (De Santis, 1980).

\section{Odontosema Kieffer, 1909 \\ O. albinerve Kieffer, 1909 \\ O. anastrephae Borgmeier, 1935}

Odontosema Kieffer é um gênero neotropical, com apenas duas espécies conhecidas, $O$. albinerve (Estado do Pará) e O. anastrephae, obtida de Anastrepha fraterculus em goiabas no Estado de São Paulo (Borgmeier, 1935; Lima, 1948). Exemplares não identificados de Odontosema foram obtidos de larvas de moscas do gênero Anastrepha em Veracruz no México (Hemández-Ortiz et al., 1994), de $A$. fraterculus na região de Pelotas - RS (Salles, 1996) e de C. capitata na Costa Rica (Wharton et al., 1981). 


\section{Tropideucoila Ashmead, 1903}

T. rufipes Ashmead, 1903

T. angrensis Borgmeier, 1935

T. weldi Lima, 1940

Tropideucoila é um gênero endêmico da região neotropical, que pertence ao grupo Zaeucoila (Dias \& Gallardo, 1997). Apenas três espécies de Tropideucoila são conhecidas, T. rufipes, coletada em Chapada (MT); T. angrensis, coletada em Angra dos Reis, (RJ). Os registros de hospedeiros e frutos associados dessas duas espécies são desconhecidos. T. weldi foi obtida de Silba pendula - provavelmente Neosilba pendula (Bezzi, 1919), em Campo Grande (RJ) (Ashmead, 1903a, Weld, 1921; Borgmeier, 1935; Lima, 1940; De Santis, 1980; McAlpine \& Steyskal, 1982).

Loiácono \& Diaz (1977) constataram a presença de T. weldi na província de Punta Lara em Buenos Aires na Argentina, porém não foram apresentados os registros dos hospedeiros.

\section{Trybliographa Förster, 1869}

O gênero Trybliographa foi revisado por Nordlander (1981). É constituído basicamente por espécies holárticas. Alguns gêneros de parasitóides de moscas-dasfrutas foram incorporados à Trybliographa, e.g., Pseudeucoila, gênero composto por espécies neotropicais, considerado sinônimo júnior de Trybliographa (Ihering, 1914; Weld, 1932; Borgmeier, 1935; Lima, 1962; De Santis, 1980; Nordlander, 1981;1982a).

Boscan \& Godoy (1998) relataram a presença de Trybliographa brasiliensis (Ihering) na Venezuela parasitando moscas-das-frutas em manga e goiaba. Legner \& Goieden (1987) verificaram o parasitismo natural de uma espécie de Trybliographa em Rhagoletis completa Cresson nos Estados do Texas e Novo México (EUA). 


\section{MATERIAL E MÉTODOS}

\subsection{Obtenção das amostras}

As amostras de eucoilíneos foram coletadas por pesquisadores de várias localidades do Brasil. Foi examinado ainda, amostras de Eucoilinae depositadas no Departamento de Entomologia - ESALQ/USP. Dessa forma, foi possível obter material de todas as regiões brasileiras:

Região Norte: Amazonas - Iranduba e Manaus

Região Nordeste: Bahia - Conceição de Almeida

Região Centro-Oeste: Goiás - Goiândira; Mato Grosso do Sul - Aquidauana e Terenos

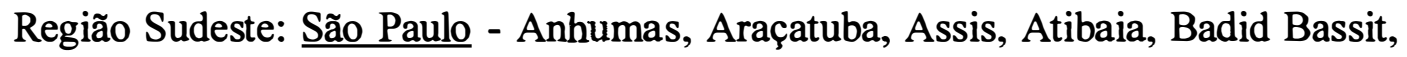
Caconde, Campinas, Cândido Rodrigues, Conchal, Florínia, Garça, Itu, Jaci, Jundiaí, Luiz Antônio, Mogi das Cruzes, Monte Alegre do Sul, Narandiba, Nazaré Paulista, Patrocínio Paulista, Pedreira, Pindorama, Piracicaba, Pirassununga, Presidente Prudente, Regente Feijó, Rosana, Santópolis do Aguapeí, São Bento do Sapucaí, São Carlos, São José da Bela Vista, São José do Rio Preto, São Paulo, Sorocaba, Taquaritinga, Tarabaí, Ubatuba; Rio de Janeiro - Campo Grande e Rio de Janeiro.

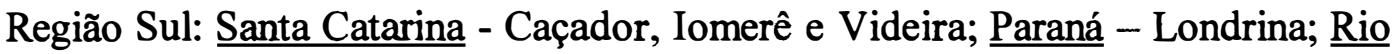
Grande do Sul - Vacaria e Pelotas.

Os exemplares foram conservados em frascos com álcool $70 \%$ devidamente etiquetados. Através das informações contidas nas etiquetas, foi possível estabelecer a distribuição geográfica desses parasitóides, bem como as associações com seus hospedeiros e frutíferas. Entretanto, a associação entre um espécie de parasitóide e a 
larva hospedeira só foi estabelecida, quando de uma amostra de frutos, emergiram apenas uma espécie de parasitóide e uma espécie da mosca hospedeira.

\subsection{Preparação das amostras para identificação}

Os Eucoilinae foram preparados em dupla montagem, fixados em triângulos na região da mesopleura, através de cola branca ou esmalte incolor. Após a montagem, os exemplares foram devidamente etiquetados e acondicionados em caixas entomológicas e depositados na coleção do Departamento de Entomologia da ESALQ-USP.

\subsection{Identificação dos parasitóides}

A identificação dos gêneros foi baseada em Weld (1952). A identificação específica foi obtida através das descrições originais e também por comparações com exemplares da coleção do Departamento de Entomologia - ESALQ/USP.

Os exemplares identificados foram enviados à Dra. Norma Beatriz Diaz, Museo de La Plata, Argentina, para a confirmação específica.

As moscas hospedeiras da família Tephritidae coletadas no Estado de São Paulo foram identificadas pelo Eng. Agr. Miguel F. de Souza Filho (Instituto Biológico) e os Lonchaeidae pelo Prof. Manoel Araécio Uchôa Fernandes (Universidade Federal do Mato Grosso do Sul).

\subsection{Chave de identificação}

Foi elaborada uma chave ilustrada de identificação para as espécies de Eucoilinae coletadas neste estudo. $\mathrm{O}$ gênero Tropideucoila foi incluído na chave de identificação baseando-se nos caracteres apresentados em Weld (1952). 


\subsection{Caracterização das espécies}

Foram utilizadas séries de 20 exemplares (10 machos e 10 fềmeas) para a caracterização da maioria das espécies.

Utilizou-se uma ocular micrométrica acoplada ao microscópio estereoscópico para efetuar as seguintes medidas:

1 - comprimento do corpo

2 - comprimento do metasoma

3 - altura do metasoma

4 - comprimento do mesoescuto

5 - largura do mesoescuto (região das tégulas)

6 - comprimento do escutelo

7 - largura do escutelo

8 - comprimento da cúpula escutelar

9 - largura da cúpula escutelar

10 - altura da cabeça

11 - largura da cabeça

12 - antena (comprimento dos flagelômeros)

13 - comprimento da asa anterior

14 - comprimento da $1^{\underline{a}}$ radial abcissa

15 - comprimento da $2^{\underline{a}}$ radial abcissa

\subsection{Ilustrações}

A cabeça, o mesosoma e o metasoma após completamente secos, foram montados em bases apropriadas de alumínio, stubs, através de fita adesiva de dupla face e esmalte incolor. Logo após, essas amostras foram recobertas com uma fina camada de ouro através do metalizador utilizado como sputter coater e, assim, examinadas ao microscópio eletrônico de varredura do Núcleo de Apoio à Pesquisa - Microscopia Eletrônica Aplicada à Pesquisa Agropecuária (NAP/MEPA) - ESALQ/USP. 
As asas anteriores e posteriores foram retiradas dos exemplares, mantidas em álcool $70 \%$, e, logo em seguida, distendidas em lâmina de microscopia, às quais eram adicionadas uma gota de glicerina e então cobertas com lamínulas. Os esquemas das asas foram feitos com auxílio de câmara clara acoplada ao microscópio estereoscópico. Esquemas do mesoescuto e escutelo também foram obtidos com o uso de câmara clara, para ilustrar os caracteres utilizados na chave identificação. Os esquemas foram elaborados pela Biol. Patrícia Milano, exceto as figuras do escutelo e placa pronotal de A. nordlanderi, que foram adaptadas de Wharton et al. (1998) e do mesoescuto e asa anterior dos espécimens do gênero Tropideucoila, adaptadas de Weld (1952).

3.7 Terminologia (baseada em Nordlander, 1982b, Goulet \& Huber, 1993; Schilthuizen et al., 1998):

(1) Sulco malar: Sulco que se estende da margem ventral dos olhos compostos até a base das mandíbulas (Figura 1).

(2) Placa pronotal: Parte dorsal do pronoto que se articula com a cabeça e com a parte anterior do mesoescuto, separando as laterais do pronoto. É constituída pela parte anterior e pela parte posterior que são unidas pela ponte pronotal (Figura 2A).

(3) Notaulices: Um par de sulcos convergentes no mesoescuto, dividindo-o em duas partes, medial e lateral. Representado por linhas de pêlos em algumas espécies (Figuras 1 e 2B).

(4) Cúpula escutelar: Projeção da cutícula do escutelo, variável em forma e tamanho (Figuras 1 e 2B).

(5) Disco escutelar: Região do escutelo que circunda a cúpula. Apresenta variações em sua superficie, podendo ser areolada, pontuada, rugosa e estriada (Figura 2B).

(6) Fóveas anteriores: Orifícios de forma variada, presentes em número de dois na parte anterior do escutelo (Figura 2B).

(7) Fóvea cupular: Orifício localizado na parte posterior da cúpula escutelar (Figura 2B). 
(8) Barras laterais: Porção póstero-lateral do mesoescuto, usualmente triangulares, localizadas lateralmente às fóveas basais do escutelo (Figura 2B).

(9) Depressão lateral do escutelo: Localizada na porção lateral do escutelo, abaixo das barras laterais, geralmente pubescênte. Pode apresentar borda definida ou não, nesse caso, confundindo-se com a área do disco escutelar (Figura 1).

(10) Orificio subalar: Fenda longitudinal localizada na parte superior da mesopleura, logo abaixo das tégulas (Figura 1).

(11) Tégulas: Escleritos arredondados que cobrem a base das asas anteriores (Figura 1).

(12) Cavidade ântero-ventral: Orifício localizado na parte inferior da metapleura, logo abaixo das carenas metapleurais (Figura 1).

(13) Carenas metapleurais: Três carenas longitudinais presentes na metapleura de algumas espécies (Figura 1).

(14) Célula radial: Célula subtriangular localizada na asa anterior. É composta por três nervuras: radius, $1^{\mathrm{a}}$ radial abcissa e $2^{\mathrm{a}}$ radial abcissa. Pode ser fechada ou aberta na margem costal (Figuras 1 e $2 \mathrm{C}$ ).

(15) Radius: Nervura que fecha a célula radial na sua margem costal (Figura 1C).

(16) $1^{\mathrm{a}}$ radial abcissa: Nervura que compõem a célula radial, disposta em continuidade à nervura subcostal (Figura $2 \mathrm{C}$ ).

(17) $2^{\mathrm{a}}$ radial abcissa: Nervura que compõem a célula radial (Figura 2C).

(18) Célula costal: Célula localizada no terço basal da asa anterior, delimitada pelas nervuras subcostal na parte inferior e radius na parte lateral, porém, aberta na margem costal (Figura 2C).

(19) Anel piloso: Pêlos distribuídos em forma de anel (completo ou não) na base do tergito III do abdômen. Pode ser bastante denso (lanoso) ou composto por pêlos esparsos (Figura 1). 


\subsection{Cálculo do Parasitismo}

Foi calculada a percentagem de parasitismo (\%) dos eucoilíneos sobre larvas de moscas frugívoras em algumas frutíferas dos Estados do Amazonas (duas localidades), São Paulo (37 localidades) e do Rio Grande do Sul (uma localidade), baseando-se em Nascimento et al. (1984):

\section{$\% \mathrm{P}=\underline{\text { Número de parasitóides emergidos }} \times 100$ \\ Número de pupários coletados}

Para as demais localidades não foi possível o cálculo de parasitismo, pois não havia registros do número de pupários obtidos em cada amostra. 


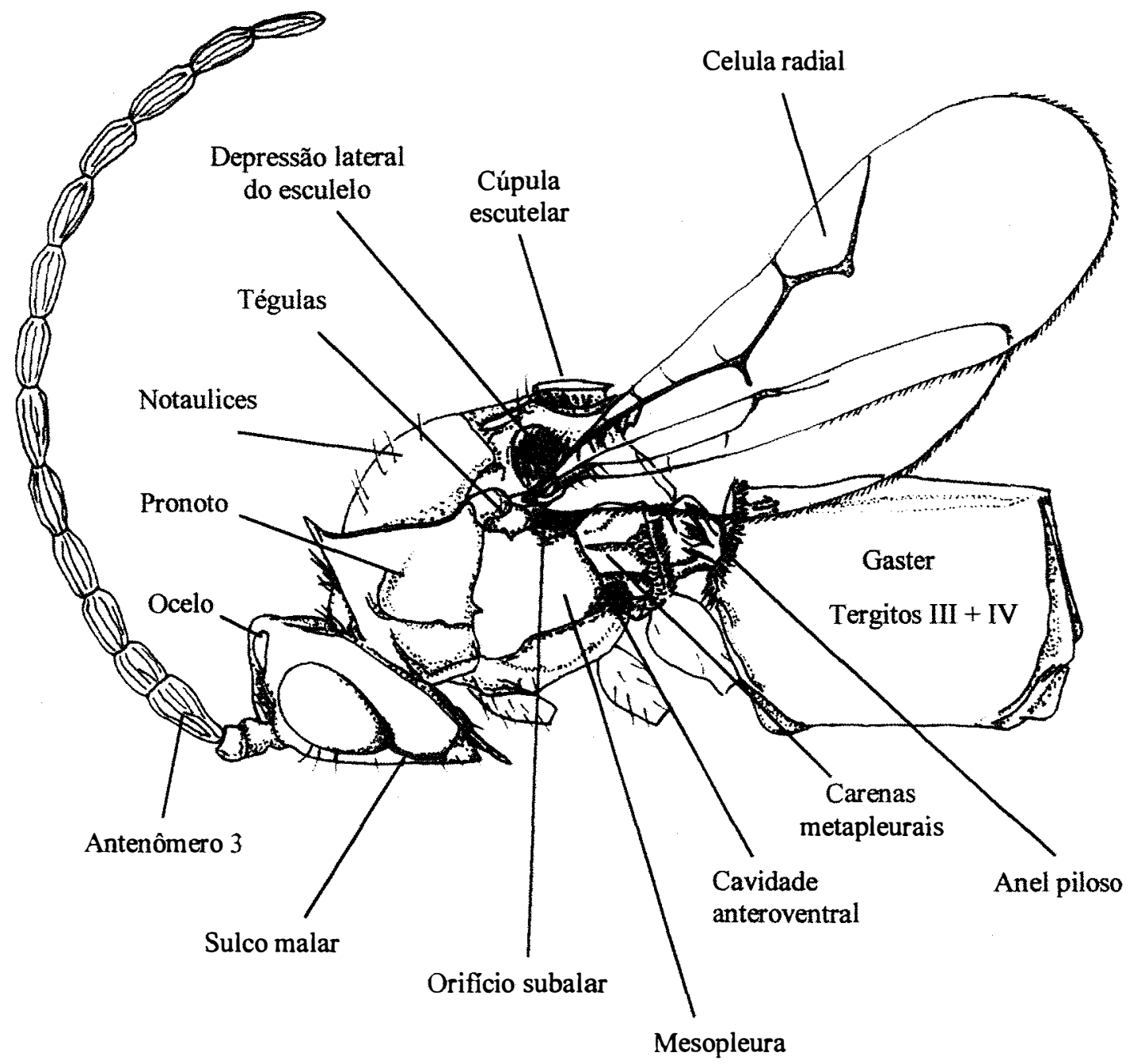

Figura 1: Eucoilinae adulto, apresentando as estruturas taxônomicas da cabeça, mesosoma e metasoma (vista lateral). 
A

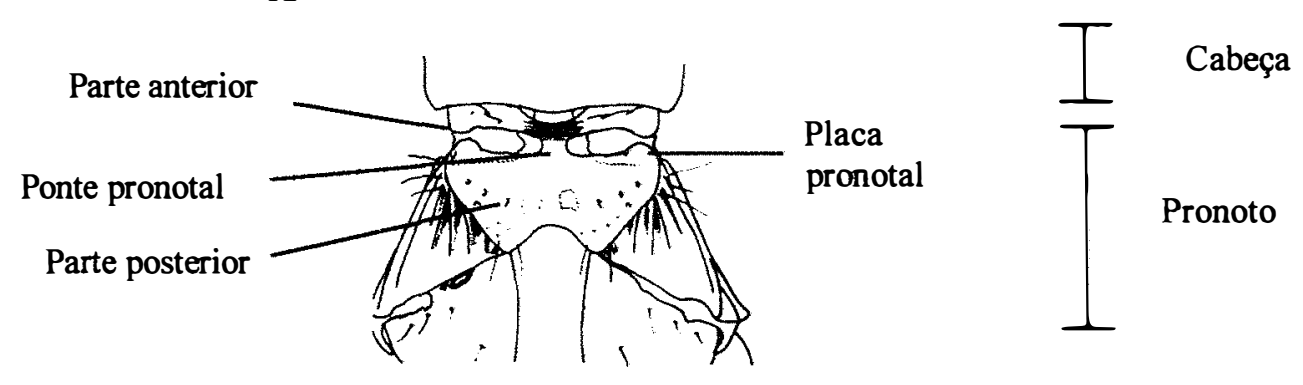

B
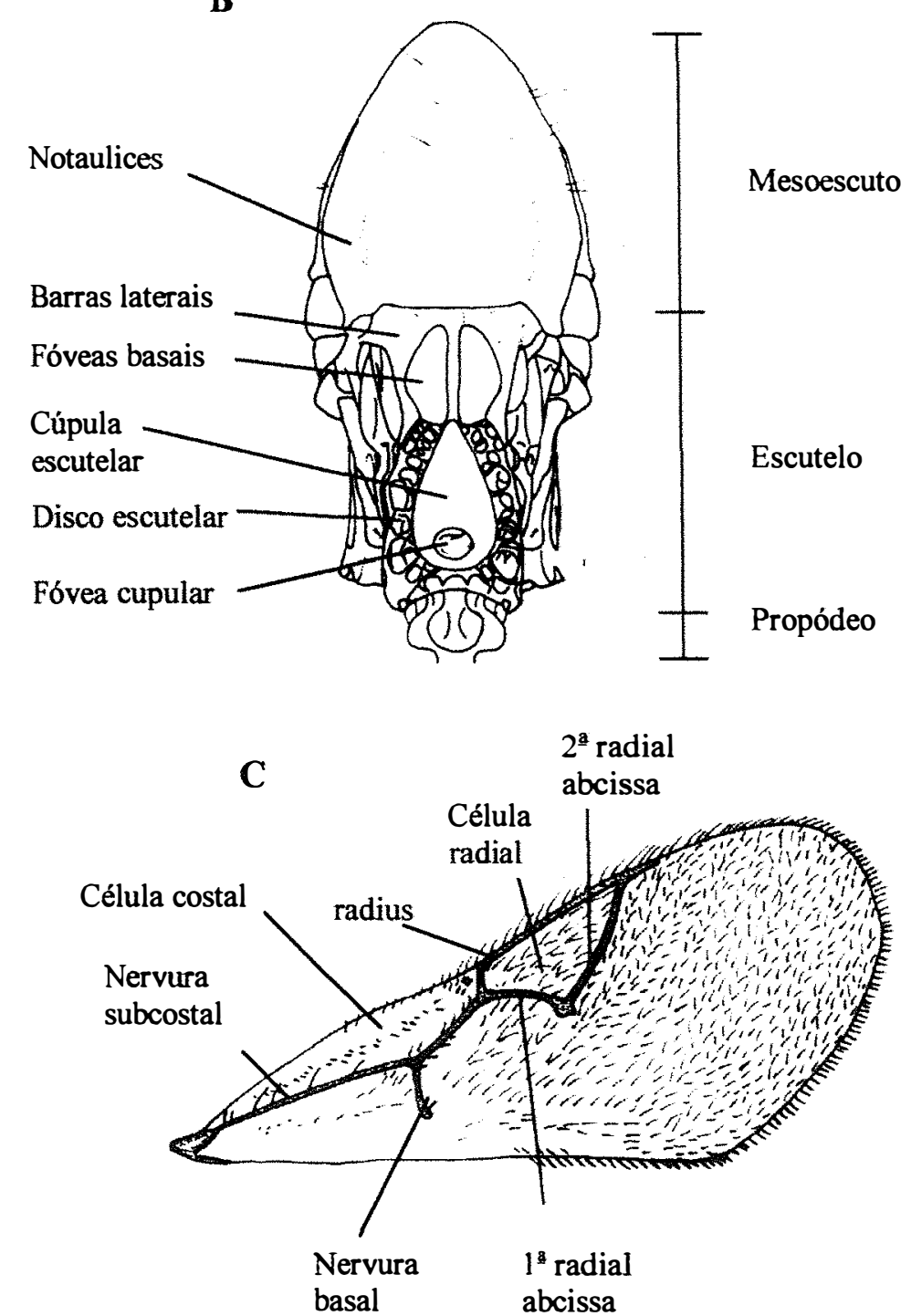

Figura 2. Características morfológicas dos Eucoilinae. A. Placa pronotal; B. Mesosoma, em vista dorsal, apresentando as estruturas do mesoescuto e escutelo; C. Asa anterior. 


\section{RESULTADOS E DISCUSSĀO}

\subsection{Espécies de Eucoilinae}

Foram examinadas 170 amostras de 51 municípios das cinco regiões do Brasil totalizando 2025 eucoilíneos. Entretanto, somente em 27 municípios foram constatados eucoilíneos parasitóides de larvas de tefritóideos (867 exemplares). Desses, foram identificadas seis espécies, entretanto, a espécie do gênero Trybliographa está em fase de descrição (N. B. Diaz - Museo de La Plata). As demais espécies identificadas foram: Aganaspis nordlanderi Wharton, Aganaspis pelleranoi (Brèthes), Dicerataspis flavipes (Kieffer), Lopheucoila anastrephae (Rhower) e Odontosema anastrephae Borgmeier (Tabela 1). Essas espécies representaram $42,82 \%$; as demais $(57,18 \%)$ ou eram parasitóides de Drosophilidae, tais como as espécies do gênero Leptopilina ou a identificação não foi possível (Tabela 1).

Aganapis pelleranoi foi o parasitóide mais abundante, representando $29,93 \%$ de todos os eucoilíneos associados à larvas de moscas em frutos (Tabela 1). Essa espécie é também o eucoilíneo mais comumente obtido em levantamentos realizados na Argentina (Ovruski, 1995) e na Costa Rica (Wharton et al., 1998).

Algumas espécies de Eucoilinae registradas na literatura para o Brasil, tais como as três espécies do gênero Tropideucoila (T. angrensis Borgmeier, 1935, T. rufipes Ashmead, 1903 e $T$. weldi Lima, 1940) não foram obtidas neste trabalho. Provavelmente, isso esteja relacionado ao fato de que nenhuma amostra do Estado do Mato Grosso foi estudada e também ao reduzido número de amostras do Estado do Rio de Janeiro - únicos locais de registro para essas espécies. 
Tabela 1. Espécies e número de eucoilíneos examinados

\begin{tabular}{l|c|r}
\hline \hline \multicolumn{1}{c|}{ Espécies } & $\mathbf{N}^{\mathbf{0}}$ de exemplares & (\%) \\
\hline Aganaspis nordlanderi Wharton, 1998 & 33 & 1,63 \\
Aganaspis pelleranoi (Brèthes, 1924) & 606 & 29,93 \\
Dicerataspis flavipes (Kieffer, 1909) & 82 & 4,05 \\
Lopheucoila anastrephae (Rhower, 1919) & 83 & 4,1 \\
Odontosema anastrephae Borgmeier, 1935 & 54 & 2,67 \\
Trybliographa sp. & 9 & 0,44 \\
Outros Eucoilinae & 1158 & 57,18 \\
\hline Total & 2025 & 100,00 \\
\hline \hline
\end{tabular}


4.2 Chave ilustrada para algumas espécies de Eucoilinae (Hymenoptera, Figitidae) parasitóides de larvas frugívoras (Dip.: Tephritoidea) no Brasil. (Escalas - mm.)

1. Mesoescuto liso e brilhante, com ou sem pêlos na região das notaulices .2

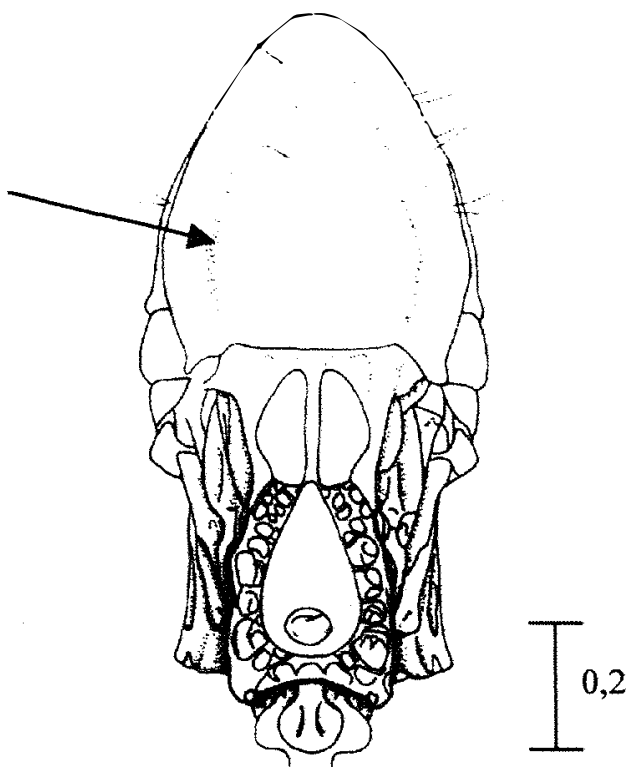

1'. Mesoescuto com 3 a 5 carenas longitudinais. 3
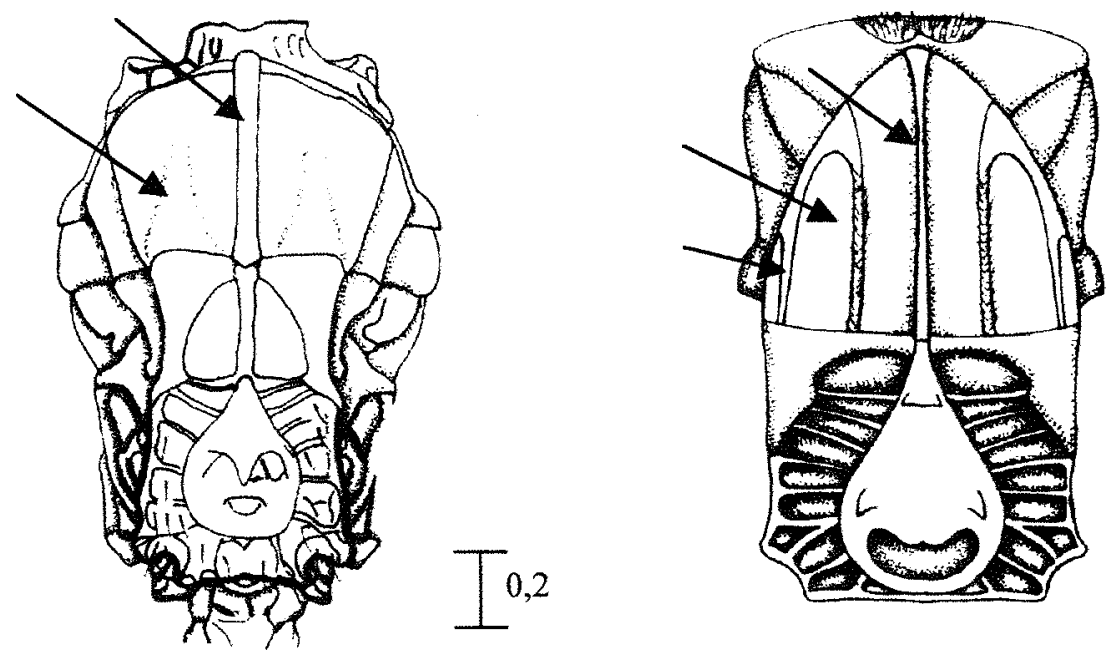
2. Asa pubescênte. .4

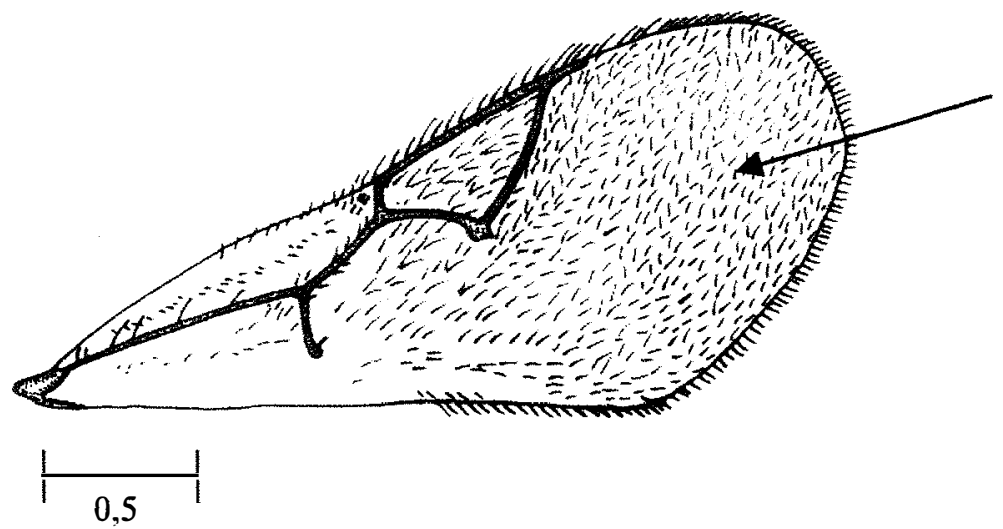

2'. Disco escutelar rugoso e com margem posterior levemente truncada ou bem côncava, formando 2 projeções em forma de dentículos (a). Antenômero 3 dos machos, encurvado e maior que o 4 (b). Placa pronotal com a margem dorsal da parte posterior bastante côncava, com as bordas laterais retas em cima e convexas na parte inferior (c) Asa hialina (d)... Odontosema anastrephae Borgmeier

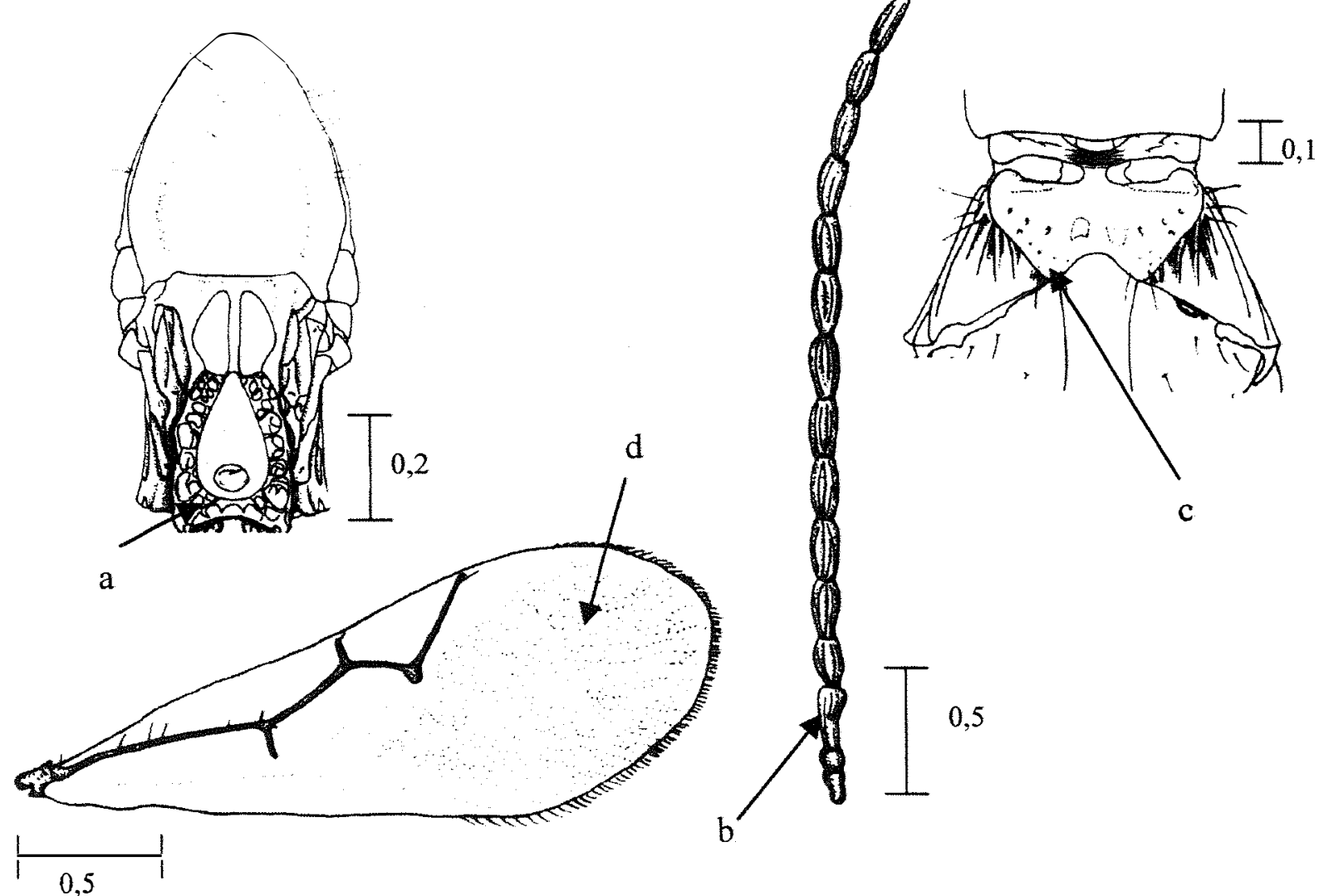


3. Asa pubescênte (a) e célula radial aberta na margem costal (b). Mesoescuto com 5 carenas longitudinais (c). Disco areolado e com a margem posterior truncada ou levemente convexa (d)

Tropideucoila Ashmead

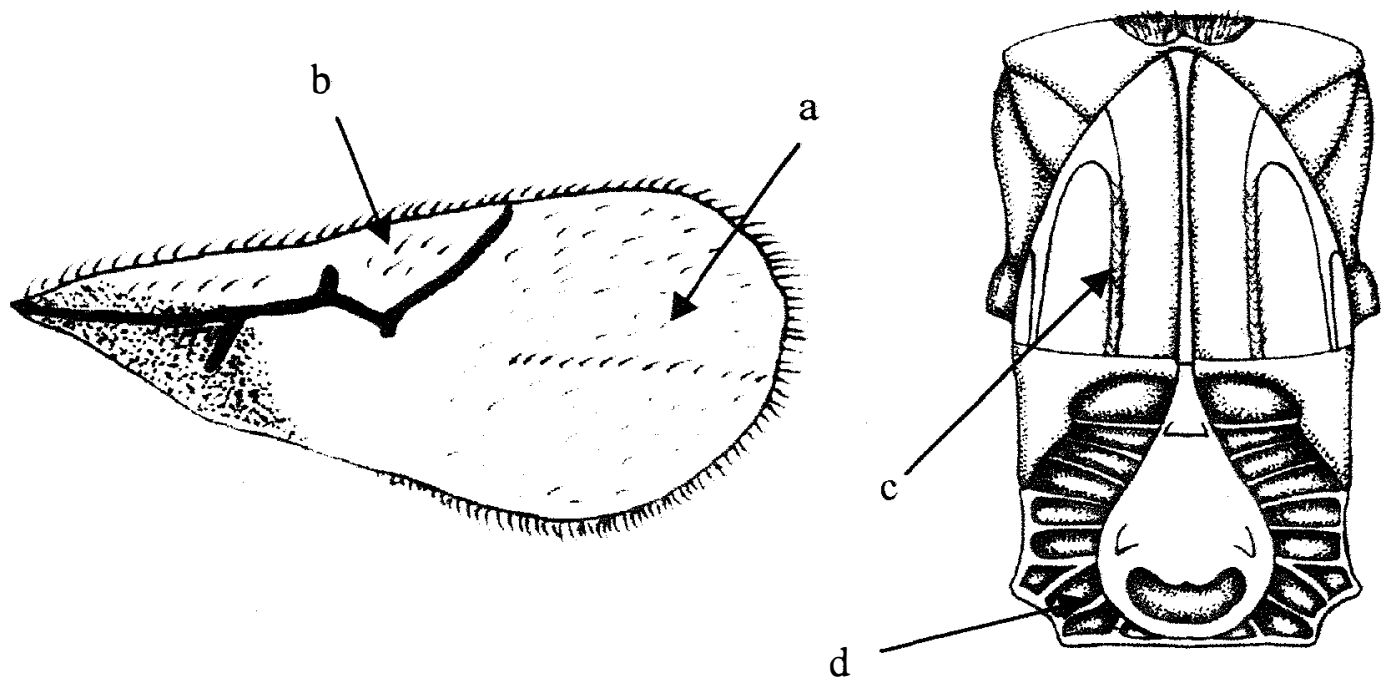

3'. Antenômero 3 dos machos encurvado, maior ou igual ao 4 (a). Placa pronotal com margem dorsal da parte posterior com emarginações (b). Asa hialina, célula radial completamente aberta na margem costal (c). Mesoescuto com três carenas longitudinais (d). Disco estriado e com a margem posterior truncada e com 4 lóbulos dorsais (e). Cúpula escutelar com a parte posterior arredondada e com um dentículo na base da fóvea da cúpula (f).

Lopheucoila anastrephae (Rhower)
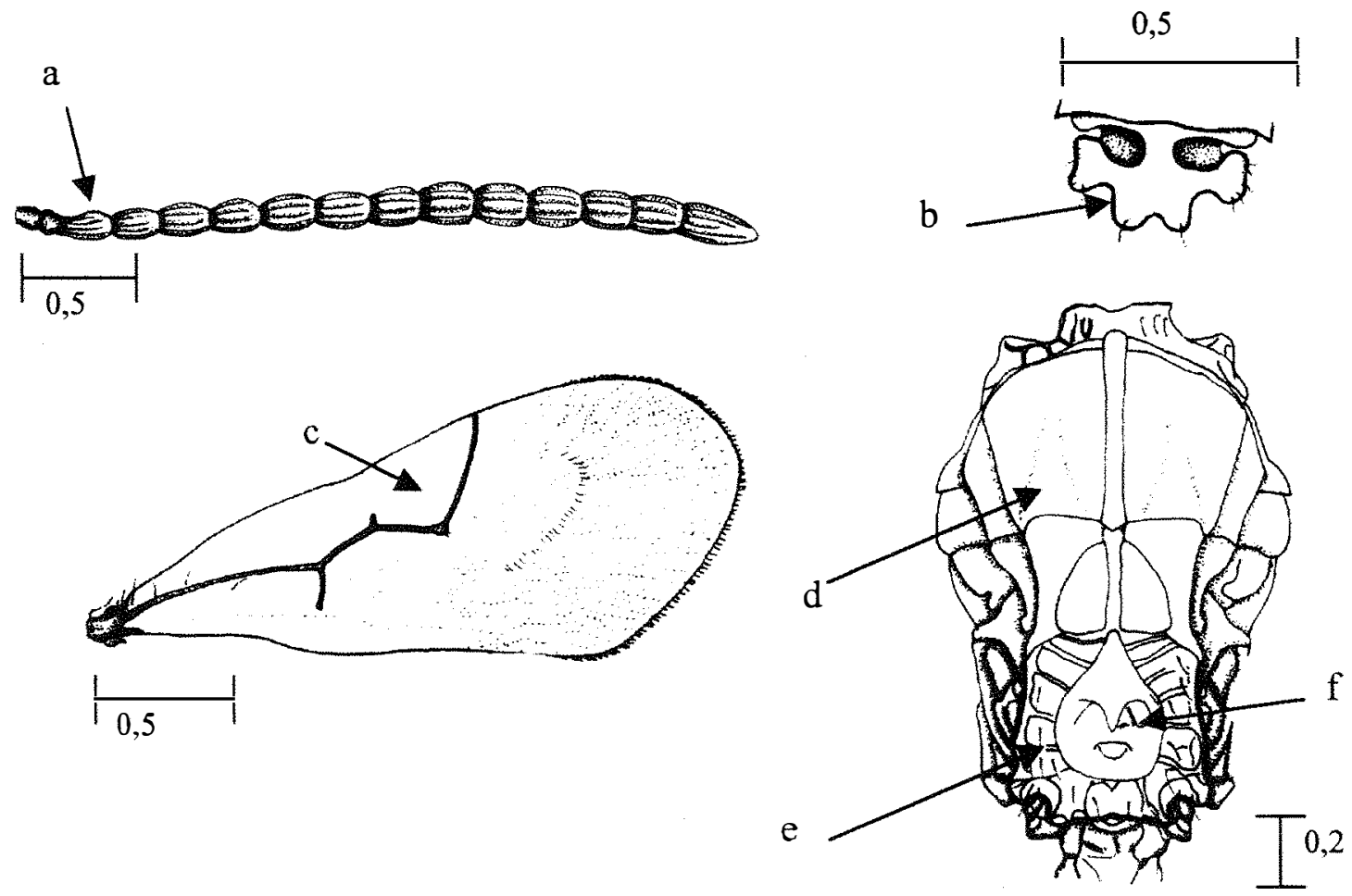

e 
4. Célula radial fechada.

.5
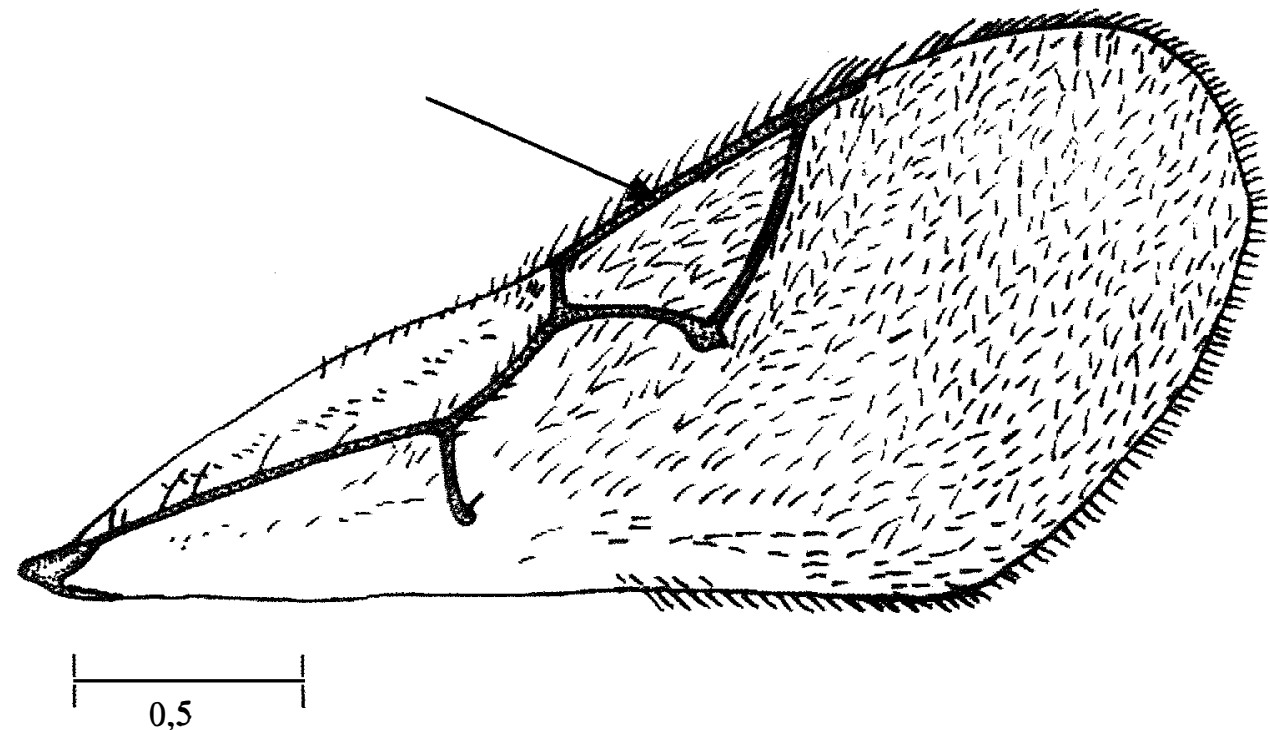

4'. Célula radial aberta

6
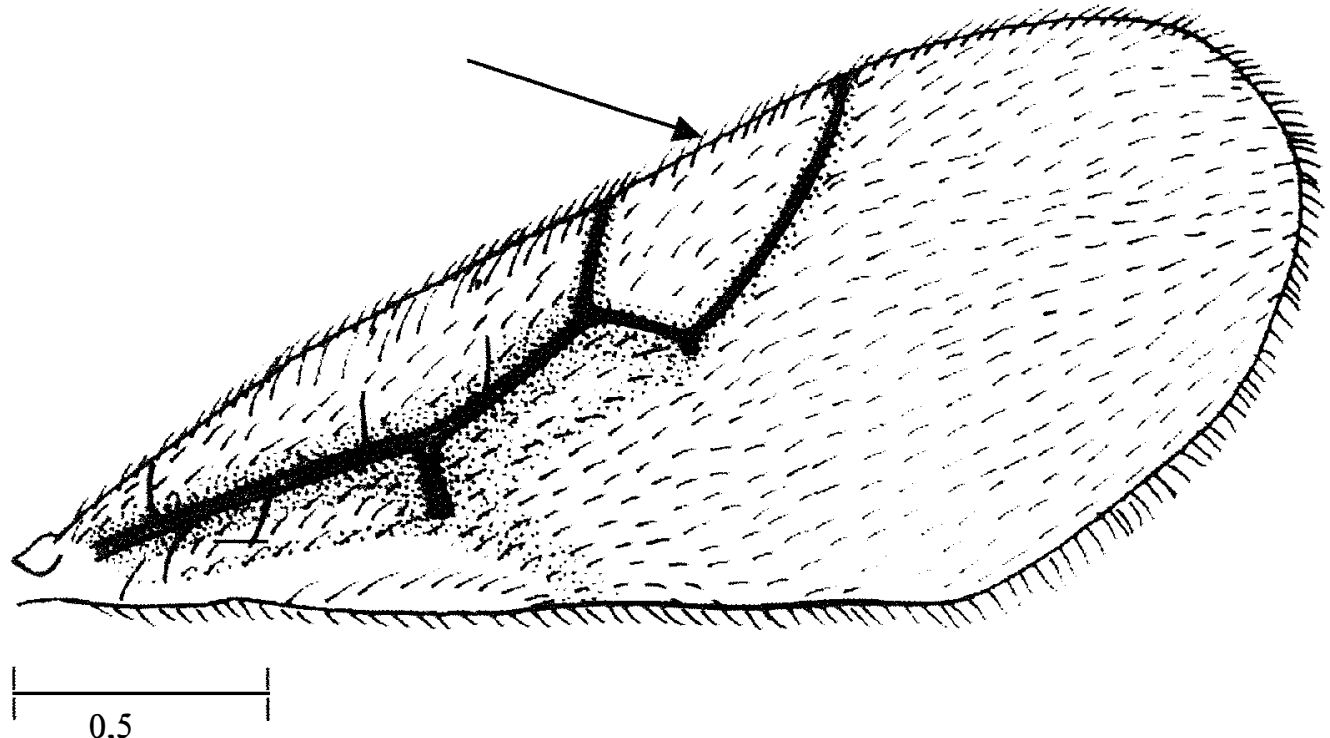
5. Antenômero 3 dos machos encurvado, maior ou igual ao 4 (a). Disco escutelar arredondado, com superfície rugosa (b); cúpula grande, larga e oval quase alcançando as margens do disco (c). Placa pronotal com a margem dorsal da parte posterior côncava e orifícios abertos (d). Aganaspis pelleranoi (Brèthes)
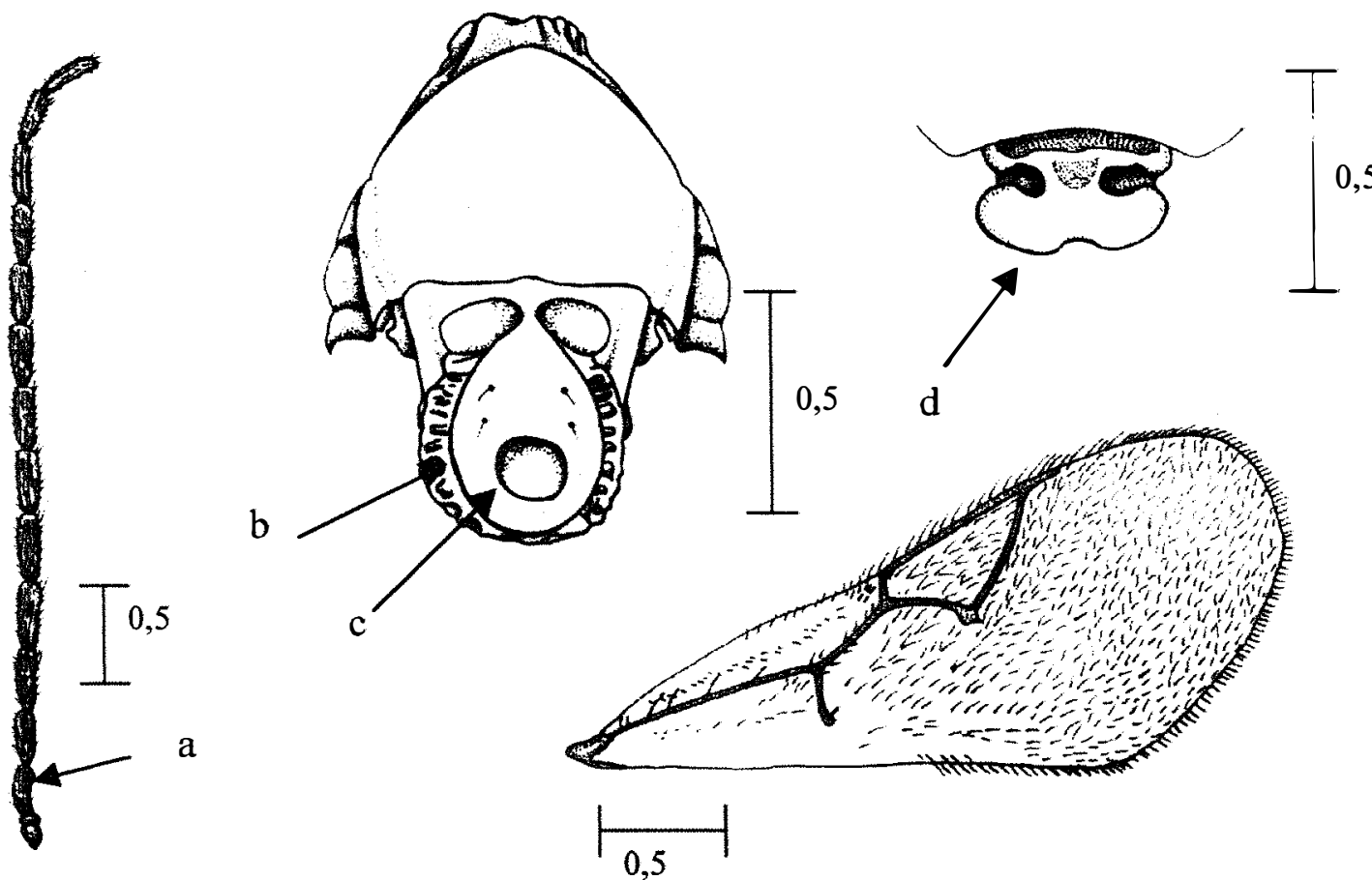

5'. Machos com antenômero 3 quase reto e menor que o 4 (a). Fêmeas com clava de 7 antenômeros (b). Disco com superfície rugosa e margem posterior arredondada ou levemente truncada $(\mathrm{c})$. Terço basal da asa anterior escurecido (d). Placa pronotal não se projetando acima da margem do mesoescuto e com ponte pronotal bastante larga (e)

Trybliographa sp.
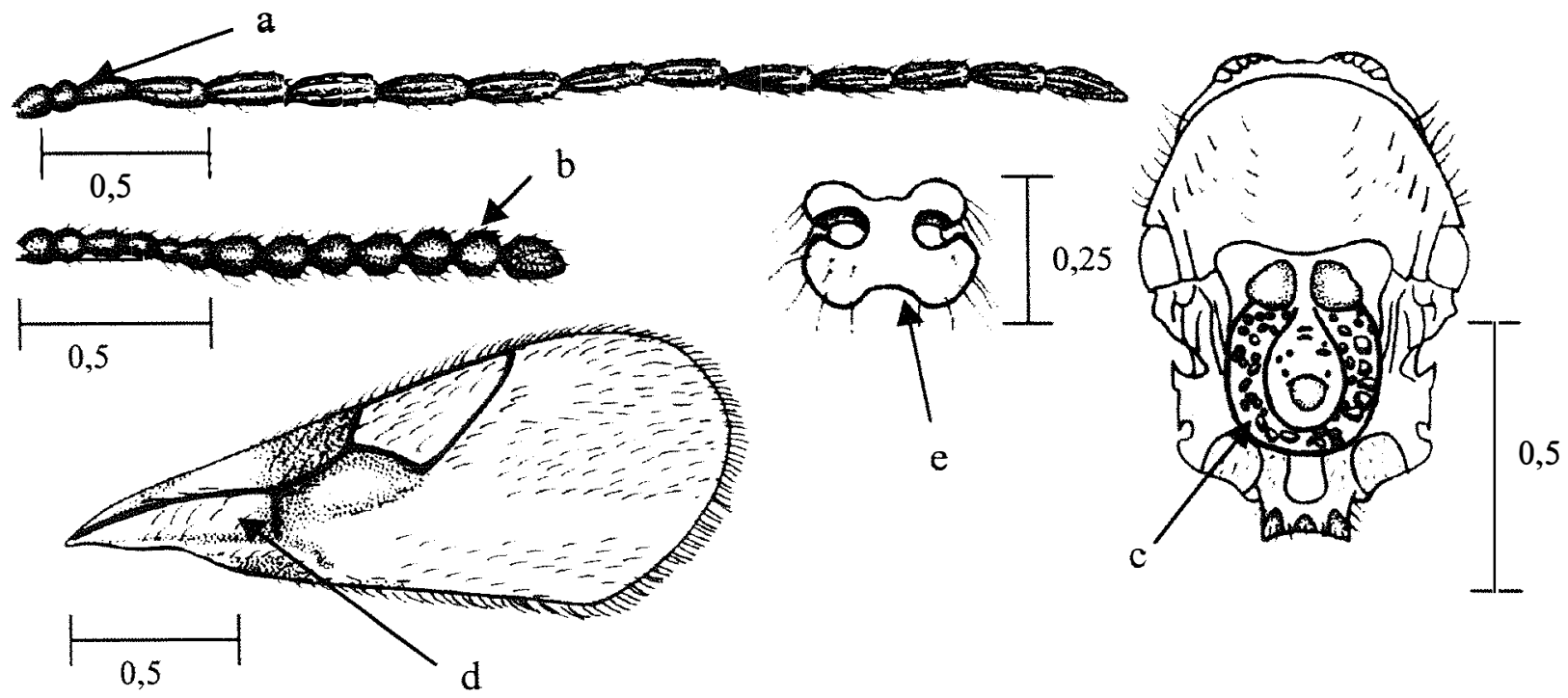
6. Antenômero 3 dos machos, encurvado e maior que o 4 (a); fềmeas com clava indistinta (b). Disco escutelar rugoso, com margem posterior arredondada ou levemente truncada e com pêlos longos (c). Cúpula arredondada (d). Placa pronotal, com margem dorsal da parte posterior côncava e com orifícios abertos (e).

Aganaspis nordlanderi Wharton
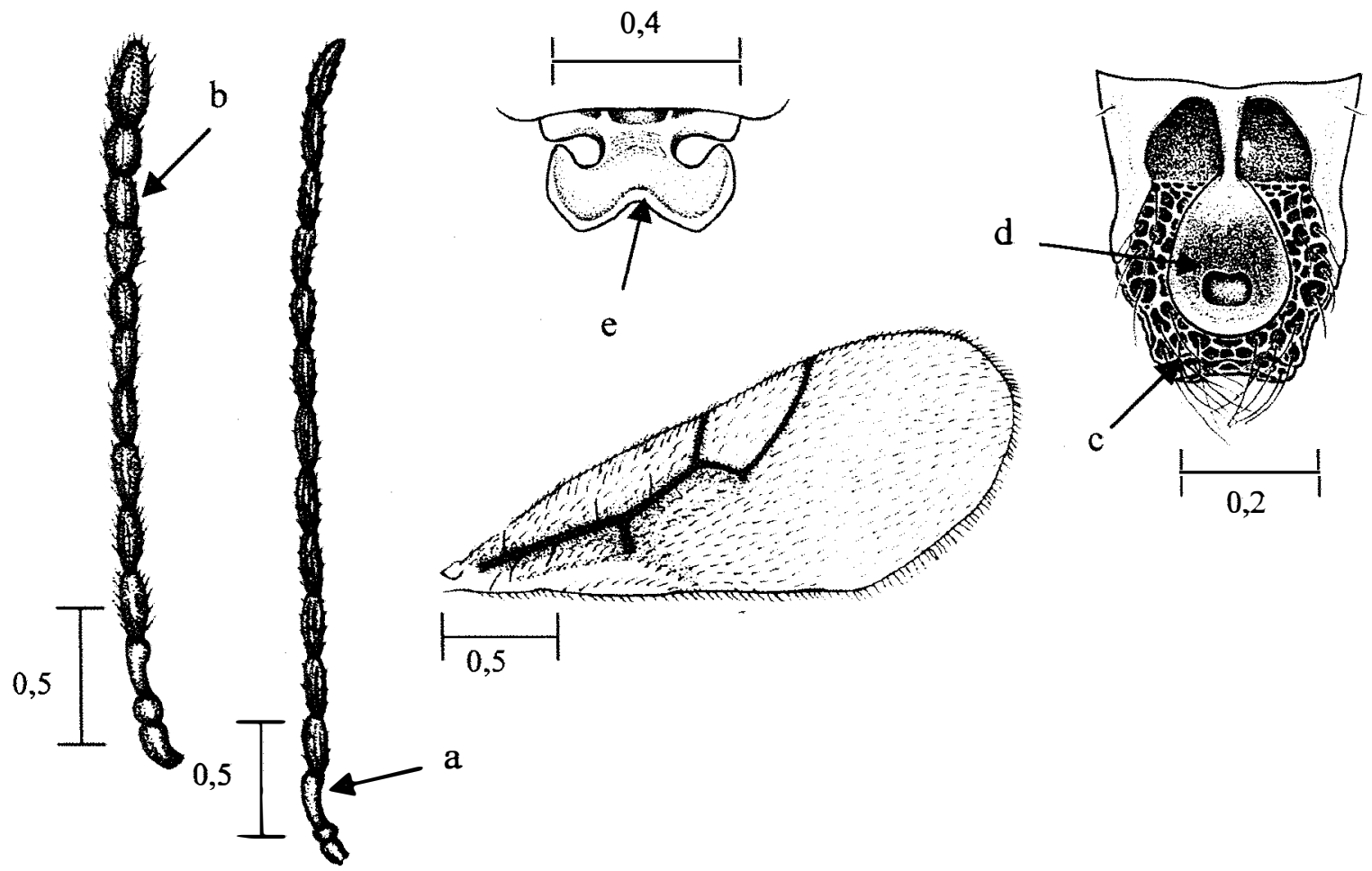

6'. Antenômero 3 do macho maior que o 4 (a); fềmeas com clava de 6 segmentos (b). Disco escutelar rugoso, margem posterior truncada e com as laterais projetando-se em forma de 2 dentes (c). Cúpula escutelar pequena (d) Dicerataspis flavipes (Kieffer)

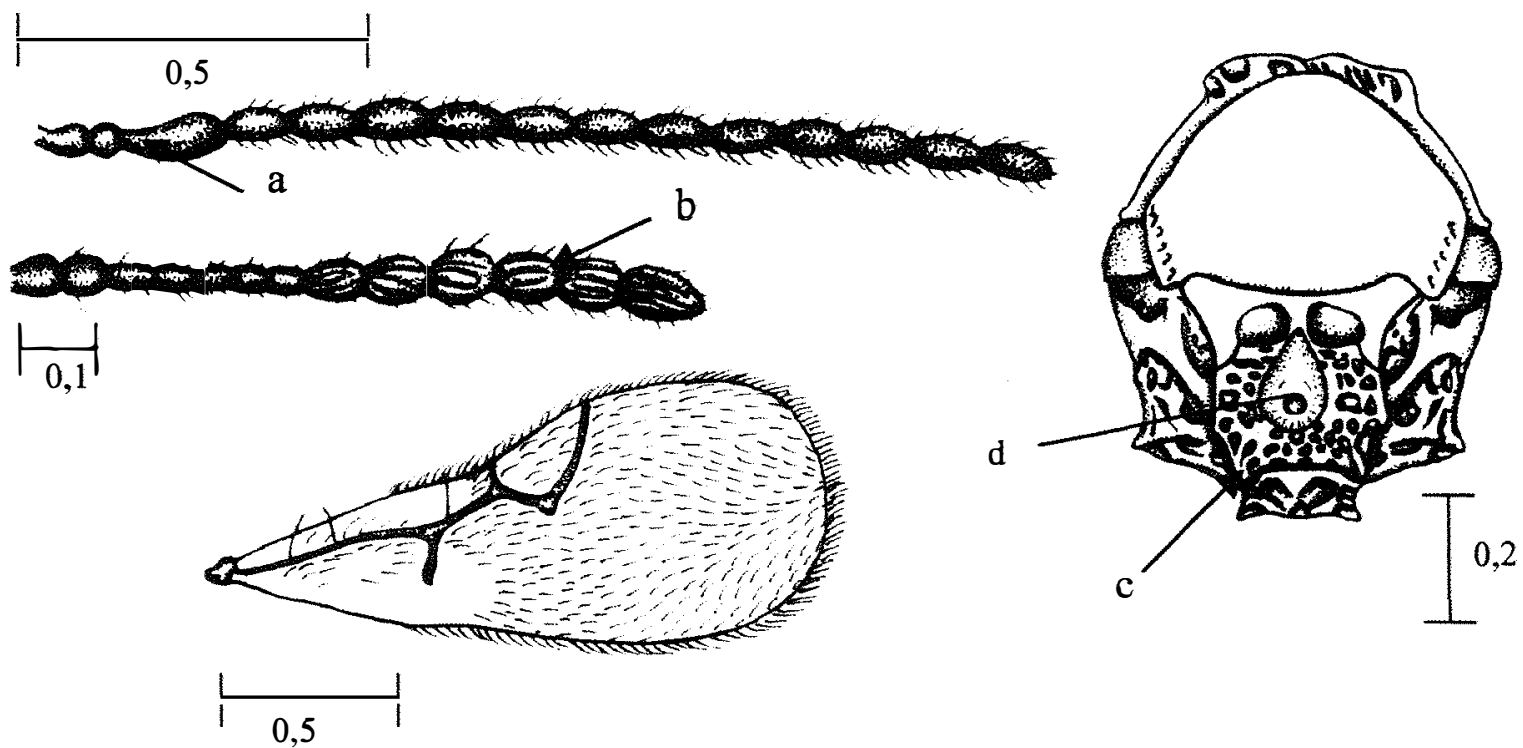




\subsection{Caracterização das espécies de Eucoilinae parasitóides de larvas frugívoras (Diptera: Tephritoidea).}

\subsubsection{Aganaspis nordlanderi Wharton, 1998}

(Figuras 3A - D; 4A - D)

Cabeça. Levemente arredondada em vista frontal (altura 0,80 - 0,87 mm e largura 0,82-0,86 mm). Sulco malar presente. Machos com o terceiro antenômero encurvado externamente e maior o quarto, margem externa achatada e com extremidade distal mais dilatada. $\mathrm{O}$ antenômero 4 é semelhante aos demais, todos com rinários e diminutas cerdas esparsas (Figuras 3A e 3B). Comprimento médio dos segmentos do flagelo (mm): 0,$34 ; 0,28 ; 0,32 ; 0,33 ; 0,33 ; 0,33 ; 0,34 ; 0,34 ; 0,34 ; 0,34 ; 0,34 ; 0,33 ; 0,35$. Antenas das fêmeas com clava indistinta e com cerdas longas distribuídas em todos os flagelômeros. O terceiro antenômero menor que o quarto, os artículos 9 a 12 mais curtos e dilatados apicalmente; $13^{\circ}$ cônico (Figura $3 \mathrm{C}$ ). Comprimento médio dos segmentos do flagelo (mm): 0,$19 ; 0,21 ; 0,21 ; 0,21 ; 0,19 ; 0,19 ; 0,18 ; 0,18 ; 0,18 ; 0,18 ; 0,30$.

Mesosoma. Placa pronotal projetando-se acima da margem anterior do mesoescuto e apresentando a margem dorsal da parte posterior distintamente côncava (Figuras 3D e 4A). Ponte pronotal bastante larga e com as partes anterior e posterior quase fundidas, com orifícios pequenos e abertos. Pronoto com tufos de pêlos na margem ântero-ventral, além de alguns pêlos longos esparsos nas laterais (Figuras 3D, 4A e 4B). Mesoescuto (comp. 1,05 - 1,30 mm e larg. 0,80-0,87 mm) liso e brilhante com quatro linhas de pêlos, duas centrais e paralelas e duas ao longo das margens laterais (Figura 4C). Escutelo (comp. 0,46-0,52 mm e larg. 0,35-0,41 mm) com barras laterais longas e lisas, alcançando quase a metade do escutelo. Fóveas anteriores mais largas na extremidade posterior próxima ao disco escutelar, que apresenta superfície rugosa e margem posterior arredondada ou levemente truncada. Parte posterior do disco com longos pêlos inseridos nas rugosidades (Figuras 4C e 4D). Cúpula escutelar arredondada, não alcançando a margem posterior do disco escutelar (comp. 0,25 - 0,32 mm e larg. 0,17-0,24 mm). Apresenta superficie levemente côncava, com fóvea cupular pequena e puncturas com pilosidade internas (Figuras $4 \mathrm{C} \mathrm{e}$ 
côncava, com fóvea cupular pequena e puncturas com pilosidade internas (Figuras $4 \mathrm{C} \mathrm{e}$ 4D). Depressão lateral do escutelo com margem posterior bem definida e com pubescência abundante (Figuras 4A e 4B). Carenas laterais do escutelo presentes e distintas das demais estruturas do escutelo. Mesopleura com orifício subalar arredondado (Figuras 4A e 4B). Metapleura com a carena superior bem definida e margem posterior com uma fileira de longas cerdas esbranquiçadas (Figuras 4A e 4B). Cavidade ântero-ventral da metapleura em forma de semicírculo com densa pilosidade interna (Figuras 4A e 4B). Carenas propodeais paralelas e curvadas externamente na porção central. Pubescência na parte central e nas laterais das carenas.

Metasoma. Mais longo que alto (comp. 1,10 - 1,54 e alt. 0,9-1,12 mm). Anel piloso denso de aspecto lanoso e completo na região dorsal (Figura 4A).

Pernas. Coxas médias com tufos de pêlos longos e esbranquiçados na porção médio-inferior. Coxas posteriores com uma fileira de cerdas curtas ao longo da metade superior, além de tufos de cerdas longas na porção inferior.

Asas anteriores. Pubescentes, com margem ciliada e escurecidas na metade basal. Nervuras escuras e bem definidas, célula radial aberta na margem costal e com densa pilosidade interna. Segunda radial abcissa quase reta $(0,65 \mathrm{~mm})$ maior que a $1^{\underline{a}}$ radial abcissa $(0,23 \mathrm{~mm})$. Célula costal bastante pilosa. Nervura subcostal com duas cerdas longas. Comprimento da asa: 2,81 -3,04 mm.

Comprimento do corpo. Macho (2,55-3,0 mm) e fềmea (3,0 mm).

Coloração. Cabeça preta, mandíbulas castanho-escuras. Antenas de machos e fềmeas com coloração uniforme (marron-escura a quase preta). Mesosoma completamente preto. Pernas marron-escuras, levemente avermelhadas. Metasoma dos machos castanho-escuro, com uma grande mancha preta no terço apical, fềmeas com metasoma castanho-avermelhado. Asas anteriores com nervuras marron-escuras.

Material examinado. BRASIL. AMAZONAS: Manaus, 27.XII.1991, 8 machos e 1 fềmea; 20. II. 1992, 6 machos e 2 fềmeas; 16. I. 1992, 7 machos e 2 fềmeas; 30. I. 1992, 1 macho; Iranduba, 27.II. 1992, 2 machos (N. M. Silva col.); SÃO PAULO: Luiz Antônio, 19. XII. 1992, 3 machos (N. W. Periotto col.); Pindorama, 9. V. 1994, 1 macho (M. F. Souza Filho col.). 
primeiros registros).

Hospedeiros. Anastrepha striata Schiner e Ceratitis capitata (Wied.) na Costa Rica (Wharton et al., 1998). No Brasil, A. striata Schiner, Anastrepha bahiensis Lima (primeiros registros) e Neosilba sp.

Discussão. Os exemplares obtidos neste trabalho apresentaram poucas variações morfométricas, exceto os obtidos de Luiz Antônio (SP), os quais eram notadamente menores. Esses foram obtidos de pupários de Neosilba sp., que são menores que os de espécies de Anastrepha, dessa forma, a quantidade de nutrientes disponíveis, pode ter exercido algum efeito no desenvolvimento desses parasitóides. Clausen et al. (1965) também constataram o efeito do regime alimentar na fase larval como um dos fatores que determinam o tamanho do parasitóide adulto.

Aganaspis nordlanderi e $A$. pelleranoi são bastante semelhantes com relação ao padrão de coloração. A diferenciação dessas espécies é baseada principalmente na célula radial da asa anterior (aberta em $A$. nordlanderi) e no escutelo, cuja cúpula é menor e com longos pêlos na parte posterior do disco em $A$. nordlanderi. 
A
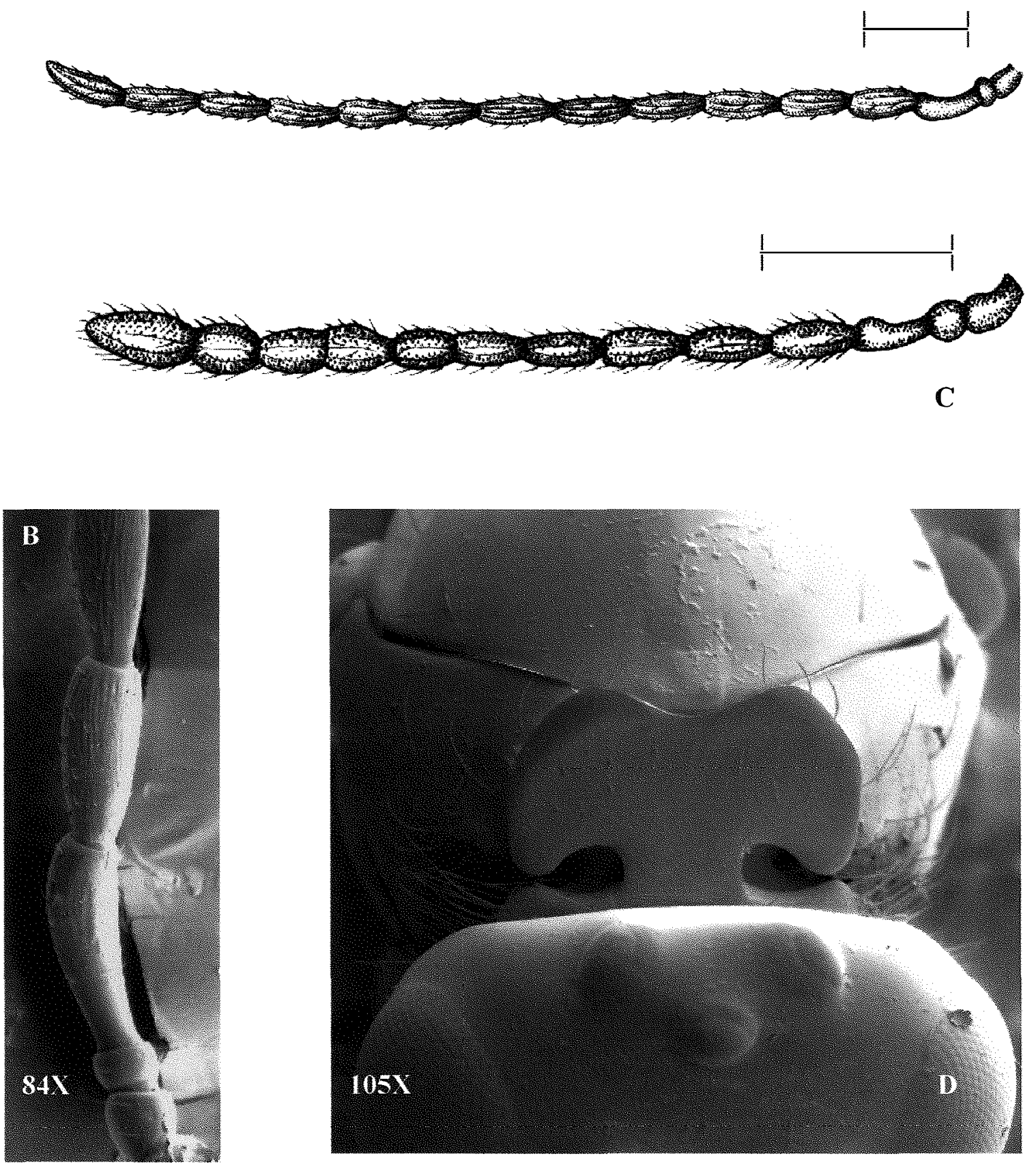

Figura 3: Aganaspis nordlanderi. A. Antena do macho (Escala $=0,5 \mathrm{~mm})$. B. Antena do macho, apresentando os antenômeros 3 e 4; C. Antena da fềmea (Escala = $0,5 \mathrm{~mm}$ ). D. Placa pronotal, vista dorso-frontal. 

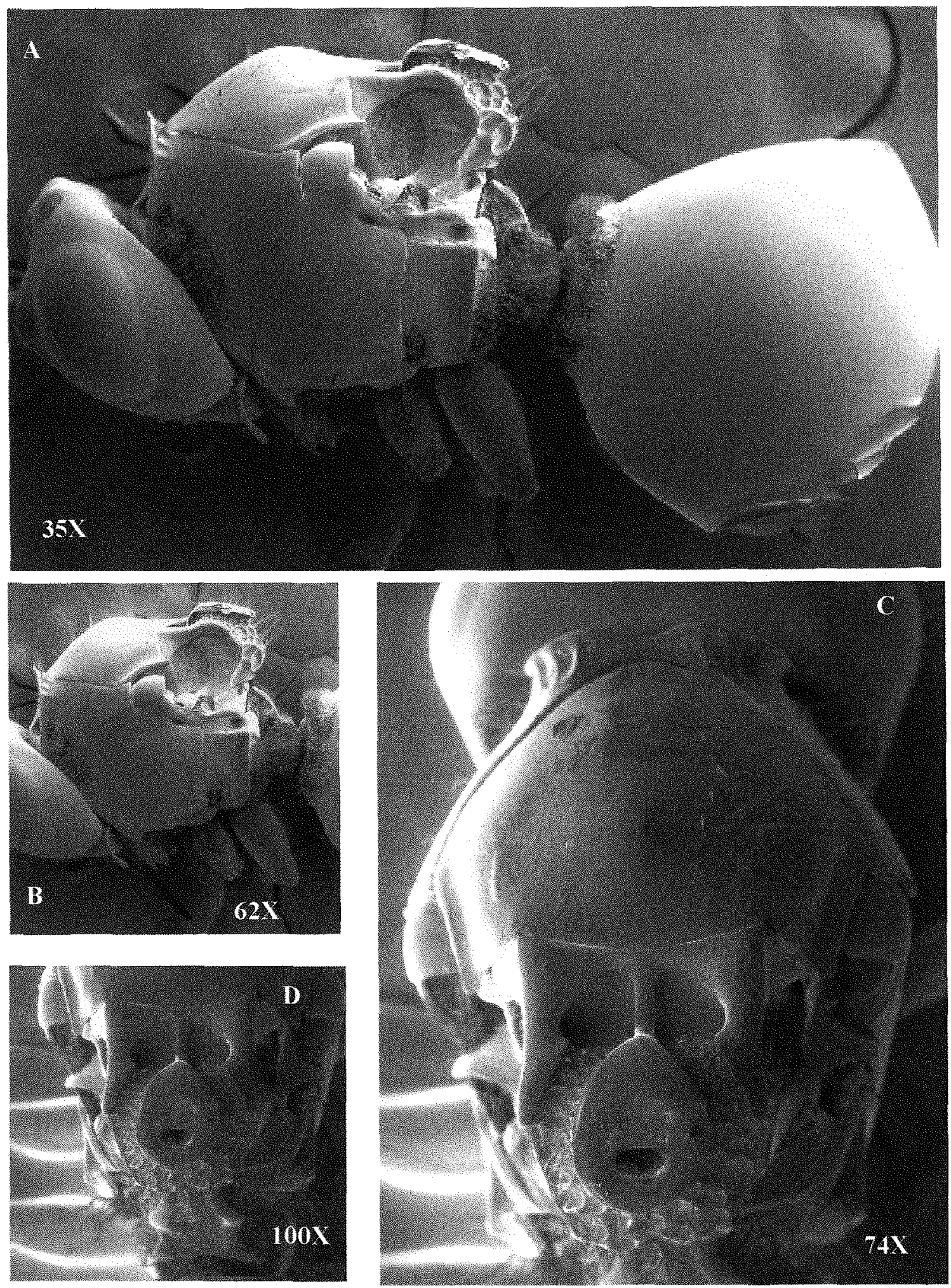

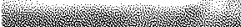

Figura 4: Aganaspis nordlanderi. A. Cabeça, mesosoma e metasoma, vista lateral; B. Mesosoma, vista lateral; C. Mesoescuto, vista dorsal; D. Cúpula escutelar, vista dorsal 


\subsubsection{Aganaspis pelleranoi (Brèthes, 1924)}

(Figuras 5A-D; 6A - C)

Aganaspis pelleranoi (Brèthes, 1924) Ovruski, 1994

Eucoila (Psychacra) pelleranoi Brèthes, 1924

Ganaspis carvalhoi Dettmer, 1929

Psychacra pelleranoi Weld, 1952

Ganaspis pelleranoi (Brèthes, 1924) De Santis, 1965

Cabeça. Em vista frontal, apresenta formato levemente arredondado, um pouco mais alta $(0,74-0,95 \mathrm{~mm})$ que larga $(0,59-0,83 \mathrm{~mm})$. Olhos compostos sem cerdas aparentes. Face lisa e brilhante. Machos apresentando o terceiro antenômero maior ou igual ao quarto, levemente encurvado externamente e com região achatada na parte externa. O antenômero 4 é semelhante, porém um pouco menor que os subseqüentes (Figura 5A). Comprimento médio dos segmentos do flagelo (mm): 0,$31 ; 0,28 ; 0,31$, 0,$31 ; 0,31 ; 0,31 ; 0,30 ; 0,30 ; 0,30 ; 0,30 ; 0,29 ; 0,28 ; 0,32$. Todos apresentam cerdas diminutas e difusas além de pontos sensoriais longitudinais (rinários). Fêmeas com antenas 13-segmentadas, clava de 7 artículos com rinários. Segmentos antenais com grande quantidade de cerdas longas e difusas. $\mathrm{O}$ terceiro antenômero mais comprido que largo, os segmentos 4 a 6 com extremidades posteriores dilatadas; 13ํำ cônico (Figura 5B). Comprimento dos segmentos do flagelo (mm): 0,$20 ; 0,16 ; 0,14 ; 0,14 ; 0,14 ; 0,15$; 0,$14 ; 0,14 ; 0,14 ; 0,14 ; 0,19$.

Mesosoma. Placa pronotal com a margem dorsal da parte posterior distintamente côncava e com pilosidade. Partes anterior e posterior completamente separadas, com orifício aberto (Figura 5C). Margem ântero-ventral do pronoto com densa pubescência esbranquiçada, além de alguns longos pêlos esparsos (Figura 5C). Mesoescuto (comp. 1,0-1,17 mm e larg. 0,71-0,95 mm) liso e brilhante (Figura 5D). Escutelo (comp. 0,46 $-0,62 \mathrm{~mm}$ e larg. $0,34-0,45 \mathrm{~mm}$ ) com barras laterais alcançando quase a metade do comprimento da cúpula escutelar (Figuras 5D e 6A). Fóveas basais do escutelo ovaladas. Disco escutelar com margem posterior arredondada, superfície pontuada ou rugosa com uma fileira de cerdas alongadas na margem posterior (Figura 5D e 6A). Cúpula escutelar 
grande, larga e ovalada (comp. 0,37-0,45 mm e larg. 0,22-0,31 mm), com três cerdas localizadas em pequenos orifícios na superfície e um anel de coloração mais clara circundando a margem externa. Fóvea cupular localizada na parte posterior, cobrindo quase toda a metade da estrutura (Figura 6A). Cúpula bastante achatada (vista lateral), pouco elevada da base do escutelo (Figuras 6B e 6C). Depressão lateral do escutelo com margem posterior definida e com pubescência interna (Figuras 6B e 6C). Metapleura com duas carenas, a superior curta, estendendo-se da margem posterior até cerca da metade da estrutura; carena inferior alcança toda a extensão da metapleura (Figuras 6B e 6C). Cavidade ântero-ventral arredondada, com tufos de pêlos internos e margem posterior da metapleura densamente pilosa (Figuras 6B e 6C). Propódeo com carenas amplamente separadas, quase paralelas e encurvadas externamente na região mediana.

Metasoma. Mais longo $(0,95-1,75 \mathrm{~mm})$ que alto $(0,76-1,60 \mathrm{~mm})$. Presença de anel piloso na base do tergito III, esse de aspecto lanoso e completo (Figura 6C).

Pernas. Coxas medianas com um feixe de longos pêlos na parte mediana e coxa posterior com um denso tufo de pêlos na metade inferior.

Asa anterior. Pubescênte e com margem ciliada. Célula radial, fechada na margem costal (comp.: 2,53-2,97 mm). A 1 ${ }^{\text {a }}$ radial abcissa com comprimento médio de $0,28 \mathrm{~mm}$, encurvada e a $2^{\underline{a}}$ radial abcissa quase reta (comp. médio $0,35 \mathrm{~mm}$ ).

Comprimento do corpo. Macho (2,28 -2,84 mm) e fềmea (2,8 - 3,44 mm).

Coloração. Cabeça preta e brilhante; mandíbulas marron-avermelhadas. Antenas de machos e fềmeas com coloração uniforme, marron-avermelhadas ou marron-escuras. Mesoescuto e mesopleura completamente pretos; metapleura preta com manchas avermelhadas. Pernas castanho-escuras. Metasoma castanho-avermelhado a castanhoescuro, com mancha escura na superfície dorsal, principalmente nos machos. Asas anteriores com nervuras castanho-escuras.

Material examinado. BRASIL. AMAZONAS: Manaus, 27. XII. 1991, 1 macho e 2 fềmeas; 29. V. 1991, 1 macho; 27. XII. 1991, 3 machos e 2 fềmeas; 20. II. 1992, 1 macho e 1 fềmea; 16. I. 1992, 3 machos e 9 fềmeas; 30. I 1992, 1 macho; 29. I. 1992, 2 machos e 2 fềmeas (N. M. Silva col.); BAHIA: Conceição de Almeida, IX. 1997, 4 machos e 9 fềmeas (R. S. Carvalho col.); GOIÁS: Goiândira, 20. V. 1998, 3 machos (L. 
R. Valle col.); SÃO PAULO: Campinas, 02. IV. 1998, 1 macho e 1 fềmea; 27. III. 1996, 5 machos e 1 fềmea; 17. III. 1997, 3 machos e 3 fềmeas; 19. XII. 1996, 5 machos e 3 fềmeas; 27. III. 1996, 4 machos e 1 fềmea; 24. XI. 1997, 2 machos; 19. XI. 1997, 2 machos; 20. XI. 1997, 10 machos e 7 fêmeas; 11. II. 1998, 1 macho; 12. I. 1995, 3 machos e 5 fềmeas; São Paulo, 4. XI. 1993, 1 macho; 21. II. 1995, 1 macho; Sorocaba, 5. XII. 1996, 1 fêmea; São Bento do Sapucaí, 27. I. 1995, 3 machos; Badid Bassit, 9. IV. 1997, 1 macho; Atibaia, 7. IV. 1998, 1 macho (M. F. Souza Filho col.); RIO DE JANEIRO: Campo Grande, 2 macho e 1 fềmea (J. P. Araújo col.); PARANÁ: Londrina, 10. II. 1996, 2 machos e 3 fêmeas (A. O. Menezes Júnior col.); SANT A CATARINA: Caçador, XII. 1993, 5 machos e 1 fềmea; Iomerê, 18. IV. 1994, 44 machos e 54 fềmeas; 23. IX. 1994, 1 macho e 1 fêmea; 23. IX. 1994, 5 machos e 3 fềmeas; Videira, 23. IX.1994, 1 macho e 1 fềmea (I. Nora col.); RIO GRANDE DO SUL: Vacaria, XII. 1997, 4 machos e 9 fềmeas (R. L. Sugayama col.); Pelotas, 21. XI. 1997, 1 macho; 27. XI. 1997, 2 fềmeas; 25. XI. 1997, 1 fềmea; 19. XI. 1997, 5 machos e 15 fềmeas; 19. XI. 1997, 7 fềmeas; 19. XI. 1997, 1 macho e 10 fềmeas; 25. XI. 1997, 1 fềmea; 25. XI. 1997, 1 macho; 25. XI. 1997, 8 fềmeas; 25. XI. 1997, 120 machos e 145 fềmeas; 28. XI. 1997, 2 fềmeas; 21. XI. 1997, 13 machos e 24 fềmeas; 21. XI. 1997, 4 fềmeas; 20. III. 1998, 4 machos (L. A. B. Salles col.).

Distribuição geográfica. Brasil (SP, Dettmer, 1929; SC, De Santis, 1980; RS, Salles, 1996; BA, Matrangolo et al., 1997; PR, Menezes Jr. et al., 1997; GO, Veloso, 1997; AM; RJ, Primeiras citações), Argentina (De Santis, 1967), Bolívia (Wharton et al., 1998), El Salvador (Ovruski et al., 1996), Panamá (Wharton et al., 1998), Guatemala (Wharton et al., 1998), Belize (Wharton et al., 1998), Nicarágua (Diaz, 1994), Peru (Haywardi, 1943; Clausen, 1978), México (Aluja et al., 1990), Costa Rica (Wharton et al., 1981) e Colômbia (Yepes \& Velez, 1989). Foi introduzido em 1942 de Tucuman na Argentina para o Peru (Haywardi, 1943; Clausen, 1978; Wharton, 1989).

Hospedeiros. Anastrepha ludens (Loew), A. obliqua (Macquart) (Aluja et al., 1990), A. serpentina (Wiedemann) (Lima, 1940), Anastrepha striata Schiner (Clausen, 1978), A. distincta Greene (Katiyar et al., 1995), A. fraterculus (Wiedemann) (Brèthes, 1924), Ceratitis capitata (Wiedemann) (De Santis, 1965), Rhagoletis turpiniae 
Hernández-Ortiz (Hernández-Ortiz, 1993) e Neosilba perezi (Romero \& Ruppel) (Lourenção et al., 1996), Neosilba batesi (Curran) (Wharton et al., 1998), Lonchaea sp. (Borgmeier, 1935) e Silba pendula (De Santis, 1980). Os registros de Lonchaea sp. e Silba pendula encontrados na literatura, estão provavelmente referindo-se às espécies do gênero Neosilba McAlpine e dessa forma, esses registros devem ser redefinidos (McAlpine \& Steyskal, 1982). Anastrepha amita Zucchi, 1979 e Anastrepha bahiensis Lima, 1937 são registradas pela primeira vez como hospedeiras de $A$. pelleranoi.

Discussão. Com base nos exemplares examinados, verificou-se que não há grandes variações intra-específicas. As variações mais comumente observadas, foram com relação ao tamanho. É a primeira referência dessa espécie parasitando Anastrepha amita Zucchi, 1979 e Anastrepha bahiensis Lima, 1937. É também, pela primeira vez registrada nos Estados do Amazonas e Rio de Janeiro. Na literatura nacional tem sido comumente referido como Ganaspis carvalhoi Dettmer. 

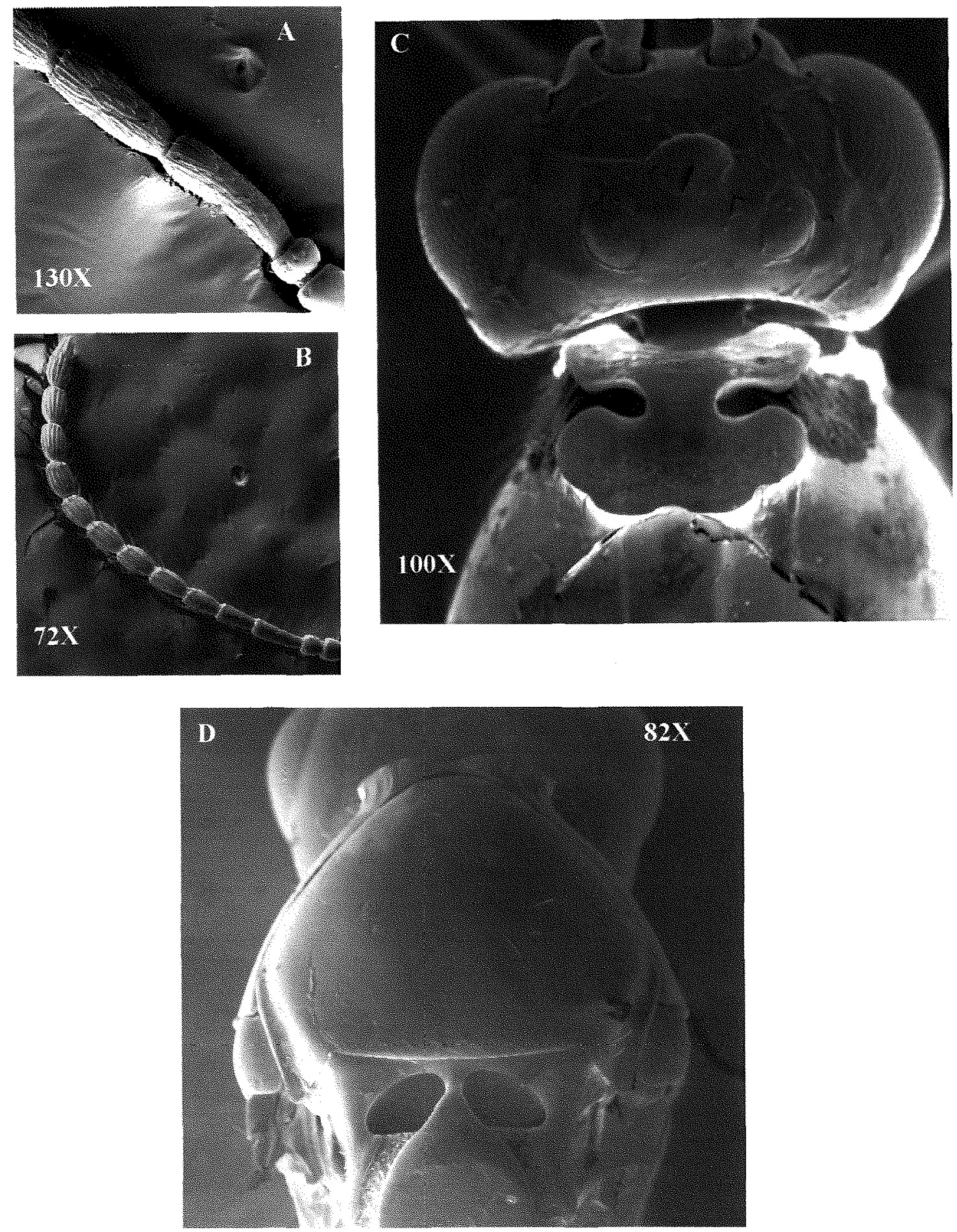

Figura 5: Aganaspis pelleranoi. A. Antenômeros 3 e 4 do macho; B. Antena da fềmea; C. Placa pronotal, vista dorso-frontal; D. Mesoescuto, vista dorsal. 

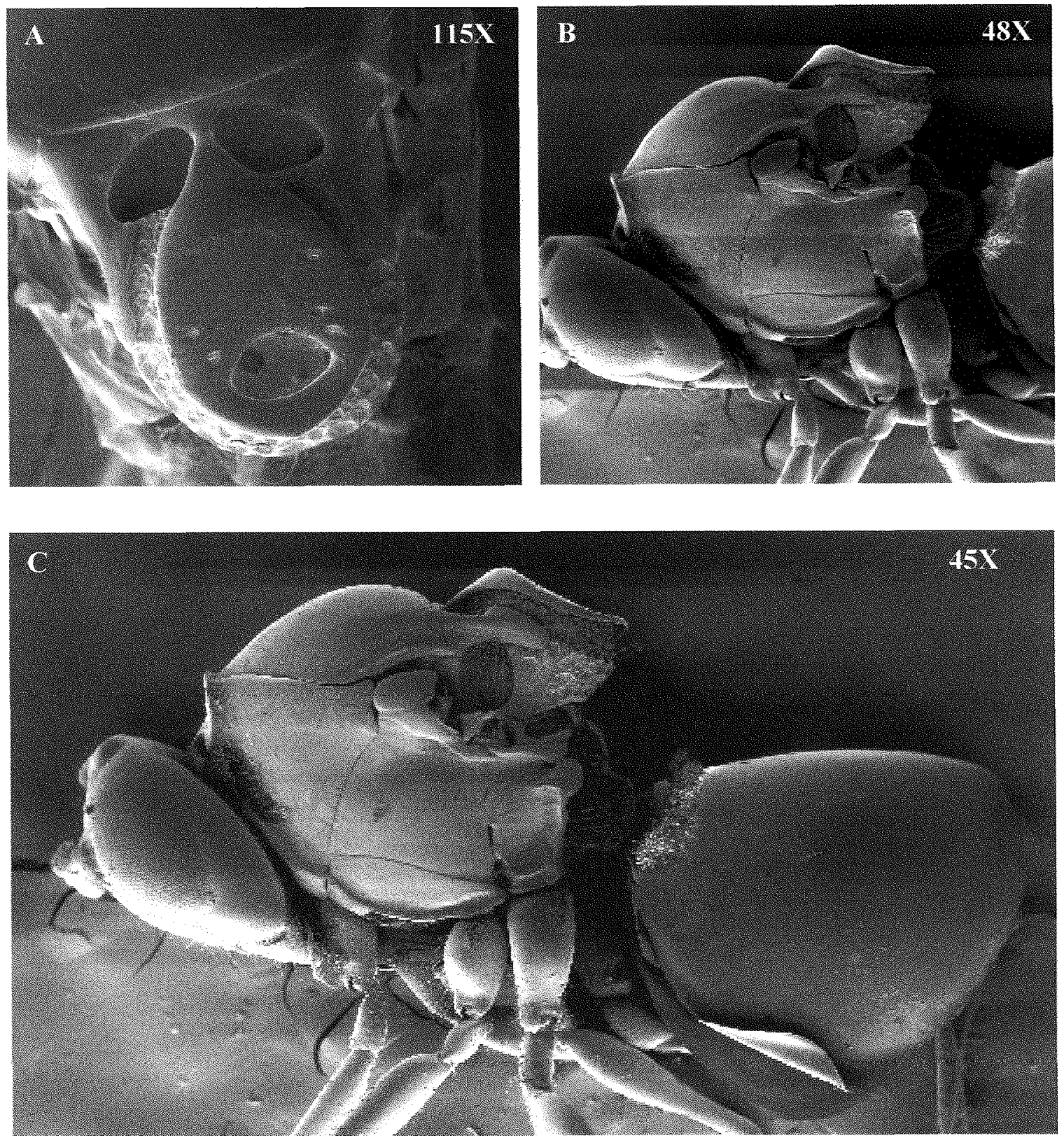

Figura 6: Aganaspis pelleranoi. A. Cúpula escutelar vista dorsal; B. Mesoescuto, vista lateral; C. Cabeça, mesosoma e metasoma, vista lateral. 


\subsubsection{Dicerataspis flavipes (Kieffer, 1909)}

(Figuras 7A - E; 8A - C)

Dicerataspis flavipes (Kieffer, 1909) Weld (1952)

Dissodontaspis flavipes Kieffer, 1909

Cabeça. Arredondada (alt. média 0,57 mm e larg. média 0,54 $\mathrm{mm}$ ) com sulco malar presente (Figura 7A). Machos com o terceiro antenômero maior que os demais e fortemente encurvado externamente; lado externo com a superficie bem achatada (Figura 7B). O quarto antenômero igual aos subseqüentes, exceto os cinco últimos que afilam-se gradualmente (comp. médio - mm: 0,$21 ; 0,15 ; 0,15 ; 0,15 ; 0,15 ; 0,15 ; 0,15 ; 0,15 ; 0,15$; $0,14 ; 0,14 ; 0,14 ; 0,16)$. Cerdas esparsas e rinários presentes em todos os flagelômeros. Antenas das fềmeas com clava de seis segmentos, distinguiveis apenas pela presença de rinários. Presença de longas cerdas em todos os flagelômeros. O antenômero 3 é maior que o quarto; os segmentos 4 a 7 semelhantes em forma e tamanho, os segmentos 8 a 12 subcilíndricos e o $13^{\text {o }}$ cônico (comp. médio - mm: 0,08;0,05;0,05;0,05;0,06;0,09; 0,$09 ; 0,10 ; 0,10 ; 0,10 ; 0,13$ ) (Figura 7C).

Mesosoma. Parte posterior da placa pronotal com a margem dorsal levemente côncava e com pêlos eretos ao longo de toda margem dorsal. Partes anterior e posterior da placa pronotal separadas, originando orifícios laterais abertos. A parte posterior da placa pronotal não se projeta acima da margem anterior do mesoescuto (Figura 7D). Presença de tufos de pêlos longos na margem ântero-ventral do pronoto (Figura 7D). Partes laterais do pronoto pilosas. Mesoescuto (comp. 0,55 - 0,77 mm e larg. 0,50-0,61 $\mathrm{mm}$ ) liso e brilhante, com poucos pêlos na região das notaulices (Figura 7E). Escutelo de forma retangular (comp. 0,25-0,31 mm e larg. 0,21-0,24 mm), com a margem posterior bem côncava, com duas projeções dentiformes conspícuas (Figuras 7E e 8A). Superficie do disco escutelar areolada-rugosa com pêlos curtos na região posterior, inseridos nos orifícios das rugosidades. Fóveas anteriores largas quase esféricas (Figuras 7E e 8A). Cúpula pequena (comp. 0,12-0,17 mm e larg. $0,10-0,12 \mathrm{~mm}$ ) não alcançando a margem posterior do disco, com um anel de coloração mais clara circundando toda a margem da cúpula, superfície interna mais escura e com duas puncturas com pêlos (Figuras 7E e 8A). Barras laterais curtas e lisas com pequenos 
orifícios abaixo (Figuras 7E e 8A). Depressão lateral do escutelo com margem posterior definida e pubescência ausente (Figuras $8 \mathrm{~B}$ e $8 \mathrm{C}$ ). Mesopleura convexa e com orifício subalar esférico (Figuras 8B e 8C). Metapleura com carenas desenvolvidas e com tufos de pêlos na porção inferior da margem externa. Cavidade ântero-ventral grande e com densa pubescência intema (Figuras 8B e 8C). Carenas propodeais curtas, amplamente separadas na base e convergindo-se posteriormente.

Metasoma. Mais longo $(0,60-0,71 \mathrm{~mm})$ que alto $(0,45-0,61 \mathrm{~mm})$. Anel piloso com pêlos esparsos e incompletos na região dorsal (Figura $8 \mathrm{C}$ ).

Pernas. Coxas medianas com tufos de pêlos longos na parte dorso-lateral. Coxa posterior com uma faixa de pêlos curtos na região posterior, além de um tufo de pêlos longos na parte médio-inferior.

Asas anteriores. Apresentando terço basal pouco piloso e o restante da asa densamente pubescênte. Margem costal e apical com longos cílios. Nervuras escuras; célula radial completamente aberta na margem costal, $2^{\underline{a}}$ radial abcissa encurvada (comp. médio $0,29 \mathrm{~mm}$ ) maior que a $1^{\underline{a}}$ radial abcissa (comp. médio $0,14 \mathrm{~mm}$ ); radius longo com uma cerda ereta no ápice. Asa com 1,55 a 1,75 mm.

Comprimento do corpo. Macho (comp. 1,36 - 1,56 mm) e fềmea (comp.1,32 $1,37 \mathrm{~mm})$.

Coloração. Cabeça preta; mandíbulas castanho-claras. Machos e fềmeas com antenas de coloração uniforme, geralmente castanho-escuras a quase pretas. Mesosoma e metasoma completamente pretos. Pernas castanho-claras; coxas marron-escuras. Nervuras castanho-escuras nos machos e mais claras nas fềmeas.

Material examinado. BRASIL. SÃO PAULO: Nazaré Paulista, 19. VII. 1996, 14 machos; 11. VII. 1996, 38 machos e 27 fềmeas; Campinas, 07. II. 1996, 1 macho e 1 fềmea; 30. XI. 1994, 1 macho, (M. F. Souza Filho col.).

Distribuição geográfica. Brasil (PA, Kieffer, 1909; SP, primeira referência)

Hospedeiros. Anastrepha spp. (Wharton et al., 1998) e Anastrepha amita Zucchi (primeiro registro).

Discussão. Foi descrita inicialmente no gênero Dissodontaspis, de fềmeas coletadas no Estado do Pará no início deste século (Kieffer, 1909). Foi verificado no 
presente estudo, que alguns exemplares de Dicerataspis apresentavam asas anteriores escurecidas na metade basal, diferindo dos demais, que possuem asas hialinas. Além disso, esses exemplares, eram maiores que os demais. Devido aos métodos de coleta e armazenamento dos frutos, não foi possível estabelecer com precisão as associações dessa espécie com seus hospedeiros. 

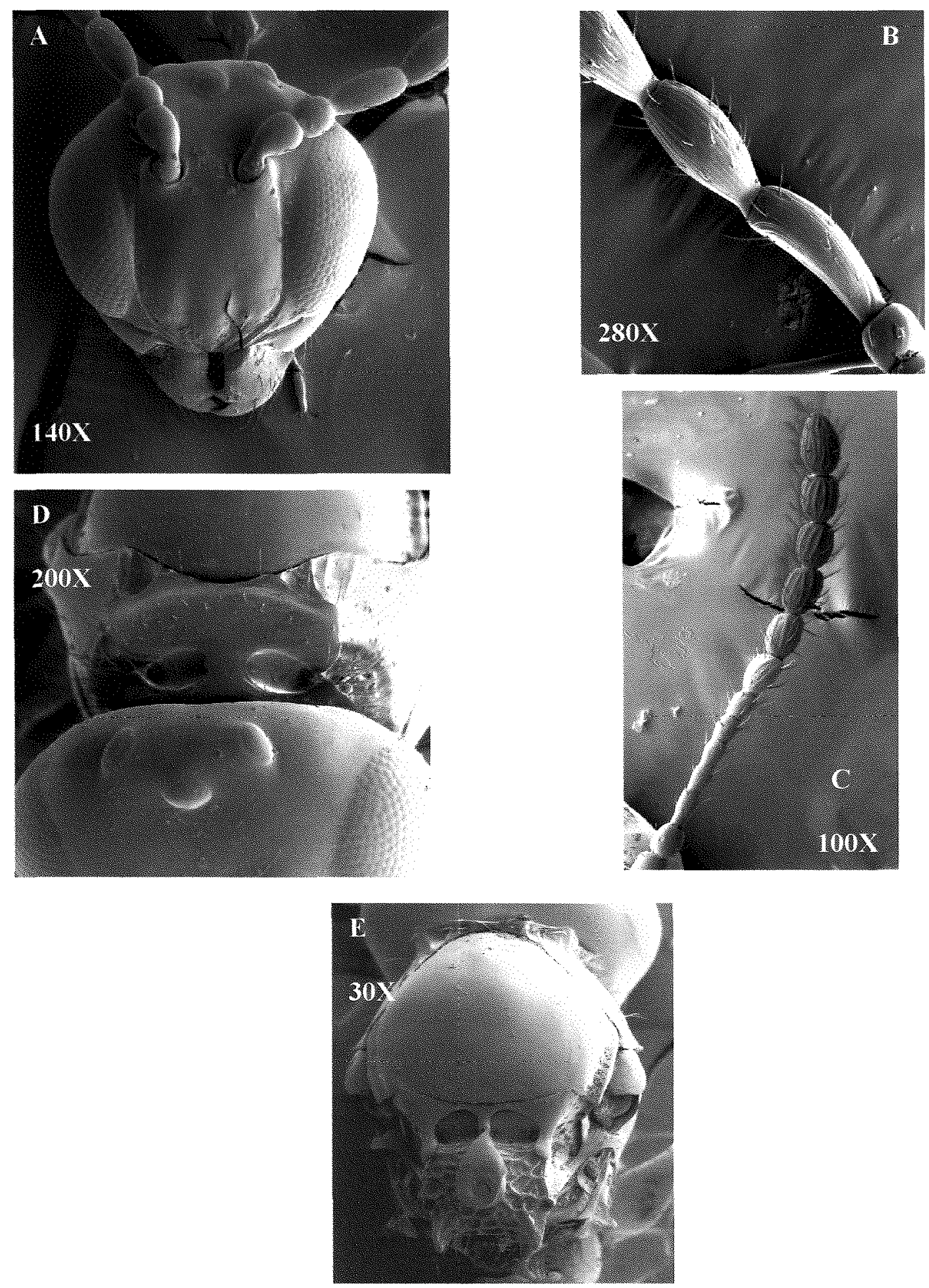

Figura 7: Dicerataspis flavipes. A. Cabeça, vista frontal; B. Antenômeros 3 e 4 do macho; C. Antena da fêmea; D. Placa pronotal, vista dorso-frontal; E. Mesoescuto, vista dorsal. 

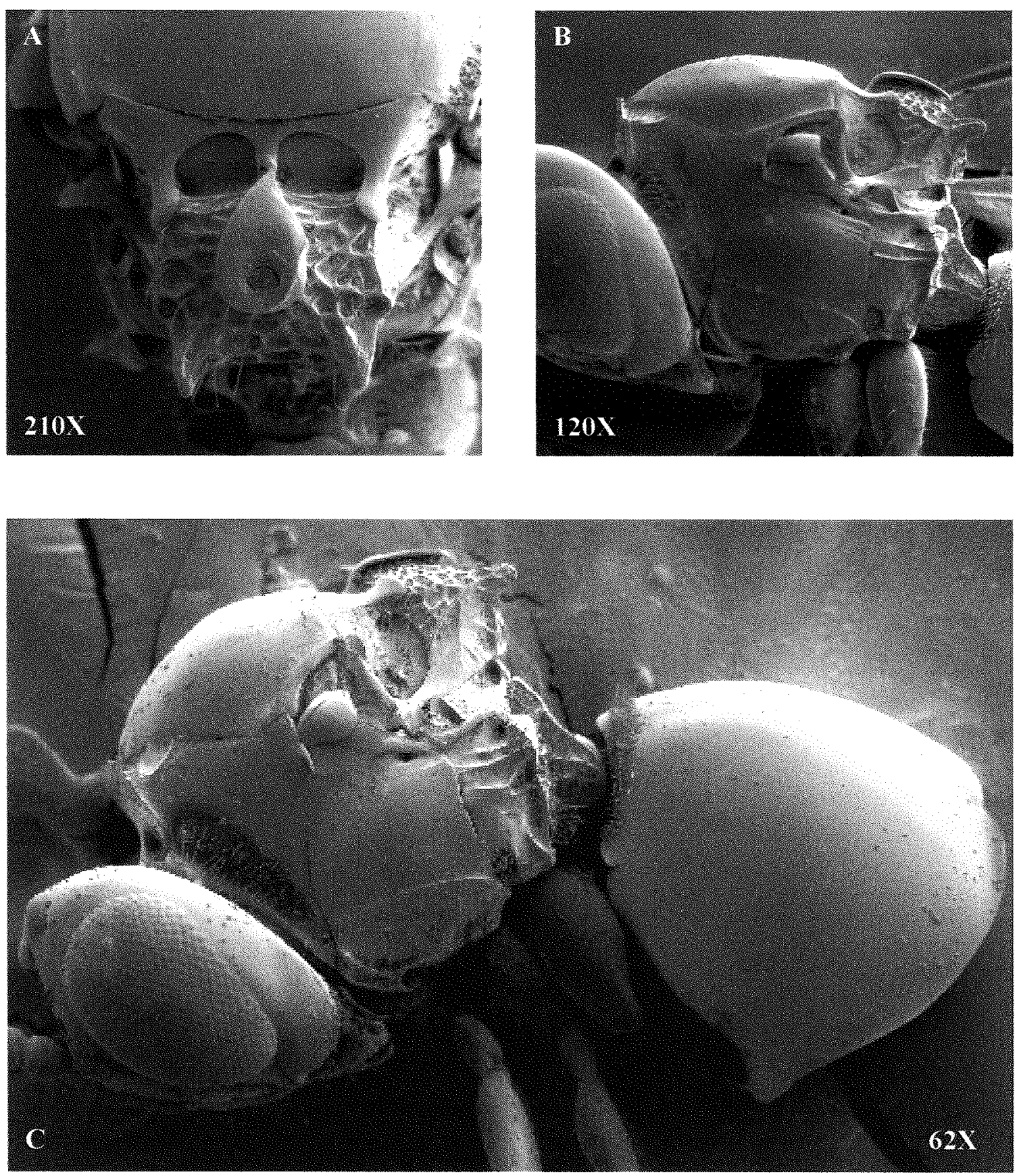

Figu ra 8: Dicerataspis flavipes. A. Cúpula, vista dorsal; B. Mesosoma, vista lateral; C. Cabeça, mesosoma e metasoma, vista lateral. 


\subsubsection{Lopheucoila anastrephae (Rhower, 1919)}

(Figuras 9A - D; 10A - D)

Lopheucoila anastrephae (Rhower, 1919) Weld, 1951

Diglyphosema anastrephae Rhower, 1919

Cabeça: Em vista frontal, mais alta $(0,76-0,86 \mathrm{~mm})$ que larga $(0,68-0,75$ $\mathrm{mm})$. Sulco malar presente. Machos com o terceiro antenômero fortemente encurvado externamente e maior que o quarto (Figura 9A). Esse é semelhante em tamanho e forma aos demais segmentos, com exceção do último, que é mais desenvolvido (comp. médio dos segmentos do flagelo - mm: 0,$22 ; 0,20 ; 0,20 ; 0,20 ; 0,20 ; 0,21 ; 0,21 ; 0,21 ; 0,21 ; 0,20$; $0,20 ; 0,20 ; 0,25)$. Flagelômeros moniliformes e achatados, com rinários em todos os artículos, cerdas não aparentes. Fêmeas com clava de 8 segmentos. Terceiro antenômero maior que o quarto, que é menor que os subseqüentes. Do quinto ao $12^{\circ}$ antenômeros, os artículos são moniliformes, semelhantes em forma e tamanho, com a parte central mais desenvolvida que as partes apical e distal. A parte distal dos segmentos da clava são fortemente truncados; $13^{\mathrm{o}}$ artículo maior e cônico. Comprimento médio dos segmentos do flagelo - mm: 0,16;0,13;0,17;0,19;0,19;0,19;0,19;0,19;0,19;0,19;0,28 (Figura 9B).

Mesosoma. Placa pronotal com a margem dorsal da parte posterior emarginada, com quatro lóbulos. Partes anterior e posterior da placa pronotal quase fundidas e com a superfície da parte posterior estriada (Figura 9C). Presença de longos pêlos ao redor de toda a margem dorsal dessa estrutura (Figura 9C). Mesoescuto (comp. 0,94-1,10 mm e larg. $0,70-0,80 \mathrm{~mm}$ ) com três carenas paralelas bastante pronunciadas, sendo que a carena central não alcança a margem do escutelo, com uma fileira de pêlos sobre cada uma das carenas laterais (Figura 9D). Escutelo retangular (comp. 0,45 - 0,55 e larg. 0,31 $-0,36 \mathrm{~mm}$ ) com margem posterior emarginada apresentando quatro projeções ou dentes (Figuras 9D e 10A). Superficie do disco escutelar com estrias que se originam da base da cúpula até a margem do disco escutelar (Figuras 9D e 10A). Cúpula pequena e ovalada (comp. 0,21 - 0,24 mm e larg. 0,14-0,17 mm) não alcançando a margem posterior do disco, com uma projeção dentiforme na parte anterior da fóvea cupular 
(Figuras 9D e 10A). Barras laterais longas e lisas, alcançando quase a metade do escutelo (Figura 10A). Depressão lateral do escutelo com margem posterior pouco definida e com densa pubescência. (Figuras 10B e 10C). Mesopleura com orifício subalar arredondado (Figuras 10B e 10C). Metapleura com carenas conspícuas e com pêlos longos na margem póstero-inferior da metapleura. Cavidade ântero-ventral da metapleura em forma de fenda e com densa pubescência interna (Figuras 10B e 10C). Carenas propodeais divergindo da base ao centro, de onde convergem para a parte posterior do propódeo.

Pernas. Coxas medianas com tufos de longos pêlos na metade inferior. Coxas posteriores com uma fileira de cerdas curtas ao longo da parte médio-superior e ainda tufos de cerdas longas na porção inferior dessa estrutura.

Metasoma. Mais longo $(1,12-1,40 \mathrm{~mm})$ que alto $(0,78-0,90 \mathrm{~mm})$. Presença de anel piloso na base do terceiro tergito do abdômen, incompleto na parte dorsal. Base do tergito III com estrias longitudinais (Figuras 10C e 10D).

Asas anteriores. Hialinas (não pubescentes), com margem ciliada na região apical. Nervuras amarelo-claras, célula radial completamente aberta; radius curto não alcançando a margem costal da asa. Célula radial com a $1^{\mathrm{a}}$ radial abcissa menor (comp. médio: $0,21 \mathrm{~mm}$ ) que a $2^{\mathrm{a}}$ radial abcissa (comp. médio: $0,38 \mathrm{~mm}$ ). Comprimento total da asa $(1,90-2,37 \mathrm{~mm})$.

Comprimento total do corpo. Macho $(2,36-2,50 \mathrm{~mm})$ e fềmea $(2,32-2,92$ $\mathrm{mm})$

Coloração. Cabeça preta; mandíbulas marron-escuras. Antenas de machos e fêmeas totalmente escuras, quase negras. Mesosoma e metasoma completamente pretos. Pernas castanho-claras.

Material examinado. BRASIL. SÃO PAULO: Regente Feijó, 27. XI. 1996, 3 machos; São Bento do Sapucaí, 1. III. 1996, 1 macho; 1. III. 1996, 10 machos e 14 fềmeas; Campinas (Granja Fernandes), 25. VI. 1997, 2 machos; 20. XI. 1997, 8 machos e 18 fềmeas; 11. II. 1998, 2 machos e 2 fềmeas; 9. V. 1997, 1 macho; 18. I. 1996, 3 machos; Assis, 5. II. 1998, 3 machos; Campinas, 30. VII. 1997, 5 machos; 13. II. 1995, 5 machos; Garça, 13. VIII. 1997, 1 macho; Limeira, 20. IV. 1998, 1 fềmea (M. F. Souza 
Filho col.); MATO GROSSO DO SUL: Terenos, 14. V. 1993, 2 machos e 1 fềmea; Aquidauana, 28. V. 1996, 2 fềmeas (M. A. Uchôa F.).

Distribuição geográfica. México, Trinidad, Peru e Brasil (MS, SP) (Weld, 1951a); Costa Rica, Panamá e Argentina (Wharton et al., 1998), Colombia (Terán, 1980).

Hospedeiros. Anastrepha sp. (Rhower, 1919), Anastrepha fraterculus (Wiedemann) (Weld, 1951a); Lonchaea sp. (Weld, 1951a); Neosilba batesi (Curran) (Wharton et al., 1998); Ceratitis capitata (Wied.) (Terán, 1980). Os antigos registros de Lonchaea sp. observados na literatura, devem estar provavelmente se referindo à alguma espécie do gênero Neosilba (McAlpine \& Steyskal, 1982). Anastrepha amita Zucchi e Anastrepha pseudoparallela (Loew) (primeiros registros).

Discussão. Não foram constatadas variações morfométricas significativas entre os indivíduos examinados. Existem relatos na literatura de outra espécie desse gênero no Brasil, L. truncicola Weld, porém, os caracteres utilizados para separação das espécies desse gênero são inconsistentes. Apenas a forma da parte posterior da cúpula (truncado em $L$. truncicola e arredondado em $L$. anastrephae) é utilizada para a separação das espécies (Weld, 1951a). No sentido de se esclarecer a posição dessas espécies, os tipos precisarão ser examinados. 

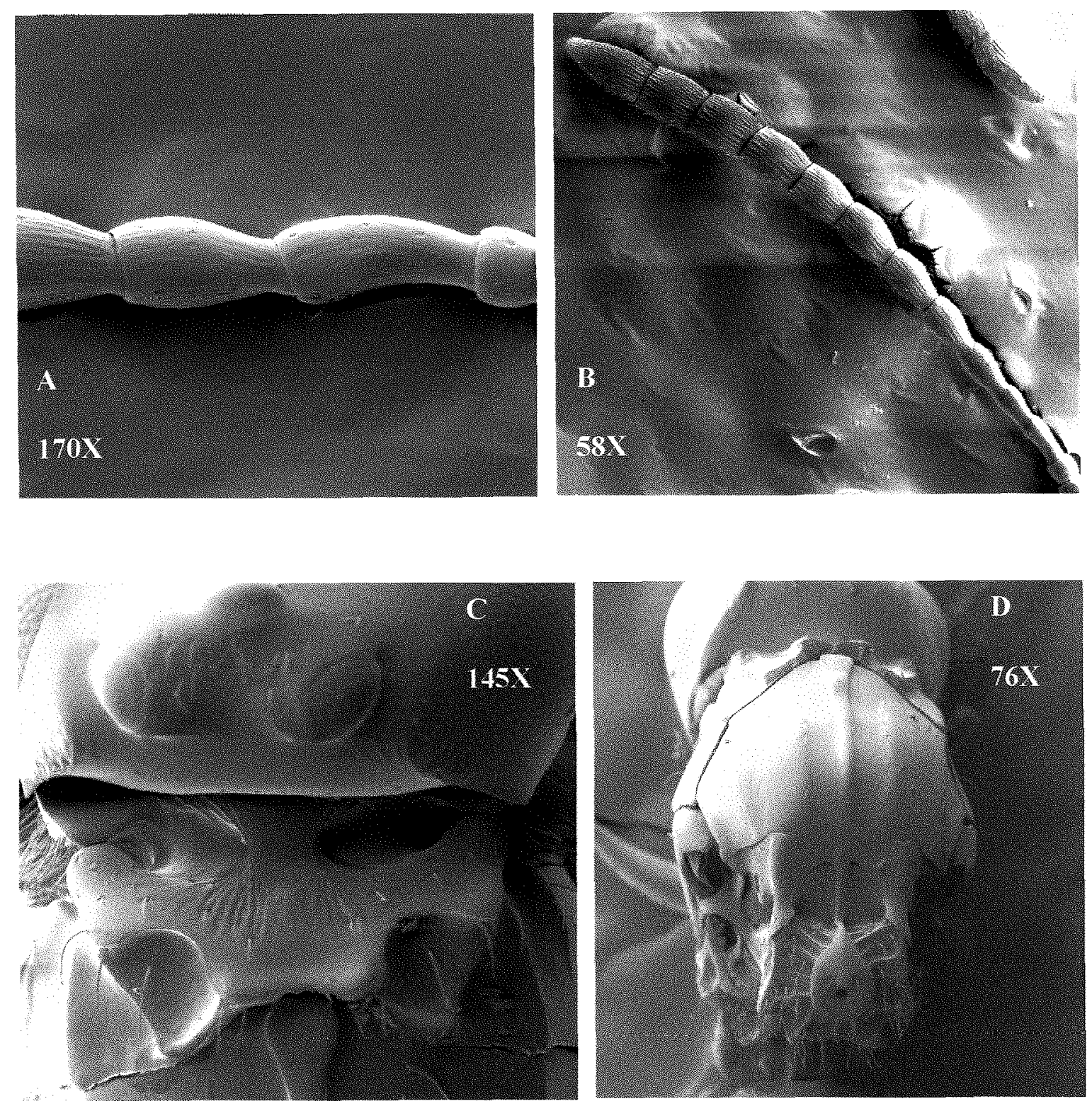

Figura 9: Lopheucoila anastrephae. A. Antenômeros 3 e 4 do macho; B. Antena da fêmea; C. Placa pronotal, vista dorso-frontal; D. Mesoescuto, vista dorsal. 

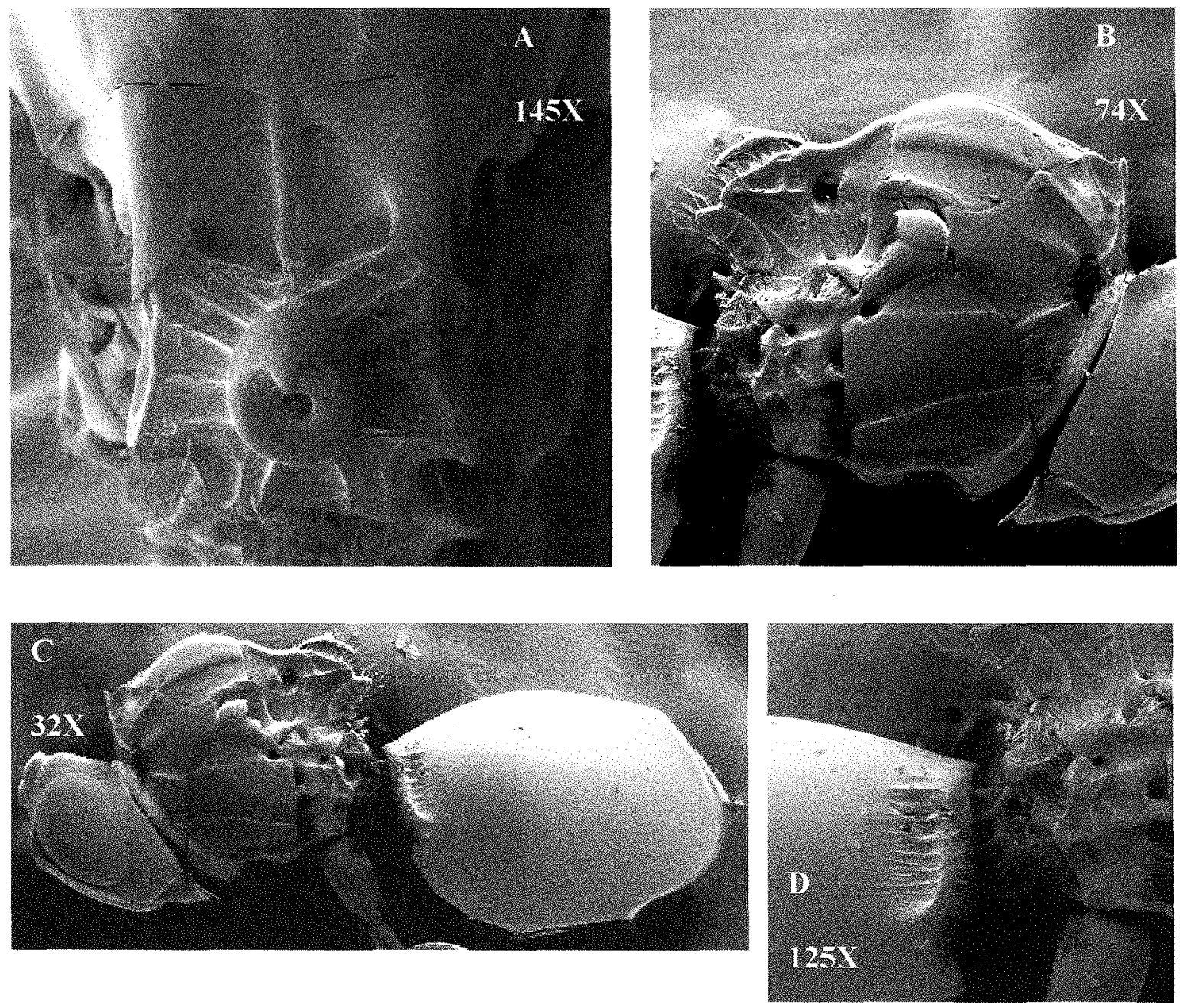

Figura 10: Lopheucoila anastrephae. A. Cúpula, vista dorsal; B. Mesosoma, vista lateral; C. Cabeça, mesosoma e metasoma, vista lateral; D. Metasoma, vista lateral, apresentando detalhes das estrias na base do tergito III. 


\subsubsection{Odontosema anastrephae Borgmeier, 1935}

(Figuras $11 \mathrm{~A}-\mathrm{D} ; 12 \mathrm{~A}-\mathrm{C}$ )

Cabeça. Mais alta $(0,80-0,88 \mathrm{~mm})$ que larga $(0,62-0,70 \mathrm{~mm})$ em vista frontal. Machos com o terceiro antenômero mais longo que os demais, exceto o último (Figura 11A). O quarto antenômero é menor que o quinto, porém apresenta forma semelhante aos segmentos subseqüentes, exceto o $15^{\underline{0}}$ que é mais afilado (comp. médio dos flagelos em mm: 0,$26 ; 0,21 ; 0,24 ; 0,25 ; 0,26 ; 0,26 ; 0,25 ; 0,25 ; 0,25 ; 0,25 ; 0,25 ; 0,25 ; 0,27$ ). Antenas das fềmeas com clava de seis segmentos. Terceiro antenômero mais longo que os demais, exceto o último. Os segmentos 4 a 7 com tamanho, forma e coloração semelhantes (comp. médio dos segmentos do flagelo em mm: 0,$10 ; 0,06 ; 0,05 ; 0,06$; 0,$07 ; 0,13 ; 0,13 ; 0,13 ; 0,13 ; 0,13 ; 0,17$ ) (Figura 11B).

Mesosoma. Margem dorsal da parte posterior da placa pronotal distintamente côncava e com longas cerdas ao longo da margem, bordas laterais retas em cima e convexas na parte inferior (Figura 11C). Partes anterior e posterior da placa pronotal quase fundidas (Figura 11C). Margem ântero-ventral do pronoto com pêlos curtos. Pronoto com carenas nas laterais (Figura 11C). Mesoescuto (comp. 1,03-1,20 mm e larg. 0,63-0,72 mm) com quatro fileiras de cerdas longas e eretas, duas centrais e paralelas e duas próximas às margens laterais do pronoto (Figura 11D). Escutelo (comp. $0,44-0,46 \mathrm{~mm}$ e larg. $0,25-0,31 \mathrm{~mm}$ ) com a parte posterior fortemente côncava, originando duas projeções em forma de dentes (Figuras 11D e 12A). Superfície do disco escutelar areolada-rugosa com pilosidade originando das rugosidades. Barras laterais do escutelo lisas, fóveas anteriores profundas e em forma de semicírculo, separadas por uma carena pouca pronunciada do escutelo (Figura 12A). Cúpula escutelar alcançando a margem posterior do disco escutelar (comp. 0,23-0,30 mm e larg. 0,13-0,17 mm), ovalada e com pêlos longos originando de pequenas puncturas presentes na superfície da estrutura (Figuras 11D e 12A). Depressão lateral do escutelo com margem definida e com pubescência pouco evidente (Figuras 12B e 12C). Mesopleura com orifício subalar em forma de uma estreita fenda longitudinal (Figuras 12B e 12C). Metapleura com duas carenas. Cavidade ântero-ventral da metapleura ovalada (Figuras 12B e 12C). Propódeo com carenas longas, quase paralelas, próximas na base porém, afastadas a partir da parte 
mediana.

Metasoma. Em vista lateral é mais longo $(1,0-1,75 \mathrm{~mm})$ que alto $(0,81-1,25$ $\mathrm{mm})$. Presença de anel piloso de aspecto lanoso na base do tergito III, completo na região dorsal. Presença de uma segunda linha de pêlos esparsos logo após o anel lanoso, porém incompleto na região dorsal (Figura 12C).

Pernas. Coxa média com tufos de pêlos alongados e coxas posteriores com um pequeno tufo de pêlos longos na parte médio-inferior.

Asas anteriores. Hialinas, sem pubescência. Margem ciliada na região apical. Célula radial completamente aberta na margem costal e radius curto não alcançando a margem da asa. As nervuras são amareladas, bem claras com algumas cerdas longas ao longo da nervura subcostal. A $1^{\underline{a}}$ radial abcissa é menor (comp. médio: 0,24 mm) que a $2^{\mathrm{a}}$ radial abcissa (comp. médio: 0,39 $\mathrm{mm}$ ). Comprimento total da asa varia de 2,18 a 2,66 $\mathrm{mm}$.

Comprimento total do corpo. Macho $(2,40-2,72 \mathrm{~mm})$ e fềmea $(2,34-3,24$ $\mathrm{mm})$.

Coloração. Cabeça preta; mandíbulas castanho-escuras. Antenas dos machos completamente pretas, fêmeas com os sete primeiros segmentos marron-avermelhados e os seis últimos segmentos (clava) pretos. Mesosoma e metasoma pretos. Pernas castanho-claras, levemente avermelhadas. Nervuras amareladas, bem pálidas.

Material examinado. BRASIL. AMAZONAS: Manaus, 27. XII. 1991, 1 macho (N. M. Silva col.); MATO GROSSO DO SUL: Terenos, 14. V. 1993, 2 machos e 2 fềmeas; Aquidauana, 10. II. 1994, 1 macho (M. A. Uchôa F. col.); SÃO PAULO: São Bento do Sapucaí, 1. III. 1996, 1 macho; Campinas, 12. XI. 1997, 1 fềmea; 20. XI. 1997, 1 macho e 4 fềmeas; 11. II. 1998, 2 fềmeas; 19. X. 1994, 12 machos e 4 fềmeas; Assis, 5. II. 1998, 1 fềmea; Piracicaba (ESALQ), 5. I. 1997, 1 macho (M. F. Souza Filho col.); SANTA CATARINA: Iomerê, 18. IV. 1994, 11 machos e 9 fềmeas (I. Nora col.); RIO GRANDE DO SUL: Pelotas, 28. XI. 1997, 1 macho (L. A. B. Salles col.).

Distribuição geográfica. Brasil (SP - Borgmeier, 1935; Lima, 1948; RS - Salles, 1996; AM e SC - Primeiros registros) e Costa Rica (Wharton et al., 1981), México (Hernández-Ortiz et al., 1994). 
Hospedeiros. Anastrepha striata Schiner, 1868 e Anastrepha fraterculus (Wied.) (Borgmeier, 1935; Hernández-Ortiz et al., 1994), Anastrepha spp. e Ceratitis capitata (Wied.) (Wharton et al., 1981)

Discussão. Odontosema é um gênero neotropical constituído por duas espécies, $O$. albinerve Kieffer e $O$. anastrephae. Baseando-se nos exemplares examinados, constatou-se que as duas espécies são muito relacionadas. A única diferença observada foi a forma da margem dorsal da placa pronotal, reta em $O$. anastrephae e arredondada em $O$. albinerve. Portanto é necessário o exame dos tipos, no sentido de se esclarecer a posição sistemática dessas espécies. É a primeira constatação $O$. anastrephae nos Estados do Amazonas e Santa Catarina. 

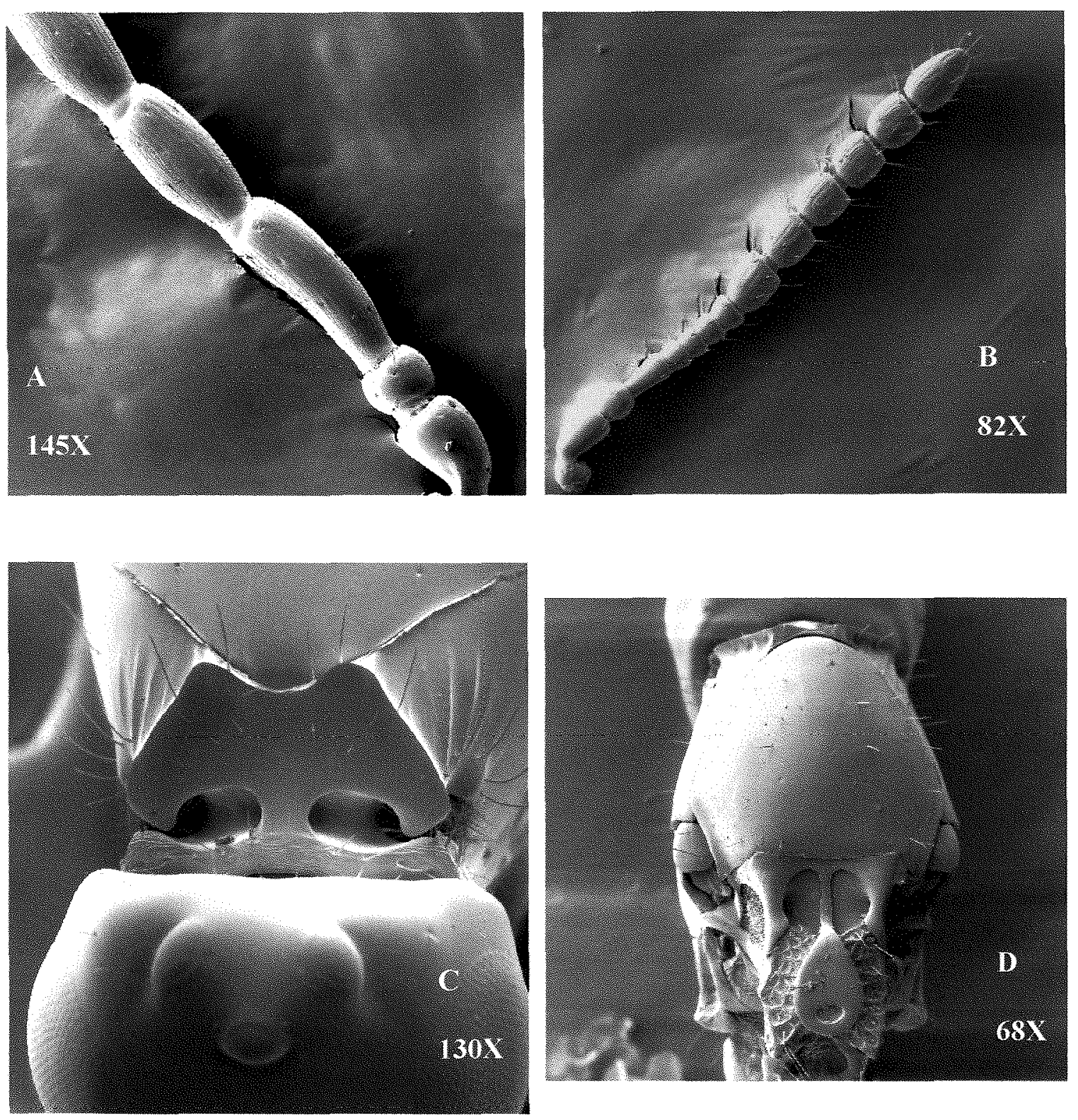

Figura 11: Odontosema anastrephae. A. Antenômeros 3 e 4 do macho; B. Antena da fêmea; C. Placa pronotal, vista dorso-frontal; D. Mesoescuto, vista dorsal. 

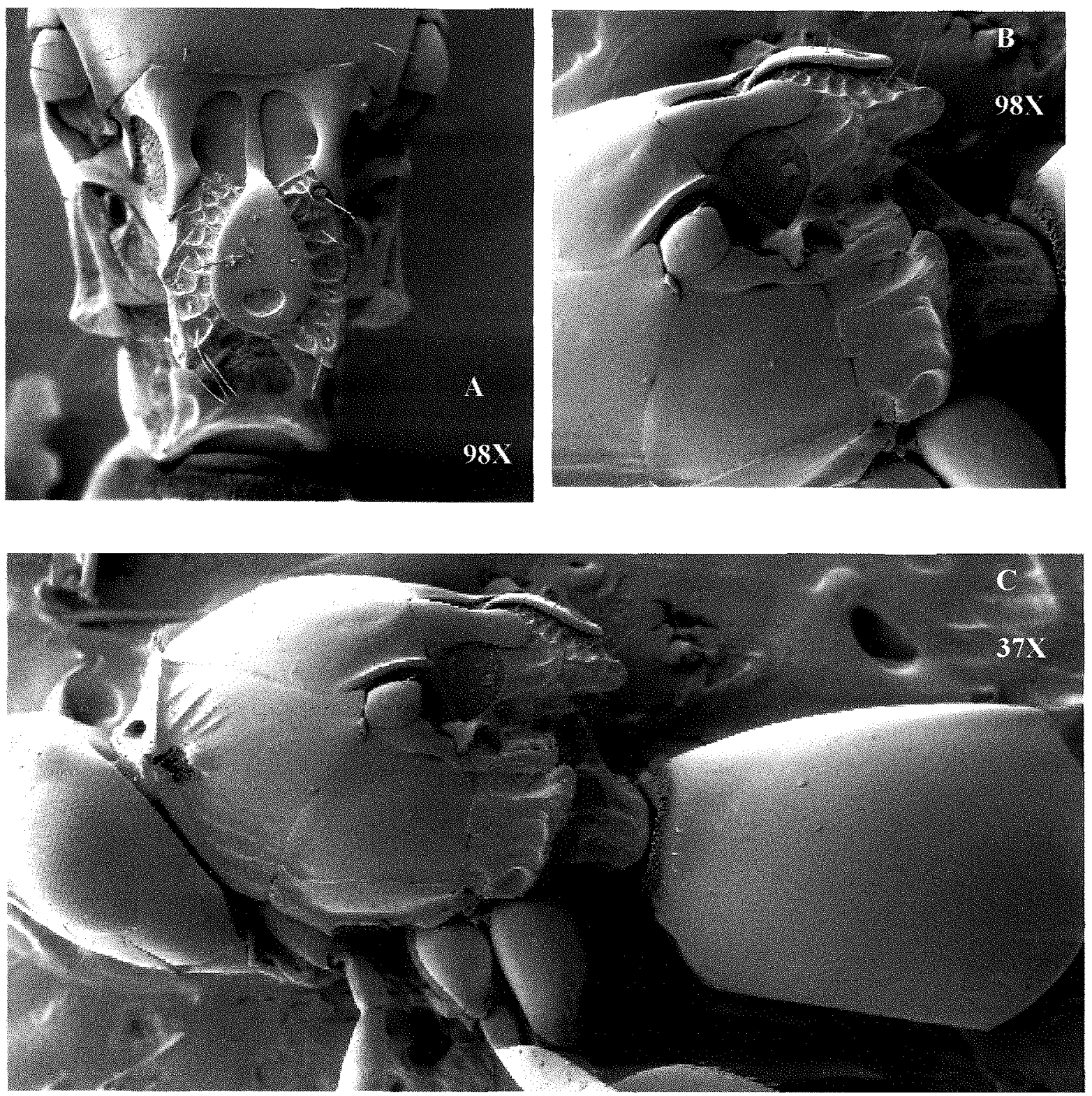

Figura 12: Odontosema anastrephae. A. Cúpula escutelar, vista dorsal; B. Cúpula escutelar, vista lateral e detalhes da mesopleura e da metapleura; D. Cabeça, mesosoma e metasoma, vista lateral. 


\subsubsection{Trybliographa sp.}

(Figuras 13A - F)

Cabeça. Mais alta $(0,70-0,75 \mathrm{~mm})$ que larga $(0,59-0,65 \mathrm{~mm})$, face com dois sulcos longitudinais e paralelos originando-se na parte mediana e prolongando-se até a base do clípeo. Face, genas e mandíbulas pilosas. Sulco malar presente. Machos com o teceiro antenômero levemente encurvado ou quase reto menor que o quarto (Figura 13A). Antenômero 4 alongado e com a extremidade distal levemente dilatada, semelhante em forma e tamanho aos artículos subseqüentes (comp. médio dos segmentos do flagelo - mm): 0,$17 ; 0,25 ; 0,27 ; 0,28 ; 0,27 ; 0,26 ; 0,26 ; 0,25 ; 0,25 ; 0,25$; $0,25 ; 0,24 ; 0,26)$. Todos os flagelômeros com rinários e cerdas esparsas (Figura 13A). Antenas das fềmeas com clava de sete segmentos. $\mathrm{O}$ terceiro antenômero com a parte apical mais dilatada, maior que o quarto. Os artículos 4 a 6 semelhantes em forma e tamanho (comp. médio dos segmentos do flagelo - mm: 0,11;0,07;0,07;0,07;0,12; $0,12 ; 0,12 ; 0,12 ; 0,12 ; 0,12 ; 0,16)$ (Figura 13B).

Mesosoma. Placa pronotal não se projetando acima da margem do mesoescuto e com as partes anterior e posterior completamente afastadas, originando orifícios abertos. Ponte mediana bastante larga. Margem dorsal da parte posterior da placa pronotal bem côncava e circundada por longos pêlos, que geralmente ultrapassam a margem do mesoescuto (Figura 13C). Pronoto com a parte ântero-ventral com pubescência abundante e as partes laterais com pêlos esparsos. Mesoescuto (comp. 0,86-0,95 mm e larg. 0,63-0,67 mm) liso, com duas fileiras de longas pêlos na região das notaulices, que se dobram e prolongam-se na região anterior em outras duas fileiras nas margens laterais (Figura 13D). Escutelo (comp. 0,39 - 0,45 mm e larg. 0,28 - 0,32 mm) apresentando disco escutelar com superfície rugosa e margem posterior arredondada ou levemente truncada, com pêlos longos inseridos nos orifícios das rugosidades (Figura 13D). Barras laterais lisas e longas, alcançando quase um terço do comprimento do escutelo e com amplos orifícios abaixo. Fóveas anteriores bastante largas (Figura 13D). Cúpula escutelar ovalada (comp. 0,24 - 0,27 mm e larg. 0,16 - 0,18 mm), com a superficie apresentando cavidades irregulares na parte anterior e pequenas puncturas com pilosidade interna próximas à margem da estrutura. Fóvea cupular pequena e 
circular, localizada na parte posterior (Figura 13D). Depressão lateral do escutelo com margem bem definida e com pubescência pouco abundante, carenas laterais presentes e distintas das demais estruturas da região lateral do escutelo. Mesopleura sem orifício subalar. Metanoto com carena superior bem desenvolvida e densa pubescência na margem externa. Cavidade ântero-ventral mais alta que larga e com pilosidade interna (Figura 13E). Carenas propodeais paralelas e bem separadas, principalmente na porção mais central.

Metasoma. Mais longo $(0,84-1,03 \mathrm{~mm})$ que alto $(0,75-0,81 \mathrm{~mm})$ em vista lateral. Anel piloso na base do tergito III com tufos de pêlos densos, porém incompletos na região dorsal (Figura 13E).

Pernas. Coxas médias e posteriores com tufos de longos pêlos esbranquiçados nas partes médio-inferiores da estrutura.

Asas anteriores. Densamente pubescentes, com margem ciliada e com a metade basal escurecida, principalmente na região que circunda a nervura subcostal e basal. Célula radial fechada, porém o segmento da radius que fecha a célula na margem costal é bastante débil. Primeira radial abcissa (comp. médio: $0,26 \mathrm{~mm}$ ) encurvada e $2^{\underline{a}}$ radial abcissa (comp. médio: 0,48 $\mathrm{mm}$ ) quase reta. Célula radial densamente pilosa. Nervuras escuras, subcostal com sete cerdas eretas ao longo de seu comprimento (Figura 13F). Comprimento total da asa anterior: 2,05-2,17 mm.

Comprimento total do corpo. Macho (1,87-2,25 mm) e fềmea (2,10 mm).

Coloração. Cabeça completamente preta; mandíbulas marrom-escuras. Antenas dos machos, marron-avermelhadas. Fêmeas com os seis primeiros segmentos do flagelo castanho-claros, os demais sete segmentos (clava) completamente pretos. Mesoescuto e mesopleura pretos, metapleura marron-avermelhada. Pernas castanho-escuras. Metasoma castanho-avermelhado, superficie dorsal com uma mancha escura. Metade basal da asas anteriores marron-avermelhada, principalmente em volta das nervuras subcostal e basal.

Material examinado. BRASIL. SÃO PAULO: São Bento do Sapucaí, 27. I. 1995, 2 machos; 1. III. 1996, 2 machos; Regente Feijó, 7. V. 1997, 1 macho; Campinas, 16. IV. 1997, 1 fềmea; 20. XI. 1997, 1 macho; 13. II. 1996, 1 fêmea; Florínea, 16. IV. 
1998, 1 macho; (M. F. Souza Filho col.).

Distribuição geográfica. Brasil (SP - primeiro registro).

Hospedeiros. Anastrepha spp. e Neosilba spp. (primeiras referências para o Brasil).

Discussão. Essa espécie está sendo descrita pela Dra. Norma Díaz (Museo de La Plata), com base em exemplares coletados no Mato Grosso do Sul. Trybliographa sp. não foi muito abundante nos levantamentos realizados neste estudo, tendo sido encontrada apenas no Estado de São Paulo. Não foram constatadas variações morfométricas significativas nos exemplares coletados. É primeira constatação de uma espécie do gênero Trybliographa no Estado de São Paulo. 


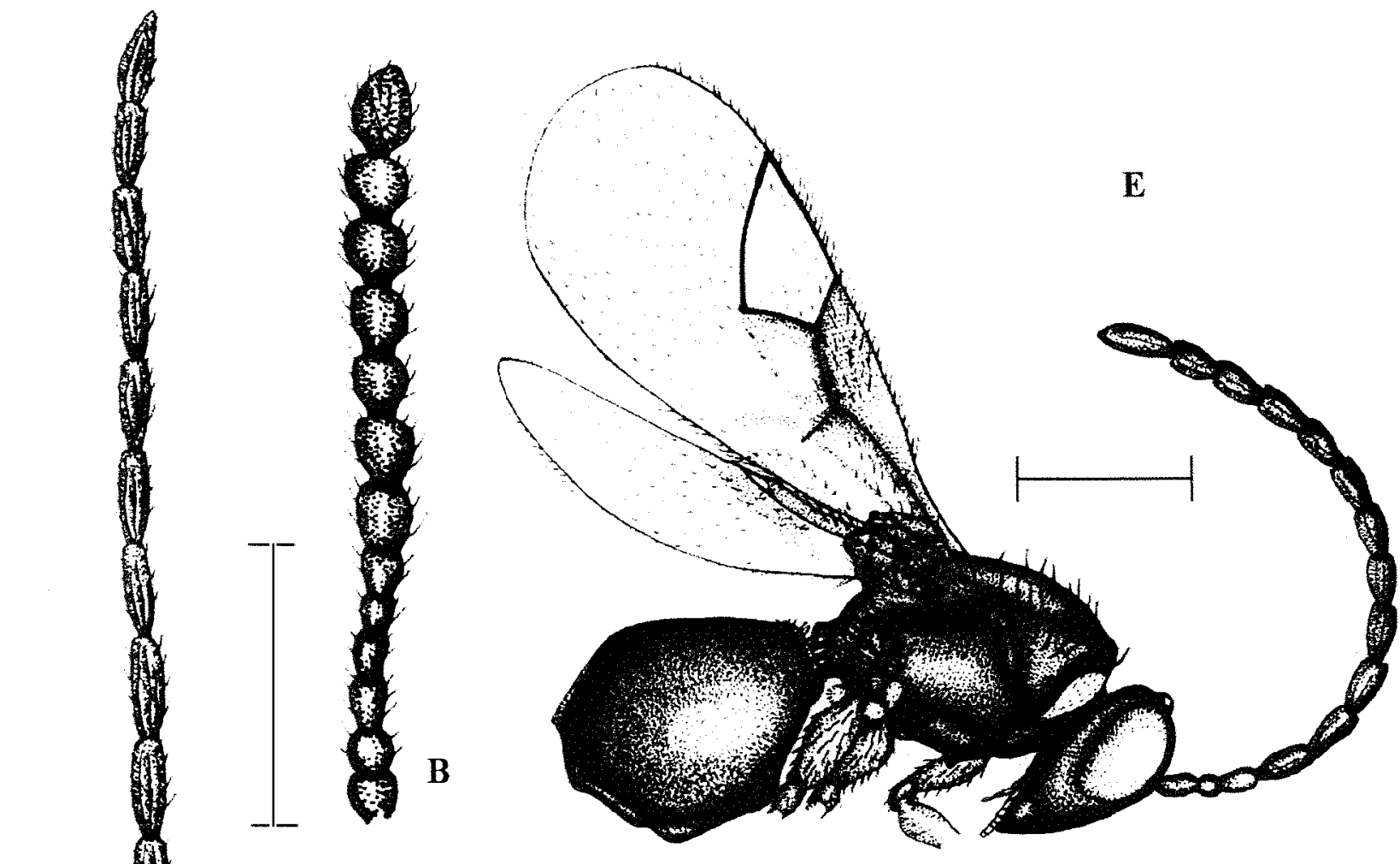

A

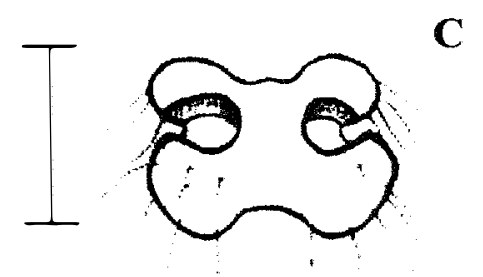

$\mathbf{F}$

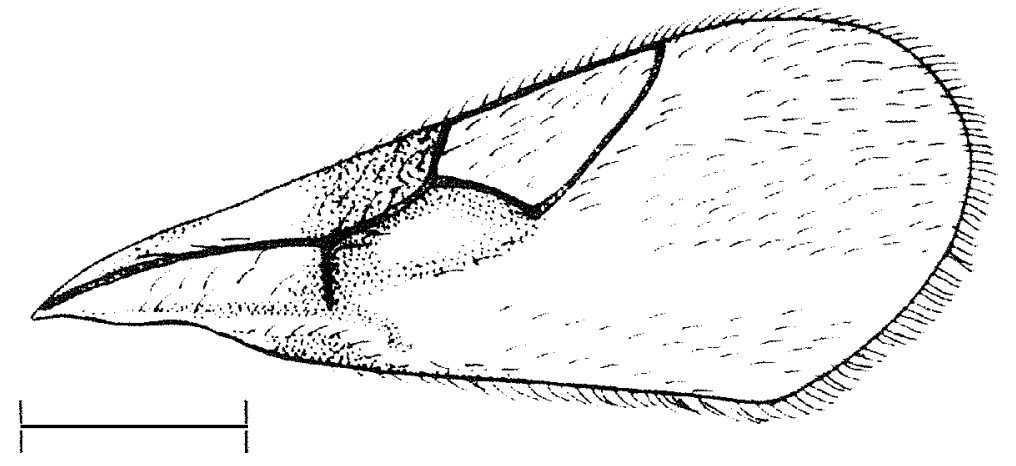

$\mathbf{D}$

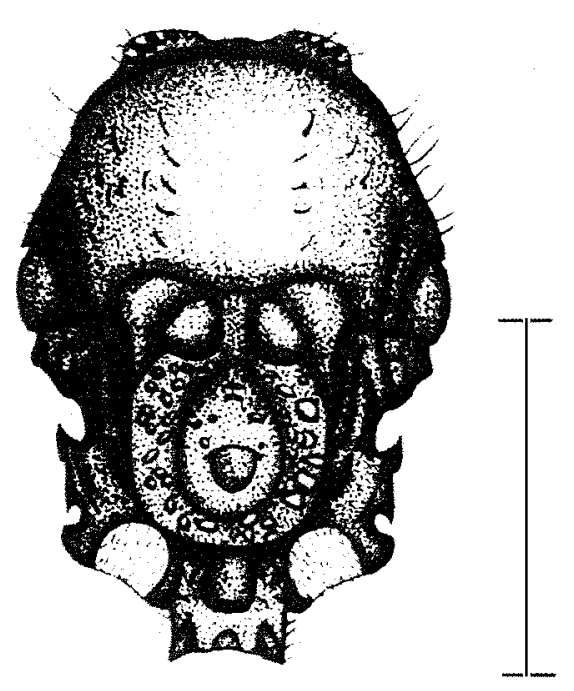

Figura 13: Trybliographa sp. A. Antena do macho; B. Antena da fềmea; C. Placa pronotal; D. Mesosoma, vista dorsal; E. Macho, vista lateral; F. Asa anterior. (Escalas A. B, D, E, F =0.5 mm: C $=0,2 \mathrm{~mm}$ ). 


\subsection{Distribuição geográfica dos Eucoilinae no Brasil.}

Os eucoilíneos estão amplamente distribuídos no Brasil. Algumas espécies estão sendo registradas pela primeira vez nos seguintes Estados: Amazonas (A. pelleranoi, $A$. nordlanderi e $O$. anastrephae); Rio de Janeiro (A. pelleranoi), São Paulo (D. flavipes e Trybliographa sp.) e Santa Catarina ( $O$. anastrephae). Foram também estudados exemplares coletados nos Estados da Bahia, Mato Grosso do Sul, Paraná e Rio Grande do Sul, locais onde já haviam sido constatados anteriormente (Tabela 2 e Figural 4). Tropideucoila rufipes Ashmead, que ocorre no Estado do Mato Grosso, Tropideucoila weldi Lima e Tropideucoila angrensis Borgmeier constatadas no Estado do Rio de Janeiro, não foram obtidas neste estudo. Dicerataspis flavipes já havia sido constatada no Estado do Pará (Kieffer, 1909; De Santis, 1980).

Na região Sul, observou-se uma menor diversidade de eucoilíneos, apenas duas espécies (A. pelleranoi e $O$. anastrephae). Essas espécies são as mais amplamente distribuídas, sendo encontradas em praticamente todas as regiões do Brasil. Aganaspis nordlanderi está mais restrito à região Norte, porém, alguns exemplares também foram obtidos no Estado de São Paulo (Tabela 2 e Figura 14). Essa espécie foi originalmente descrita de exemplares da Costa Rica (Wharton et al., 1998). Assim, provavelmente esteja adaptada à região equatorial; provável motivo da sua abundância na região Amazônica brasileira. Dicerataspis flavipes e Trybliographa sp. apresentaram a menor distribuição geográfica, ocorrendo apenas no Estado de São Paulo. Lopheucoila anastrephae foi obtido apenas nos Estados de Mato Grosso do Sul e São Paulo e, como Trybliographa sp., parece estar restrito à região Centro-Sul do Brasil.

Deve-se ressaltar que devido ao número reduzido de amostras examinadas, tornase prematuro o estabelecimento preciso da distribuição dessas espécies no Brasil. Porém é bastante provável que os eucoilíneos estejam presentes em todos os locais de ocorrência dos tefritóideos. 
Tabela 2. Distribuição e número das espécies de Eucoilinae parasitóides de larvas frugivoras (Dip.: Tephritidae e Lonchaeidae) no Brasil.

\begin{tabular}{|c|c|c|c|c|c|c|c|}
\hline $\begin{array}{l}\text { Regiōes } \\
\text { Municípios }\end{array}$ & $\begin{array}{c}A . \\
\text { nordlanderi }\end{array}$ & \begin{tabular}{|c|}
$A$. \\
pelleranoi
\end{tabular} & $\begin{array}{c}D . \\
\text { flavipes }\end{array}$ & $\begin{array}{c}L . \\
\text { anastrephae }\end{array}$ & $\begin{array}{c} \\
\text { anastrephae }\end{array}$ & \begin{tabular}{|c|} 
Trybliographa \\
sp.
\end{tabular} & Total \\
\hline $\begin{array}{l}\text { NORTE } \\
\text { Iranduba-AM }\end{array}$ & 2 & 4 & 0 & 0 & 0 & 0 & 6 \\
\hline Manaus - AM & 27 & 24 & 0 & 0 & 1 & 0 & 52 \\
\hline $\begin{array}{l}\text { NORDESTE } \\
\text { Conceição de } \\
\text { Almeida - BA } \\
\end{array}$ & 0 & 13 & 0 & 0 & 0 & 0 & 13 \\
\hline $\begin{array}{l}\text { CENTRO-OESTE } \\
\text { Aquidauana- MS } \\
\end{array}$ & 0 & 0 & 0 & 2 & 1 & 0 & 3 \\
\hline Goiândira - GO & 0 & 3 & 0 & 0 & 0 & 0 & 3 \\
\hline Terenos-MS & 0 & 0 & 0 & 3 & 4 & 0 & 7 \\
\hline $\begin{array}{l}\text { SUDESTE } \\
\text { Assis - SP }\end{array}$ & 0 & 0 & 0 & 3 & 1 & 0 & 4 \\
\hline Atibaia-SP & 0 & 1 & 0 & 0 & 0 & 0 & 1 \\
\hline Campinas - SP & 0 & 49 & 3 & 45 & 24 & 3 & 124 \\
\hline Campo Grande - RJ & 0 & 3 & 0 & 0 & 0 & 0 & 3 \\
\hline Florínia-SP & 0 & 0 & 0 & 0 & 0 & 1 & 1 \\
\hline Garça - SP & 0 & 0 & 0 & 1 & 0 & 0 & 1 \\
\hline Limeira - SP & 0 & 0 & 0 & 1 & 0 & 0 & 1 \\
\hline Luiz Antônio - SP & 3 & 0 & 0 & 0 & 0 & 0 & 3 \\
\hline Nazaré Paulista - SP & 0 & 0 & 79 & 0 & 0 & 0 & 79 \\
\hline Pindorama - SP & 1 & 0 & 0 & 0 & 0 & 0 & 1 \\
\hline Piracicaba - SP & 0 & 8 & 0 & 0 & 1 & 0 & 9 \\
\hline Regente Feijó- SP & 0 & 0 & 0 & 3 & 0 & 1 & 4 \\
\hline $\begin{array}{l}\text { São Bento do } \\
\text { Sapucai - SP } \\
\end{array}$ & 0 & 3 & 0 & 25 & 1 & 4 & 33 \\
\hline São Paulo - SP & 0 & 2 & 0 & 0 & 0 & 0 & 2 \\
\hline Sorocaba - SP & 0 & 1 & 0 & 0 & 0 & 0 & 1 \\
\hline
\end{tabular}


Tabela 2. Distribuição e número das espécies de Eucoilinae parasitóides de larvas frugívoras (Dip.: Tephritidae e Lonchaeidae) no Brasil.

\begin{tabular}{l|c|c|c|c|c|c|c}
\hline $\begin{array}{l}\text { SUL } \\
\text { Caçador -SC }\end{array}$ & 0 & 6 & 0 & 0 & 0 & 0 & 6 \\
\hline Iomerê - SC & 0 & 106 & 0 & 0 & 20 & 0 & 126 \\
\hline Londrina-PR & 0 & 5 & 0 & 0 & 0 & 0 & 5 \\
\hline Pelotas-RS & 0 & 363 & 0 & 0 & 1 & 0 & 364 \\
\hline Vacaria-RS & 0 & 13 & 0 & 0 & 0 & 0 & 13 \\
\hline Videira-SC & 0 & 2 & 0 & 0 & 0 & 0 & 2 \\
\hline Total & 33 & 606 & 82 & 83 & 54 & 9 & 867 \\
\hline \hline
\end{tabular}




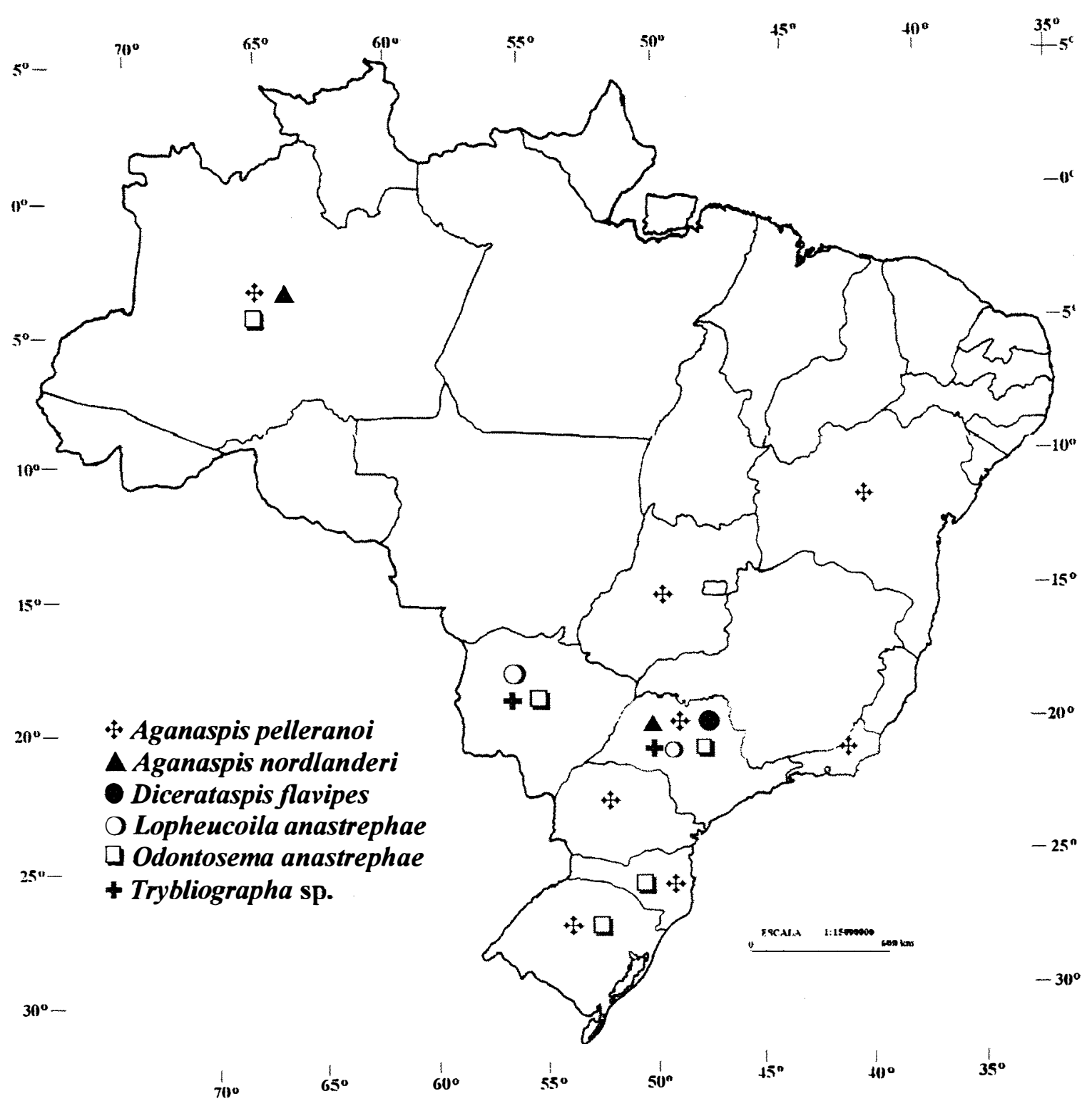

Figura 14: Distribuição das espécies de Eucoilinae parasitóides de larvas frugívoras (Dip.: Tephritidae e Lonchaeidae) no Brasil. 


\subsection{Relação Tritrófica (Eucoilinae/hospedeiro/frutífera)}

Os eucoilíneos estão associados tanto às espécies do gênero Anastrepha quanto às espécies de lonqueídeos, exceto $D$. flavipes que foi obtido somente de tefritídeos. Portanto, esses parasitóides demonstram pouca especificidade por seus hospedeiros (Tabela 3). Os braconídeos (Opiinae), parasitóides de tefritídeos, também apresentam pouca especificidade pelos hospedeiros (Leonel Jr., 1991).

Os parasitóides foram obtidos de pupários de tefritóideos coletados em 34 espécies de 15 famílias de frutíferas (Tabelas 3 e 4). A. pelleranoi foi observado parasitando larvas de seis espécies de moscas em oito famílias de frutíferas, porém $84,15 \%$ dos exemplares foram obtidos de larvas de moscas em mirtáceas, sendo 44,22\% de cereja-da-terra (Eugenia involucrata DC.) e $22,44 \%$ de goiaba (Psidium guajava L.) (Tabela 4). Portanto, A. pelleranoi apresenta maior atração pelos frutos de Myrtaceae. Tal fato pode estar relacionado ao maior número de frutos dessa família amostrados neste estudo. Todavia, esse parasitóide foi também dominante em araçá e goiaba (Myrtaceae), no Estado do Paraná (Menezes et al., 1997).

Dicerataspis flavipes apresentou especificidade para as espécies de Anastrepha, tendo sido obtido de larvas em apenas três espécie de frutíferas: pombeiro (Citharexylum myrianthum Cham.), manga (Mangifera indica L.) e carambola (Averrhoa carambola L.) (Tabela 3). A maioria dos exemplares de D. flavipes foi obtida de carambola (96,34\%), nas quais havia também uma grande quantidade de drosofilídeos (Tabela 4). Provavelmente, essa espécie parasita principalmente larvas de moscas da família Drosophilidae, já que são parasitóides bem menores do que aqueles associados às larvas de Tephritoidea (Wharton et al., 1998).

Lopheucoila anastrephae $(34,94 \%)$ e $O$. anastrephae $(1,85 \%)$ foram coletados em frutos da família Passifloraceae (Tabela 4). Nesses frutos, observou-se uma predominância de Anastrepha pseudoparallela (Loew) (Tephritidae) e de espécies do gênero Neosilba (Lonchaeidae), indicando uma possível preferência desses parasitóides à essas espécies, já que foram os únicos eucoilíneos coletados nesses frutos. A maioria dos exemplares de $O$. anastrephae foi obtida de goiaba $(77,77 \%)$ nos municípios de 
Campinas (SP) e Iomerê (SC) (Tabelas 2 e 4). Na Costa Rica, O. anastrephae parasita espécies de Anastrepha em goiaba e de C. capitata e lonqueídeos em citros. Na Argentina, $L$. anastrephae foi obtida de larvas de $A$. fraterculus em goiabas, enquanto que na Costa Rica, só foi obtida de lonqueídeos em goiaba, citros, café, tangerina e laranja (Wharton et al., 1998).

Aganaspis pelleranoi, D. flavipes e $L$. anastrephae foram associados à Anastrepha amita Zucchi em pombeiro no Estado de São Paulo (primeiros registros). É também o primeiro registro de $A$. nordlanderi associado à Anastrepha bahiensis Lima em mapati (Pouroma cecropiaefolia Mart.) no Estado do Amazonas e às espécies do gênero Neosilba em Pouteria torta (Mart.) (Sapotaceae), no Estado de São Paulo (Tabela 3).

A espécie do gênero Trybliographa parasita espécies de Neosilba (Lonchaeidae) em pimenta (Capsicum sp.), no Estado de São Paulo (primeiro registro) (Tabela 3). Essa espécie foi obtida também de larvas de moscas em maracujá-doce (Passiflora alata Dryander), pêssego - Prunus persica (L), café (Coffea arabica L.) e a duas espécies de ingá - Inga affinis DC. e Inga sessilis (Vell.). Todavia, como ocorrido com as demais espécies, a associação com as respectivas espécies de moscas não foi possível devido à metodologia de coleta e armazenamento dos frutos (Tabela 3). 
Tabela 3. Espécies de eucoilíneos, seus hospedeiros e frutos hospedeiros das larvas frugívoras (Dip.: Tephritoidea).

\begin{tabular}{|c|c|c|c|}
\hline Parasitóides & Hospedeiros & Frutos hospedeiros & Família \\
\hline \multirow{5}{*}{$\begin{array}{l}\text { Aganaspis } \\
\text { nordlanderi }\end{array}$} & A. striata & goiaba (Psidium guajava) & Myrtaceae \\
\hline & A. bahiensis & mapati (Pourouma cecropiaefolia) & Moraceae \\
\hline & Neosilba sp. & mapati & Moraceae \\
\hline & Neosilba sp. & Pouteria torta (Mart.) & Sapotaceae \\
\hline & $\begin{array}{l}\text { Hospedeiro } \\
\text { desconhecido }\end{array}$ & café (Coffea arabica) & Rubiaceae \\
\hline \multirow{8}{*}{$\begin{array}{l}\text { Aganaspis } \\
\text { pelleranoi }\end{array}$} & Anastrepha sp. & café & Rubiaceae \\
\hline & A. bahiensis & taperebá (Spondias mombin) & Anacardiaceae \\
\hline & A. striata & goiaba & Myrtaceae \\
\hline & A. amita & $\begin{array}{l}\text { pombeiro } \\
\text { (Citharexylum myrianthum) }\end{array}$ & Verbenaceae \\
\hline & A. obliqua & taperebá & Anacardiaceae \\
\hline & A. fraterculus & $\begin{array}{l}\text { cereja-da-terra } \\
\text { (Eugenia involucrata) } \\
\text { pitanga (Eugenia uniflora) } \\
\text { ameixa (Prunus domestica) } \\
\text { uvaia (Eugenia pyriformis) } \\
\text { guamirin (Eugenia sp.) } \\
\text { guabiroba (Campomanesia sp.) }\end{array}$ & $\begin{array}{l}\text { Myrtaceae } \\
\text { Myrtaceae } \\
\text { Rosaceae } \\
\text { Myrtaceae } \\
\text { Myrtaceae } \\
\text { Myrtaceae }\end{array}$ \\
\hline & Neosilba sp. & mapati & Moraceae \\
\hline & $\begin{array}{l}\text { Hospedeiro } \\
\text { desconhecido }\end{array}$ & $\begin{array}{l}\text { pêssego (Prunus persica) } \\
\text { ameixa (Prunus domestica) } \\
\text { araticum (Rollinia sp.) } \\
\text { sete copas (Terminalia catappa) } \\
\text { jambo d'água (Syzygium aqueum) } \\
\text { grumixama (Eugenia brasiliensis) } \\
\text { jambo (Syzygium malaccensis) } \\
\text { araçá (Psidium sp.) } \\
\end{array}$ & \begin{tabular}{|l|} 
Rosaceae \\
Rosaceae \\
Annonaceae \\
Combretaceae \\
Myrtaceae \\
Myrtaceae \\
Myrtaceae \\
Myrtaceae \\
\end{tabular} \\
\hline \multirow{2}{*}{$\begin{array}{c}\begin{array}{c}\text { Dicerataspis } \\
\text { flavipes }\end{array} \\
\end{array}$} & Anastrepha sp. & $\begin{array}{l}\text { carambola (Averrhoa carambola) } \\
\text { manga (Mangifera indica) }\end{array}$ & $\begin{array}{l}\text { Oxalidaceae } \\
\text { Anacardiaceae }\end{array}$ \\
\hline & A. amita & pombeiro & Verbenaceae \\
\hline \multirow{5}{*}{$\begin{array}{l}\text { Lopheucoila } \\
\text { anastrephae }\end{array}$} & A. pseudoparallela & maracujá-doce (Passiflora alata) & Passifloraceae \\
\hline & A. amita & pombeiro & Verbenaceae \\
\hline & A. fraterculus & laranja (Citrus sinensis) & Rutaceae \\
\hline & Neosilba sp. & $\begin{array}{l}\text { biribá (Rollinia mucosa) } \\
\text { maracujá (Passiflora sp.) } \\
\text { maracujá-doce } \\
\text { juá (Solanum } \mathrm{sp} .)\end{array}$ & \begin{tabular}{|l} 
Annonaceae \\
Passifloraceae \\
Passifloraceae \\
Solanaceae \\
\end{tabular} \\
\hline & $\begin{array}{l}\text { Hospedeiro } \\
\text { desconhecido }\end{array}$ & $\begin{array}{l}\text { pêssego } \\
\text { limão-cravo (Citrus limonia) } \\
\text { mexerica-cravo } \\
\text { ingá (Inga affinis) } \\
\text { goiaba } \\
\text { tangor Murkote }- \text { Hibrido } \\
\text { (Citrus sinensis } \times \text { C. reticulatus) }\end{array}$ & $\begin{array}{l}\text { Rosaceae } \\
\text { Rubiaceae } \\
\text { Rubiaceae } \\
\text { Fabaceae } \\
\text { Myrtaceae } \\
\text { Rutaceae }\end{array}$ \\
\hline
\end{tabular}


Tabela 3. Espécies de eucoilíneos, seus hospedeiros e frutos hospedeiros das larvas frugivoras (Dip.: Tephritoidea).

\begin{tabular}{|c|c|c|c|}
\hline \multirow{4}{*}{$\begin{array}{l}\text { Odontosema } \\
\text { anastrephae }\end{array}$} & Anastrepha sp. & manga & Anacardiaceae \\
\hline & A. fraterculus & cereja-da-terra & Myrtaceae \\
\hline & Neosilba sp. & $\begin{array}{l}\text { biribá } \\
\text { mapati }\end{array}$ & $\begin{array}{l}\text { Annonaceae } \\
\text { Moraceae }\end{array}$ \\
\hline & $\begin{array}{l}\text { Hospedeiro } \\
\text { desconhecido }\end{array}$ & $\begin{array}{l}\text { pequi (Caryocar brasiliense) } \\
\text { goiaba } \\
\text { maracujá } \\
\text { pêssego } \\
\text { caimito mexicano } \\
\text { (Chrysophyllum mexicamum) }\end{array}$ & $\begin{array}{l}\text { Caryocaraceae } \\
\text { Myrtaceae } \\
\text { Passifloraceae } \\
\text { Rosaceae } \\
\text { Sapotaceae }\end{array}$ \\
\hline \multirow[b]{2}{*}{ Trybliographa sp. } & Neosilba sp. & pimenta (Capsicum sp.) & Solanaceae \\
\hline & $\begin{array}{l}\text { Hospedeiro } \\
\text { desconhecido }\end{array}$ & $\begin{array}{l}\text { maracujá-doce } \\
\text { pêssego } \\
\text { café } \\
\text { ingá (Inga sessilis) } \\
\text { ingá (Inga affinis) }\end{array}$ & $\begin{array}{l}\text { Passifloraceae } \\
\text { Rosaceae } \\
\text { Rubiaceae } \\
\text { Fabaceae } \\
\text { Fabaceae }\end{array}$ \\
\hline
\end{tabular}


Tabela 4. Número de eucoilíneos e associações com os respectivos frutos hospedeiros das larvas frugívoras (Dip.: Tephritoidea) no Brasil.

\begin{tabular}{|c|c|c|c|c|c|c|c|}
\hline \multirow{2}{*}{$\begin{array}{l}\text { Frutos hospedeiros das } \\
\text { larvas frugívoras }\end{array}$} & \multicolumn{7}{|c|}{ Parasitóides } \\
\hline & \begin{tabular}{c|}
$\begin{array}{c}A . \\
\text { nordlanderi }\end{array}$ \\
\end{tabular} & $\begin{array}{c}\text { A. } \\
\text { pelleranoi }\end{array}$ & $\begin{array}{c}D . \\
\text { flavipes }\end{array}$ & $\begin{array}{c} \\
\text { anastrephae } \\
\end{array}$ & \begin{tabular}{|c|} 
\\
\\
anastrephae
\end{tabular} & $\begin{array}{c}\text { Trybliographa } \\
\text { sp. }\end{array}$ & Total \\
\hline $\begin{array}{l}\text { ANACARDIACEAE } \\
\text { Mangifera indica } \mathrm{L} . \\
\text { (manga) }\end{array}$ & 0 & 0 & 1 & 0 & 1 & 0 & 2 \\
\hline $\begin{array}{l}\text { Spondias mombin } \mathrm{L} . \\
\text { (taperebá) }\end{array}$ & 0 & 1 & 0 & 0 & 0 & 0 & 1 \\
\hline $\begin{array}{l}\text { ANNONACEAE } \\
\text { Rollinia mucosa (Jacq.) } \\
\text { (biribá) }\end{array}$ & 0 & 0 & 0 & 3 & 1 & 0 & 4 \\
\hline $\begin{array}{l}\text { Rollinia sp. } \\
\text { (araticum) }\end{array}$ & 0 & 2 & 0 & 0 & 0 & 0 & 2 \\
\hline $\begin{array}{l}\text { CARYOCARACEAE } \\
\text { Caryocar brasiliense Cam. } \\
\text { (pequi) }\end{array}$ & 0 & 0 & 0 & 0 & 1 & 0 & 1 \\
\hline $\begin{array}{l}\text { COMBRETACEAE } \\
\text { Terminalia catappa } \mathrm{L} . \\
\text { (sete-copas) }\end{array}$ & 0 & 6 & 0 & 0 & 0 & 0 & 6 \\
\hline $\begin{array}{l}\text { FABACEAE } \\
\text { Inga affinis DC. } \\
\text { (Ingá) }\end{array}$ & 0 & 0 & 0 & 4 & 0 & 1 & 5 \\
\hline $\begin{array}{l}\text { Inga sessilis (Vell.) } \\
\text { (ingá) }\end{array}$ & 0 & 0 & 0 & 0 & 0 & 2 & 2 \\
\hline $\begin{array}{l}\text { MORACEAE } \\
\text { Pourouma cecropiaefolia } \\
\text { Mart. (mapati) }\end{array}$ & 27 & 23 & 0 & 0 & 1 & 0 & 51 \\
\hline $\begin{array}{l}\text { MYRTACEAE } \\
\text { Campomanesia sp. } \\
\text { (guabiroba) }\end{array}$ & 0 & 71 & 0 & 0 & 0 & 0 & 71 \\
\hline $\begin{array}{l}\text { Eugenia involucrata DC. } \\
\text { (cereja-da-terra) }\end{array}$ & 0 & 268 & 0 & 0 & 1 & 0 & 269 \\
\hline $\begin{array}{l}\begin{array}{l}\text { Eugenia uniflora } \mathrm{L} . \\
\text { (pitanga) }\end{array} \\
\end{array}$ & 0 & 4 & 0 & 0 & 0 & 0 & 4 \\
\hline $\begin{array}{l}\text { Syzygium aqueum (Burm.) } \\
\text { (jambo d'água) }\end{array}$ & 0 & 8 & 0 & 0 & 0 & 0 & 8 \\
\hline $\begin{array}{l}\begin{array}{l}\text { Eugenia brasiliensis Lam. } \\
\text { (grumixama) }\end{array} \\
\end{array}$ & 0 & 1 & 0 & 0 & 0 & 0 & 1 \\
\hline $\begin{array}{l}\text { Eugenia sp. } \\
\text { (guamirim) }\end{array}$ & 0 & 1 & 0 & 0 & 0 & 0 & 1 \\
\hline $\begin{array}{l}\text { Syzygium malaccensis L. } \\
\text { (jambo) }\end{array}$ & 0 & 2 & 0 & 0 & 0 & 0 & 2 \\
\hline $\begin{array}{l}\text { Eugenia pyriformis Camb. } \\
\text { (uvaia) }\end{array}$ & 0 & 4 & 0 & 0 & 0 & 0 & 4 \\
\hline
\end{tabular}


Tabela 4. Número de eucoilíneos e associações com os respectivos frutos hospedeiros das larvas frugivoras (Dip.: Tephritoidea) no Brasil.

\begin{tabular}{|c|c|c|c|c|c|c|c|}
\hline $\begin{array}{l}\text { Psidium sp. } \\
\text { (araçá) }\end{array}$ & 0 & 15 & 0 & 0 & 0 & 0 & 15 \\
\hline $\begin{array}{l}\text { Psidium guajava } \mathrm{L} . \\
\text { (goiaba) }\end{array}$ & 2 & 136 & 0 & 6 & 42 & 0 & 186 \\
\hline $\begin{array}{l}\text { OXALIDACEAE } \\
\text { Averrhoa carambola } \mathrm{L} . \\
\text { (carambola) }\end{array}$ & 0 & 0 & 79 & 0 & 0 & 0 & 79 \\
\hline $\begin{array}{l}\text { PASSIFLORACEAE } \\
\text { Passiflora sp. } \\
\text { (maracujá) }\end{array}$ & 0 & 0 & 0 & 24 & 1 & 2 & 27 \\
\hline $\begin{array}{l}\text { Passiflora alata Dryander } \\
\text { (maracujá-doce) }\end{array}$ & 0 & 0 & 0 & 5 & 0 & 1 & 6 \\
\hline $\begin{array}{l}\text { ROSACEAE } \\
\text { Prunus domestica } \mathrm{L} . \\
\text { (ameixa) }\end{array}$ & 0 & 37 & 0 & 0 & 0 & 0 & 37 \\
\hline $\begin{array}{l}\begin{array}{l}\text { Prunus persica }(\mathrm{L}) . \\
\text { (pêssego amarelo) }\end{array} \\
\end{array}$ & 0 & 19 & 0 & 26 & 5 & 1 & 51 \\
\hline $\begin{array}{l}\text { RUBIACEAE } \\
\text { Coffea arabica L. } \\
\text { (café) }\end{array}$ & 1 & 4 & 0 & 0 & 0 & 1 & 6 \\
\hline $\begin{array}{l}\text { RUTACEAE } \\
\text { Citrus sinensis }(\mathrm{L} .) \\
\text { (laranja valença) }\end{array}$ & 0 & 0 & 0 & 4 & 0 & 0 & 4 \\
\hline $\begin{array}{l}\text { Citrus limonia Osbeck } \\
\text { (limão-cravo) }\end{array}$ & 0 & 0 & 0 & 6 & 0 & 0 & 6 \\
\hline $\begin{array}{l}\text { Citrus sp. } \\
\text { (mexerica-cravo) }\end{array}$ & 0 & 0 & 0 & 1 & 0 & 0 & 1 \\
\hline $\begin{array}{l}\text { C. reticulatus } \mathrm{x} C \text {. sinensis } \\
\text { (tangor Murkote - híbrido) }\end{array}$ & 0 & 0 & 0 & 1 & 0 & 0 & 1 \\
\hline $\begin{array}{l}\text { SAPOTACEAE } \\
\text { Chrysophyllum mexicanum } \\
\text { Brandegee } \\
\text { (caimito mexicano) } \\
\end{array}$ & 0 & 0 & 0 & 0 & 1 & 0 & 1 \\
\hline Pouteria torta (Mart.) & 3 & 0 & 0 & 0 & 0 & 0 & 3 \\
\hline $\begin{array}{l}\text { SOLANACEAE } \\
\text { Capsicum } \text { sp. } \\
\text { (pimenta dedo-de-moça) } \\
\end{array}$ & 0 & 0 & 0 & 0 & 0 & 1 & 1 \\
\hline $\begin{array}{l}\text { Solanum sp. } \\
\text { (juá) }\end{array}$ & 0 & 0 & 0 & 2 & 0 & 0 & 2 \\
\hline $\begin{array}{l}\text { VERBENACEAE } \\
\text { Citharexylum myrianthum } \\
\text { Cham. (pombeiro) } \\
\end{array}$ & 0 & 4 & 2 & 1 & 0 & 0 & 7 \\
\hline Total & 33 & 606 & 82 & 83 & 54 & 9 & 867 \\
\hline
\end{tabular}




\subsection{Percentagem de parasitismo}

O nível de parasitismo variou de 0,007 a 42,86\%, dependendo do local de coleta e do fruto hospedeiro das larvas das moscas (Tabelas 5 a 7). Deve-se levar em consideração, que as amostras de alguns frutos foram pouco representativas e não foram uniformes em todas as regiões. De acordo com Van Driesche (1983) a percentagem de parasitismo não é um indicador preciso do impacto que os parasitóides exercem sobre as populações de seus hospedeiros. Geralmente o nível de parasitismo é subestimado, já que os frutos são coletados e mantidos em condições de laboratório, excluindo a possibilidade de que as larvas presentes nestes frutos sejam parasitadas, o que poderia normalmente acontecer no campo (Salles, 1996). Todavia, constatou-se que o nível de parasitismo de $A$. pelleranoi em larvas de A. fraterculus em cereja-da-terra (Eugenia involucrata DC.) foi relativamente alto em Pelotas - RS (28,21\%) (Tabela 6). Resultados semelhantes foram obtidos por Salles (1996), também no município de Pelotas (RS), onde foram constatadas também apenas duas espécies: A. pelleranoi e uma espécie de Odontosema, obtida de larvas de A. fraterculus em araçá - Psidium sp. $(8,6 \%)$, goiaba $(5,5 \%)$ e cereja-da-terra $(44,1 \%)$. As variações na percentagem de parasitismo em relação ao local de coleta e espécies de frutos também foram verificadas para $A$. pelleranoi $(24,3 \%)$ em larvas em araçá-vermelho, pitomba e goiaba coletadas em três cidades do Paraná (Menezes et al., 1997). Em Tucuman na Argentina, A. pelleranoi foi observado parasitando $A$. fraterculus $(1,4 \%)$ e $C$. capitata (4,0\%) (Ovruski, 1995).

A influência das características morfológicas dos frutos, tais como a espessura do epicarpo (epiderme ou "casca") e do mesocarpo (polpa) não puderam ser avaliados, já que a maioria dos frutos avaliados apresentavam epicarpo fino e mesocarpo raso. Entretanto, em condições de laboratório, as características morfológicas dos frutos não influenciaram o parasitismo de $A$. pelleranoi, pois essa espécie tem a capacidade de

procurar larvas de moscas no interior dos frutos (Ovruski, 1994). Tal comportamento ainda não foi observado para as demais espécies de eucoilíneos. 
Tabela 5. Percentagem de parasitismo de larvas frugívoras por eucoilíneos em frutos coletados em Manaus e Iranduba (AM).

\begin{tabular}{l|c|c|c|c|c|c}
\hline \multirow{2}{*}{$\begin{array}{l}\text { Frutos hospedeiros das } \\
\text { larvas frugívoras } \\
\text { (n de pupários) }\end{array}$} & \multicolumn{6}{|c|}{ Parasitóides } \\
\cline { 2 - 7 } & \multicolumn{2}{|c|}{$\begin{array}{c}\text { Aganaspis } \\
\text { nordlanderi }\end{array}$} & \multicolumn{2}{|c|}{$\begin{array}{c}\text { Aganaspis } \\
\text { pelleranoi }\end{array}$} & \multicolumn{2}{|c}{$\begin{array}{c}\text { Odontosema } \\
\text { anastrephae }\end{array}$} \\
\cline { 2 - 7 } & $\mathbf{N}$ & $\%$ & $\mathbf{N}$ & $\%$ & $\mathbf{N}$ & $\%$ \\
\hline $\begin{array}{l}\text { goiaba } \\
(1.372)\end{array}$ & 1 & 0,07 & 1 & 0,07 & 0 & 0 \\
\hline $\begin{array}{l}\text { mapati } \\
(6.168)\end{array}$ & 23 & 0,37 & 23 & 0,37 & 1 & 0,02 \\
\hline $\begin{array}{l}\text { taperebá } \\
(13.935)\end{array}$ & 0 & 0 & 1 & 0,007 & 0 & 0 \\
\hline \hline
\end{tabular}

Tabela 6. Percentagem de parasitismo de larvas frugívoras por eucoilíneos em frutos coletados em Pelotas (RS).

\begin{tabular}{|c|c|c|c|c|}
\hline \multirow{3}{*}{$\begin{array}{l}\text { Frutos hospedeiros } \\
\text { das larvas frugívoras } \\
\text { (nº de pupários) }\end{array}$} & \multicolumn{4}{|c|}{ Parasitóides } \\
\hline & \multicolumn{2}{|c|}{ Aganaspis pelleranoi } & \multicolumn{2}{|c|}{ Odontosema anastrephae } \\
\hline & $\mathbf{N}$ & $\%$ & $\mathbf{N}$ & $\%$ \\
\hline $\begin{array}{l}\text { ameixa } \\
(236)\end{array}$ & 37 & 15,68 & 0 & 0 \\
\hline $\begin{array}{l}\text { cereja-da-terra } \\
(950)\end{array}$ & 268 & 28,21 & 1 & 0,1 \\
\hline $\begin{array}{l}\text { guabiroba } \\
(609)\end{array}$ & 52 & 8,54 & 0 & 0 \\
\hline $\begin{array}{l}\text { pitanga } \\
(249)\end{array}$ & 4 & 1,60 & 0 & 0 \\
\hline $\begin{array}{l}\text { uvaia } \\
(17) \\
\end{array}$ & 4 & 25,53 & 0 & 0 \\
\hline
\end{tabular}


Tabela 7. Percentagem de parasitismo de larvas frugivoras por eucoilíneos em frutos coletados em 37 municípios do Estado de São Paulo.

\begin{tabular}{|c|c|c|c|c|c|c|c|c|c|c|c|c|}
\hline \multirow{3}{*}{$\begin{array}{l}\text { Frutíferas } \\
\text { hospedeiras } \\
\text { das larvas } \\
\text { (nº de pupários) }\end{array}$} & \multicolumn{12}{|c|}{ Parasitóides } \\
\hline & \multicolumn{2}{|c|}{$\begin{array}{l}\text { Aganaspis } \\
\text { nordlanderi }\end{array}$} & \multicolumn{2}{|c|}{\begin{tabular}{|l|}
$\begin{array}{l}\text { Aganaspis } \\
\text { pelleranoi }\end{array}$ \\
\end{tabular}} & \multicolumn{2}{|c|}{$\begin{array}{l}\begin{array}{l}\text { Dicerataspis } \\
\text { flavipes }\end{array} \\
\end{array}$} & \multicolumn{2}{|c|}{\begin{tabular}{|l|l|}
$\begin{array}{l}\text { Lopheucoila } \\
\text { anastrephae }\end{array}$ \\
\end{tabular}} & \multicolumn{2}{|c|}{$\begin{array}{l}\text { Odontosema } \\
\text { anastrephae }\end{array}$} & \multicolumn{2}{|c|}{$\begin{array}{c}\text { Trybliographa } \\
\text { sp. }\end{array}$} \\
\hline & $\mathbf{N}$ & $\%$ & $\mathbf{N}$ & $\%$ & $\mathbf{N}$ & $\%$ & $\mathbf{N}$ & $\%$ & $\mathbf{N}$ & $\%$ & $\mathbf{N}$ & $\%$ \\
\hline $\begin{array}{l}\text { araçá } \\
(286) \\
\end{array}$ & 0 & 0 & 13 & 4,54 & 0 & 0 & 0 & 0 & 0 & 0 & 0 & 0 \\
\hline $\begin{array}{l}\text { biribá } \\
(7)\end{array}$ & 0 & 0 & 0 & 0 & 0 & 0 & 3 & 42,86 & 1 & 14,28 & 0 & 0 \\
\hline $\begin{array}{l}\text { café } \\
(956)\end{array}$ & 1 & 0,10 & 4 & 0,42 & 0 & 0 & 0 & 0 & 0 & 0 & 1 & 0,10 \\
\hline $\begin{array}{l}\text { caimito } \\
\text { mexicano } \\
(49)\end{array}$ & 0 & 0 & 0 & 0 & 0 & 0 & 0 & 0 & 1 & 2,04 & 0 & 0 \\
\hline $\begin{array}{l}\text { carambola } \\
(2271)\end{array}$ & 0 & 0 & 0 & 0 & 79 & 3,48 & 0 & 0 & 0 & 0 & 0 & 0 \\
\hline $\begin{array}{l}\text { cereja-da-terra } \\
(68)\end{array}$ & 0 & 0 & 1 & 1,47 & 0 & 0 & 0 & 0 & 0 & 0 & 0 & 0 \\
\hline $\begin{array}{l}\text { goiaba } \\
(921) \\
\end{array}$ & 0 & 0 & 9 & 0,98 & 0 & 0 & 7 & 0,76 & 18 & 1,95 & 0 & 0 \\
\hline $\begin{array}{l}\text { grumixama } \\
(394)\end{array}$ & 0 & 0 & 1 & 0,25 & 0 & 0 & 0 & 0 & 0 & 0 & 0 & 0 \\
\hline $\begin{array}{l}\text { guamirin } \\
(147)\end{array}$ & 0 & 0 & 1 & 0,68 & 0 & 0 & 0 & 0 & 0 & 0 & 0 & 0 \\
\hline $\begin{array}{l}\text { ingá } \\
(1005) \\
\end{array}$ & 0 & 0 & 0 & 0 & 0 & 0 & 5 & 0,50 & 0 & 0 & 3 & 0,30 \\
\hline $\begin{array}{l}\text { jambo } \\
(799)\end{array}$ & 0 & 0 & 2 & 0,25 & 0 & 0 & 0 & 0 & 0 & 0 & 0 & 0 \\
\hline $\begin{array}{l}\text { jambo d'água } \\
(648)\end{array}$ & 0 & 0 & 8 & 1,23 & 0 & 0 & 0 & 0 & 0 & 0 & 0 & 0 \\
\hline $\begin{array}{l}\text { laranja } \\
(30) \\
\end{array}$ & 0 & 0 & 0 & 0 & 0 & 0 & 1 & 3,33 & 0 & 0 & 0 & 0 \\
\hline $\begin{array}{l}\text { limão-cravo } \\
(698)\end{array}$ & 0 & 0 & 0 & 0 & 0 & 0 & 5 & 0,72 & 0 & 0 & 0 & 0 \\
\hline $\begin{array}{l}\text { manga } \\
(1596) \\
\end{array}$ & 0 & 0 & 0 & 0 & 1 & 0,06 & 0 & 0 & 0 & 0 & 0 & 0 \\
\hline $\begin{array}{l}\text { maracujá } \\
(98)\end{array}$ & 0 & 0 & 0 & 0 & 0 & 0 & 24 & 24,49 & 1 & 1,02 & 2 & 2,04 \\
\hline $\begin{array}{l}\text { maracujá-doce } \\
(795)\end{array}$ & 0 & 0 & 0 & 0 & 0 & 0 & 5 & 0,63 & 0 & 0 & 1 & 0,12 \\
\hline $\begin{array}{l}\text { mexerica-cravo } \\
(125)\end{array}$ & 0 & 0 & 0 & 0 & 10 & 0 & 11 & 0,80 & 0 & 0 & 0 & 0 \\
\hline
\end{tabular}


Tabela 7. Percentagem de parasitismo de larvas frugívoras por eucoilíneos em frutos coletados em 37 municípios do Estado de São Paulo.

\begin{tabular}{l|l|l|l|l|l|l|l|l|l|l|l|l}
\hline $\begin{array}{l}\text { pêssego } \\
(1199)\end{array}$ & 0 & 0 & 19 & 1,58 & 0 & 0 & 26 & 2,17 & 5 & 0,42 & 1 & 0,08 \\
\hline $\begin{array}{l}\text { pimenta } \\
(34)\end{array}$ & 0 & 0 & 0 & 0 & 0 & 0 & 0 & 0 & 0 & 0 & 1 & 2,94 \\
\hline $\begin{array}{l}\text { pombeiro } \\
(1585)\end{array}$ & 0 & 0 & 4 & 0,25 & 2 & 0,13 & 1 & 0,06 & 0 & 0 & 0 & 0 \\
\hline $\begin{array}{l}\text { tangor Murkote } \\
(88)\end{array}$ & 0 & 0 & 0 & 0 & 0 & 0 & 1 & 1,14 & 0 & 0 & 0 & 0 \\
\hline \hline
\end{tabular}




\section{CONCLUSÕES}

Os resultados obtidos neste trabalho permitem concluir que:

No Brasil, são encontradas mais comumente, seis espécies de eucoilíneos parasitóides de larvas de moscas da superfamília Tephritoidea: Aganaspis nordlanderi Wharton, 1998, Aganaspis pelleranoi (Brèthes, 1924), Dicerataspis flavipes (Kieffer, 1909), Lopheucoila anastrephae (Rhower, 1919), Odontosema anastrephae Borgmeier, 1935 e Trybliographa sp.

Aganaspis pelleranoi é o Eucoilinae mais abundante e com a maior distribuição geográfica no Brasil.

São os primeiros registros de parasitismo de:

- Aganaspis pelleranoi em larvas de Anastrepha amita Zucchi e Anastrepha bahiensis Lima.

- Aganaspis nordlanderi em larvas de Anastrepha striata Schiner e Anastrepha bahiensis no Brasil.

- Dicerataspis flavipes em larvas de Anastrepha amita.

- Lopheucoila anastrephae em larvas de Anastrepha amita e Anastrepha pseudoparallela (Loew).

- Trybliographa sp. em larvas de Neosilba sp. em pimenta (Capsicum sp.)

São os primeiros registros de ocorrência de:

- Aganaspis nordlanderi no Estado do Amazonas.

- Aganaspis pelleranoi nos Estados do Amazonas e do Rio de Janeiro.

- Dicerataspis flavipes no Estado de São Paulo.

- Odontosema anastrephae nos Estados do Amazonas e de Santa Catarina.

- Trybliographa sp. no Estado de São Paulo.

Aganaspis pelleranoi e Odontosema anastrephae são as mais atraídas para os frutos de mirtáceas.

Dicerataspis flavipes é o parasitóide mais abundante em larvas em carambola.

A percentagem de parasitismo apresenta variações de acordo com o local de coleta e com a espécie de frutífera. 


\section{REFERÊNCIAS BIBLIOGRÁFICAS}

ALUJA, M. Bionomics and management of Anastrepha. Annual Review of Entomology, v.39, p.155-178, 1994.

ALUJA, M.; GUILlEN, J.; LIEDO, P.; CABRERA, M.; RIOS, E.; ROSA, G.; CELEDONIO, H.; MOTA, D. Fruit infesting tephritids (Diptera: Tephritidae) and associated parasitoids in Chiapas, Mexico. Entomophaga, v.35, p.39-48, 1990.

ASHMEAD, W.H. Report on the parasitic. Hymenoptera of the Island of Grenada. Proceedings of the Zoological Society of London, p.744, 1895.

ASHMEAD, W.H. Some new genera in the Cynipoidea. Proceedings of the Zoological Society of Washington, v.5, p.221-223, 1903a.

ASHMEAD, W.H. Classification of the gall wasps and the parasitic cynipoids, or the superfamily Cynipoidea II. Psyche, v.10, p.59-73, 1903b.

BARANOWSKI, R.; GLENN, H.; SIVINSKI, J. Biological control of the Caribbean fruit fly (Diptera: Tephritidae). Florida Entomologist, v.76, p.245-250, 1993.

BARTLETT, K.A. The introduction and colonization in Puerto Rico of beneficial insects parasitic on West Indian fruit flies. The Journal of Agriculture of the University of Puerto Rico, v.25, n.1, p.25-31, 1941. 
BORGMEIER, T. Sobre alguns cynipideos parasiticos e cecidógenos do Brasil (Hymenoptera: Cynipidae). Archivos do Instituto de Biologia Vegetal, v.2, n.1, p.97-124, 1935.

BOSCAN, N.M.; GODOY, F. Nuevos parasitoides de moscas de las frutas de los generos Anastrepha y Ceratitis en Venezuela. Agronomía Tropical, v.46. n.4, p.465-471, 1998.

BRÈTHES, J. Vários himenópteros de la América del Sur. Nunquam Otiosus, v.2, p.10$11,1924$.

CLAUSEN, C.P. Biological control of fruit flies. Journal of Economic Entomology, v. 49, n.2, p.176-178, 1956.

CLAUSEN, C.P.; CLANCY, D.W.; CHOCK, Q.C. Biological control of the oriental fruit fly (Dacus dorsalis Hendel) and other fruit flies on Hawaii. Washington: USDA, 1965. 102p. USDA. (Technical Bulletin, 1322).

CLAUSEN, C.P. Tephritidae. In: CLAUSEN, C.P. (ed.). Introduced parasites and predators of arthropod pests and weeds: a world review. United States Department of Agriculture, Agriculture Handbook. 1978. p. 320-325.

DE SANTIS, L. Nota sobre un parasito de la mosca sudamericana de la fruta (Hymenoptera: Cynipidae). Revista de la Socidad Entomologica Argentina, v.27, n.1-4, p.73-74, 1965.

DE SANTIS, L. Catálogo de los himenópteros argentinos de la serie parasitica, incluyendo Bethyloidea. Comisión de Investigaciones Cientificas de la Provincia de Buenos Aires. 1967. 337 p. 
DE SANTIS, L.; DIAZ, N.B.; REDOLF, I.C. La mosca del girassol (Diptera, Agromyzidae) y sus himenopteros parasitoides. Dusenia, v.9, n.1, p.31-38, 1976.

DE SANTIS, L. Catálogo de los himenópteros brasileños de la serie parasitica, incluyendo Bethyloidea. Curitiba: Editora da Universidade Federal do Paraná, 1980. p.275-287.

DETTMER, H. Ganaspis carvalhoi n. sp. (Hym. Cynipidae) um novo parasita da moscas-das-frutas (Anastrepha fraterculus Wied.). Boletim Biológico de São Paulo, v.16, p.70-74, 1929.

DIAZ, N.B.; VALADARES, G. Nota sobre Agrostocynips clavatus y los agromicidos hospedantes (Hymenoptera Cynipoidea). Neotropica, v.25, n.73, p.23-26, 1979.

DIAZ, N.B. Ampliacion de la distribuicion geografica de cinipóideos parasitóides en la Republica Argentina y Brasil (Hymenoptera). Revista de la Sociedad Entomologica Argentina, v.44, n.1, p.32, 1986.

DIAZ, N.B. Presençia de Leptopilina boulardi en la republica argentina (Cyn. Eucoilinae). Neotropica, v.33, n. 89, p.36, 1987.

DIAZ, N.B. Hymenoptera Cynipoidea de Nicaragua. Revista Nicaragüense de Entomologia, v.29, p.7-14, 1994.

DIAZ, N.B.; GALLARDO, F.E.; WALSH, Paraganaspis egeria, a new genus and species of Eucoilinae (Hymenoptera: Cynipoidea). Annals of Entomological Society of America, v. 89, n. 4, p.497-500, 1996. 
DIAZ, N.B.; GALLARDO, F.E. Revision sistematica de las especies del genero Zaeucoila (Hymenoptera: Cynipoidea: Eucoilinae). Revista Nicaragüense de Entomologia, v.39, p.31-40, 1997.

DIAZ, N.B. Cynipoidea. In: MORRONE, C. (ed). Biodiversidad de artrópods argentinos. Uma perspectiva biotaxonomica. Ed. Sur, 1998. cap. 38, p.399-407.

ESKAFI, F.M; LEGNER, E.F. Description of immature stages of the cynipid Hexacola sp. near websteri (Eucoilinae: Hymenoptera), a larval-pupal parasite of Hippelates eyegnats (Diptera: Chloropidae). The Canadian Entomologist, v.106, 1043-1048, 1974.

FERGUSSON, N.D.M. The cynipoid families. In: HANSON, P.E.; GAULD, I.D. (ed). The Hymenoptera of Costa Rica, New York: Oxford University Press Inc., 1995. cap. 10, p.247-265.

GAULD, I.D; BOLTON, B. The Hymenoptera. New York: Oxford University Press, 1988. $332 \mathrm{p}$.

GOULET, H.; HUBER, J.T. Hymenoptera of the world: An identification guide to families. Otawa: Agriculture Canada, 1993. 668 p.

GUIMARÃES, J.A.; DIAZ, N.B.; ZUCCHI, R.A.; SOUZA FILHO, M.F.; UCHÔA F. M.A. Levantamento preliminar das espécies de Eucoilinae (Hymenoptera, Cynipoidea, Figitidae) associadas às moscas frugívoras (Diptera: Tephritoidea) no Brasil. In: XVII CONGRESSO BRASILEIRO DE ENTOMOLOGIA, Rio de Janeiro, Rio de Janeiro, 1998. Resumos: Rio de Janeiro, 1998a. Livro 1, p.164. 
GUIMARÃES, J.A.; ZUCCHI, R.A. Caracterização de três espécies de Eucoilinae (Hymenoptera, Cynipoidae, Figitidae) parasitóides de moscas frugivoras (Diptera: Tephritidae) no Brasil. In: XVII CONGRESSO BRASILEIRO DE ENTOMOLOGIA, Rio de Janeiro, Rio de Janeiro, 1998b. Resumos: Rio de Janeiro, 1998. Livro 2, p.962.

HAYWARD, K. Distribuición de enemigos naturales de las moscas de las frutas para su control biológico. Revista Industrial y Agricola de Tucuman, v.30, n.4-6, p.136$138,1940 \mathrm{a}$.

HAYWARD, K. Lucha biológica contra las moscas de las frutas. Revista Industrial y Agricola de Tucuman, v.30, n.10-12, p.230-233, 1940 b.

HAYWARD, K. Memoria anual del año 1940. Revista Industrial y Agricola de Tucuman, v.32, n.1-3, p.52-54, 1941.

HAYWARD, K. Memoria anual del año 1941. Revista Industrial y Agricola de Tucuman, v.32, n.1-3, p.48-49, 1942.

HAYWARD, K. Memoria anual del año 1942. Revista Industrial y Agricola de Tucuman, v.33, n.4-6, p.68-70, 1943.

HERNÁNDEZ-ORTIZ, V. Description of a new Rhagoletis species from tropical Mexico (Diptera: Tephritidae). Proceedings of Entomological Society of Washington, v.95, p.418-424, 1993.

HERNÁNDEZ-ORTIZ, V.; PÉREZ-ALONZO, R.; WHARTON, R.A. Native parasitoids associated with the genus Anastrepha (Diptera: Tephritidae) in los Tuxtlas, Veracruz, Mexico. Entomophaga, v.39, n.2, p.171-178, 1994. 
IHERING, R.V. Diagnose de uma Eucoela, parasita das moscas-das-frutas. Revista do Museu Paulista, v.9, p.224-225, 1914.

JAMES, H.C. On the life-histories and economic status of certain cynipid parasites of dipterous larvae, with descriptions of some new larval forms. Annual Applied Biology, v.15, p.287-316, 1928.

KATIYAR, K.P.; CAMACHO M., J.;GERAULD, F.; MATHEUS, R. Parasitoides hymenópteros de moscas de las frutas (Diptera: Tephritidae) en la región occidental de Venezuela. Revista de la Facultad de Agronomía (LUZ), v.12, p.303-312, 1995.

KIEFFER, J.J. Description de noveaux cynipides zoophages. Bulletin de la Societé d'Histoire Naturelle de Metz, Série 3, Tomo 2, p.57-96, 1909.

LEGNER, E.F.; GOEDEN, R.D. Larval parasitism of Rhagoletis completa (Diptera: Tephritidae) on Juglans microcarpa (Juglandaceae) in western Texas and southeastern New Mexico. Proceedings of Entomological Society of Washington, v.89, n.4, p.739-743, 1987.

LEONEL JÚNIOR, F.L. Espécies de Braconidae (Hymenoptera) parasitóides de moscas-das-frutas (Diptera: Tephritidae) no Brasil. Piracicaba, 1991. 83p. Dissertação (M.S.) - Escola Superior de Agricultura "Luiz de Queiroz", Universidade de São Paulo.

LILJEBLAD, J.; RONQUIST, F. A phylogenetic analysis of higher-level gall wasp relationships (Hymenoptera: Cynipidae). Systematic Entomology, v.23, p.229-252, 1998. 
LIMA, A.C. Alguns parasitos de mosca das frutas. Annais da Academia Brasileira de Sciencias, v.12, n.1, p.17-20, 1940.

LIMA, A.C. Entomófagos sul americanos (parasitos e predadores) de insetos nocivos a agricultura. Boletim da Sociedade Brasileira de Agronomia, v.11, n.1, p.1-82, 1948.

LIMA, A.C. Insetos do Brasil. Himenópteros. $2^{\circ}$ parte, $12^{\circ}$ tomo, 1962. 393 p.

LIN, K.S. Aganaspis, a new genera of Eucoilidae (Hymenoptera: Cynipoidea). Taiwan Agriculture Research Institut, Special Publication, v.22, p.67-79, 1987.

LOIÁCONO, M.S.; DIAZ, N.B. Anotaciones sobre himenopteros proctotrupoideos e cynipoideos argentinos (Hymenoptera: Proctotrupoidea, Cynipoidea). Neotropica, v.23, n.69, p.95-102, 1977.

LOURENÇÃO, A.L.; LORENZI, J.O.; AMBROSANO, G.M.B. Comportamento de clones de mandioca em relação a infestação por Neosilba perezi (Romero \& Ruppell) (Diptera: Lonchaeidae). Scientia Agricola, v.53, n.2-3, p.304-308, 1996.

MATRANGOLO, W.J.R.; NASCIMENTO, A.S.; CARVALHO, R.S. Criação em laboratório de Aganaspis pelleranoi (Hymenoptera: Eucoilidae), parasitóides de moscas-das-frutas (Diptera: Tephritidae). In: XVI CONGRESSO BRASILEIRO DE ENTOMOLOGIA, Salvador, Bahia, 1997. Resumos: Salvador, 1997. p.150.

McALPINE, J.F.; STEYSKAL, G.C. A revision of Neosilba Mc Alpine with a key to the world genera of Lonchaeidae (Diptera). Canadian Entomologist, v.114, p.105$137,1982$. 
MENEZES JR., A.O.; BIZETI, H.S.; ARAÚJO, E.L. Parasitóides (Hymenoptera: Braconidae: Eucoilidae) associados às moscas-das-frutas (Diptera: Tephritidae: Lonchaeidae) na região norte do estado do Paraná. In: XVI CONGRESSO BRASILEIRO DE ENTOMOLOGIA, Salvador, Bahia, 1997. Resumos: Salvador, 1997. p.126.

NASCIMENTO, A.S.; MESQUITA, A.L.M.; ZUCCHI, R.A. Parasitism of pupae of Anastrepha spp. (Dip.: Tephritidae) by Doryctobracon areolatus (Szépligeti, 1911) (Hym.: Braconidae) in citrus and tropical fruits. Anais do IV Japan - Brasil symposium on science and tecnology, v.2, n.4, p.239-246, 1984.

NORDLANDER, G. A review of the genus Trybliographa Förster, 1869 (Hymenoptera, Cynipoidea: Eucoilidae). Entomologica Scandinavica, v.12, p.381-402, 1981.

NORDLANDER, G. Systematics and phylogeny of an interrelated group of genera within the family Eucoilidae (Insecta: Hymenoptera, Cynipoidea). Stockholm, 1982a. 34p. Thesis (Ph.D.) - Dept. of Zoology, University of Stockholm.

NORDLANDER, G. Identities and relationships of the previously confused genera Odonteucoila, Coneucoila, and Trichoplata (Hymenoptera, Cynipoidea: Eucoilidae). Entomologica Scandinavica, v.13, p. 269-292, 1982b.

NORDLANDER, G. Vad vet vi om parasitiska Cynipoidea? Entomologisk Tidskrift, v.105, p.36-40, 1984.

NORDLANDER, G.; ZHIWEI, L.; RONQUIST, F. Phylogeny and historical biogeography of the cynipoid wasp family Ibaliidae (Hymenoptera). Systematic Entomology, v.21, p.151-166, 1996. 
OVRUSKI, S.M.; FIDALGO, P. Use of parasitoids (Hym.) in the control of fruit flies (Dip.: Tephritidae) in Argentina: Bibliographic review (1937 - 1991). IOBC/WPRS Bulletin, v.17, n.6, p.84-92, 1994.

OVRUKI, S.M. Aganaspis pelleranoi (Hym.: Eucoilidae) parasitóide de larvas de Ceratitis capitata (Diptera: Tephritidae). Revista de la Sociedad Entomologica Argentina, v.53, n.1-4, p.121-127, 1994a.

OVRUSKI, S.M. Immature stages of Aganaspis pelleranoi (Brèthes) (Hymenoptera: Cynipoidea: Eucoilidae), a parasitoid of Ceratitis capitata (Wied.) and Anastrepha spp. (Diptera: Tephritidae). The Journal of Hymenoptera Research, v.3, p.233239, 1994b.

OVRUSKI, S.M. Pupal and larval-pupal parasitoids (Hymenoptera) obtained from Anastrepha spp. and Ceratitis capitata (Dip.: Tephritidae) pupae collected in four localities of Tucuman Province, Argentina. Entomophaga, v.40, n.3-4, p.367-370, 1995.

OVRUSKI, S.M.; FUENTES, S.; NUNEZ, F.; GRANADOS ZUNIGA, J.G. Himenópteros parasitóides de moscas de la fruta (Diptera: Tephritidae) presentes en la República de El Salvador. Revista de Ingenieros Agrónomos de El Salvador, v.14, p.8-14, 1996.

QUINLAN, J. Hymenoptera Cynipoidea: Eucoilidae. In: Handbooks for the Identifications of British Insects. Royal Entomological Society of London. Vol. 8, part l(b), London. 1978. p.1-58. 
QUINLAN, J. A revisionary classification of the Cynipoidea (Hymenoptera) of the Ethiopian Zoogeographical Region. Aspiceratinae (Figitidae) and Oberthuerellinae (Liopteridae). Bulletin of the British Museum (Natural History) Entomology, v.39, n.2, p.85-133, 1979.

REYES, J.; SANTIAGO, G.; LIMON, F. Mexican fruit fly eradication program. In: V INTERNATIONAL SYMPOSIUM ON FRUIT FLIES OF ECONOMIC IMPORTANCE, Penang, Malaysia, 1998. Resumos: Penang, 1998. p.128.

RITCHIE, A.J. Superfamily Cynipoidea. In: GOULET, H.; HUBER, J.T. (ed.). Hymenoptera of the world: An identification guide to families. Otawa: Agriculture Canada, 1993. cap.12, p.521-536.

RHOWER, S.A. Description of a new cynipoid from Trinidad. Proceedings of the Entomological Society of Washington, v.21, p.156, 1919.

RONQUIST, F. Morphology, phylogeny and evolution of cynipoid wasps. Comprehensive Summaries of Uppsala Dissertations from the Faculty of Science and Tecnology. Uppsala, 1994. 29p. Thesis (Ph. D.) - Uppsala University.

RONQUIST, F. Phylogeny and early evolution of the Cynipoidea (Hymenoptera). Systematic Entomologist, v.20, p.309-335, 1995a.

RONQUIST, F. Phylogeny and classification of the Liopteridae, an archaic group of cynipoid wasps (Hymenoptera). Entomologica Scandinavica, supplement 46, 1995b, $73 \mathrm{p}$.

SALLES, L.A.B. Bioecologia e controle de moscas-das-frutas sul-americana. Pelotas RS: Embrapa - CPACT, 1995. 58 p. 
WELD, L.H. Notes on certain genera of parasitic Cynipidae proposed by Ashmead with descriptions of genotypes. Proceedings of the United States National Museum, v.59, p.433-451, 1921.

WELD, L.H. Synonymical and descriptive note on Pseudeucoila brasiliensis (R. V. Ihering, 1905) (Hym., Cynipidae). Revista de Entomologia, v.2, n.1, p.24-27, 1932.

WELD, L.H. New Eucoilinae (Hymenoptera: Cynipoidea). Proceedings of Entomological Society of Washington, v.53, n.4, p.223-226, 1951 .

WELD, L.H. A new species of Trybliographa (Hymenoptera: Cynipidae). Proceedings of the Hawaiian Entomological Society, v.14, n.2, p.331-332, 1951 b.

WELD, L.H. Cynipoidea (Hym.) 1905-1950. Privately printed, Ann Arbor, Michigan, USA, 1952.351p.

WHARTON, R.A.; GILSTRAP, F.E.; RHODE, R.H.; FISCHEL-M, M.; HART, W.G. Hymenoptera egg-pupal and larval-pupal parasitoids of Ceratitis capitata and Anastrepha spp. (Diptera: Tephritidae) in Costa Rica. Entomophaga, v.26, p.285290, 1981.

WHARTON, R.A. Classical biological control of fruit-infesting Tephritidae. In: ROBBINSON, A.S.; HOOPER, G., (ed.). Fruit flies; their biology, natural enemies and control. New York: Elsevier, 1989. cap. 9.1, p.303-313.

WHARTON, R.A.; OVRUSKI, S.M.; GILSTRAP, F.E. Neotropical Eucoilidae (Cynipoidea) associated with fruit-infesting Tephritidae, with new records from Argentina, Bolivia and Costa Rica. The Journal of Hymenoptera Research, v.7, n.1, p.102-115, 1998. 
WISHART, G.; MONTEITH, E. Trybliographa rapae (Westw.) (Hymenoptera: Cynipidae), a parasite of Hylemya spp. (Diptera: Anthomyiidae). The Canadian Entomologist, v.86, n.4, p.145-154, 1954.

YEPES, F.; VELEZ, R.A. Contribución al conocimiento de las moscas de las frutas (Tephritidae) y sus parasitoides en el departamento de Antioquia. Revista de la Faculdad Nacional de Medellin, v.42, n.2, p.73-98, 1989.

ZUCCHI, R.A. Mosca-das-frutas (Dip. Tephritidae) no Brasil: taxonomia, distribuição geográfica e hospedeiros. In: ENCONTRO SOBRE MOSCAS-DAS-FRUTAS, 1., Campinas, 1987. Moscas das frutas no Brasil: Anais, Campinas: Fundação Cargill, 1988. p.1-10. 